\title{
CUTTING EDGE FABRICATION \\ Investigating Timber Sheet Materials with Robotic Fabrication
}

CELINE CHENG

A 120 point thesis submitted to the Victoria University of
Wellington in partial fulfilment of the requirements for
the degree of Master of Architecture (Professional)

Victoria University of Wellington

School of Architecture

2020 


\section{ampd}

This research is part of the Advanced Manufacturing and Prototyping for design research lab at Victoria University of Wellington.

This research was accepted into the 2020 CAADRIA (Computer-Aided Architectural Design Research in Asia) Conference. 
ABSTRACT

Timber sheet materials have been used in the same manner for decades despite having a vital role in the construction industry. This often results in indistinguishable surfaces with no identity. The research developed in this thesis is the creation of a workflow to create a self-supporting structure from sheet materials using robotic fabrication and computational tools. Timber sheet materials is the key focus for this research, as timber is a material that can be altered in a variety of ways. Japanese timber connections were a strong influence for this research, due to its prolonged life span and sustainable advantages. In the past, timber fabrication techniques have been limited due to design limitations. Current technology, specifically parametric software combined with the robotic arm was explored to find how it can create timber connections to connect sheet materials at different angles. This method was utilised to repurpose the concept of sheet materials towards a complex structure, which adopted the idea of mass customisation over mass production.

Prototypes of timber connections were created to develop an outcome that will structurally support itself. The outcome of each prototype was evaluated and compared with one another to establish which connection would be most suited to bring forward to the self-supporting structure. Computational simulations were used to explore individual structures which created panels that were automatically flattened in the software. This allowed the digital file to be transferred to the robotic arm to be milled. Using the robotic arm was an advantage, as it can rotate around six-axis giving multiple degrees of design freedom which broadened the range of construction techniques that can be used with sheet materials. There is a high chance of human error with manual labour, therefore precision is a positive attribute of the robotic arm. The precision helped minimise waste compared to manual labour. This thesis presented an opportunity for the design/construction industry to adopt a new workflow to bring eading-edge technology to focus on sustainable materials and to steer away from the repetitions evident in buildings today. 


\section{CONTENTS}

Chapter One-Introduction

1.1 Aim and Objectives

1.2 Scope

1.3 Research Method

Chapter Two- Literature Review

2.1 Literature Review

2.2 Precedent Review

2.3 Reflection

Chapter Three- First Model Test

3.1 Laser Cut Models

3.2 Paper Models

3.3 CNC Machine Models

3.4 Digital Modelling

3.5 Connection Testing

3.6 Reflection

Chapter Four- Workspace \& Toolpath Creation

4.1 Toolpath Creation

4.2 Workspace \& Tools

4.3 Reflection

Chapter Five- Base Form

5.1 Panel Flattening

5.2 Dovetail Joint Test

5.3 Criteria Establishment

5.4 Reflection
Chapter Six- Designing

6.1 Sliding Mortise \& Tenon

6.2 Build Sequence

6.3 Cutting Process

6.4 Reflection

Chapter Seven- Form Development

7.1 Form Exploration

7.2 Iterations

7.3 Chosen Design

7.4 Lighting

7.5 Rendered Form

7.6 Reflection

Chapter Eight- Fabrication of Design

8.1 Fabricating

8.2 Errors

8.3 Assembly

8.4 The Workflow

8.5 Reflection

Chapter Nine- Discussion

9.1 Limitations

9.2 Future Research

9.3 Conclusion

Chapter Ten- References

10.1 References

10.2 Figure List 
TERMINOLOGY

ABB

Abbreviation for ASEA Brown Boveri, Robot Manufacture

AMPD

Advanced Manufacturing and Prototyping for Design. A Research Lab that this thesis is part of at the Victoria University of Wellington, New Zealand

CA

Computer Aided Design software.

CAM

Aided Manufacturing so

CNC Machine struction to drive CNC machines.

End-effector

Computer numerically controlled machine used for milling

Grasshopper

A tool attached to the end of the robotic arm such as a spindle.

HAL Robotics A Grasshopper plugin used customise and create a toolpath to be exported as Rapid code for the robot to understand.

Mass Customisation

Mass Production

The production of large amounts of standardised products usually in an assembly line.

Parameter A variable which is defined and changed to produce various design outcomes.

Parametric The use of algorithms, parameters and rules that defines a relationship to create a design.

Rapid Code

BB's proprietary scripting language used to control an ABB robotic arm.

Rhinoceros 3D Computer aided design software.

Router Bit Tool attached to the spindle used for milling/cutting which comes in a range of shapes and sizes.

TCP Tool Center Point, used to determine where the end point of the tool attached to the end-effector.

Work Surface The table the panel are constructed on

XYZ Coordinates Cartesian coordinate system where the point is determined with values in the $X, Y$ and $Z$ directions. 
Sheet materials have been used in the construction industry since 1905 (APA Wood, 2018). Such materials include plywood, MDF, laminated timber and many more. These flat materials were created for the purpose of mass production, which allows for efficiency and repetition. This causes many surfaces seen in the building industry today to be constructed in a similar manner. These materials are not structurally stable alone, instead they often rely on another structural element such as steel fixings. With the increasing concerns of environmental issues, timber is a beneficial material to use because it is renewable source and a promising building material that should be used more frequently. It is a materia that can be altered in a variety of ways, allowing it to be a multifunctional material. However, in the past. timber fabrication techniques have been limited due to design limitations.

Historical Japanese buildings are renowned for their unique use of timber connections, which have allowed many of their timber only structures to remain standing after centuries. However, these connections were manually created and were a time-consuming process to learn the proper techniques to create them. Current technology, specifically parametric software combined with a robotic arm, can be utilised to repurpose the concept of sheet materials towards complex structures. Utilising this technology will save time compared to creating the connections manually as well as using the idea of mass customisation over mass production. This research focuses on fabricating with the six-axis industrial robotic arm. The use of a digitally controlled fabrication process can broaden the boundaries which offer the opportunity to create complex designs and inform new construction techniques. Instead of a limited choice of possible construction options, every surface can be customised based on design parameters. Therefore, the aim of this research is to investigate a way to combine the sheet materials and integrate structural stability within it, to create a self-supporting structure.

\section{CHAPTER 01 \\ INTRODUCTION}




\section{RESEARCH QUESTION}

How can we create complex self-supporting structure from sheet materials using robotic fabrication and computational tools?

\section{AIM \& OBJECTIVES}

Aim: To develop a workflow to create a self-supporting structure using timber sheet materials, robotic fabrication and computational tools.

1. Develop designs of panels and connections through digital modelling to allow for an evaluation of each design.

2. Define a fully parametric code that allows easy customisation.

3. Physically fabricate iterations of connections and panels using the robotic arm.

4. Have a design of a pavilion, where part of it is fabricated at a 1:1 scale, which can be used as a case

study and analysed.
SCOPE

This research focuses on developing a workflow to create a self-supporting structure created from sheet materials using robotic fabrication and computational tools. This research involved the design, fabrication and assembly of the sheet materials to connect at different angles. To achieve this, a process was created to design a connection and create a toolpath to enable it to be fabricated by the robotic arm. The toolpath is parametric allowing customisation based on each individual's preferences. This required testing many iterations with the robotic arm to see if they can fit in and hold each panel. However, structural testing of these panels falls outside the scope of this research due to software and time constraints.

Since this thesis is focused on the development of a workflow to achieve a self-supporting structure, a full-scale physically fabricated and assembled structure also falls outside the scope of this research, due to cost and time constraints. Instead, a part of the structure will be physically fabricated and assembled to prove the connections work and can hold itself together without needing nails or screws. 
IDENTIFYING RESEARCH QUESTION

$$
\text { INVESTIGATING }
$$

IITERATURE REVIEW

Timber sheet materials

Parametric design

Robotic fabrication

THEORY

$\downarrow$
CRITICAL ANALYSIS

PRECEDENTS

STAGE 2

EXPLORING \& DESIGNING

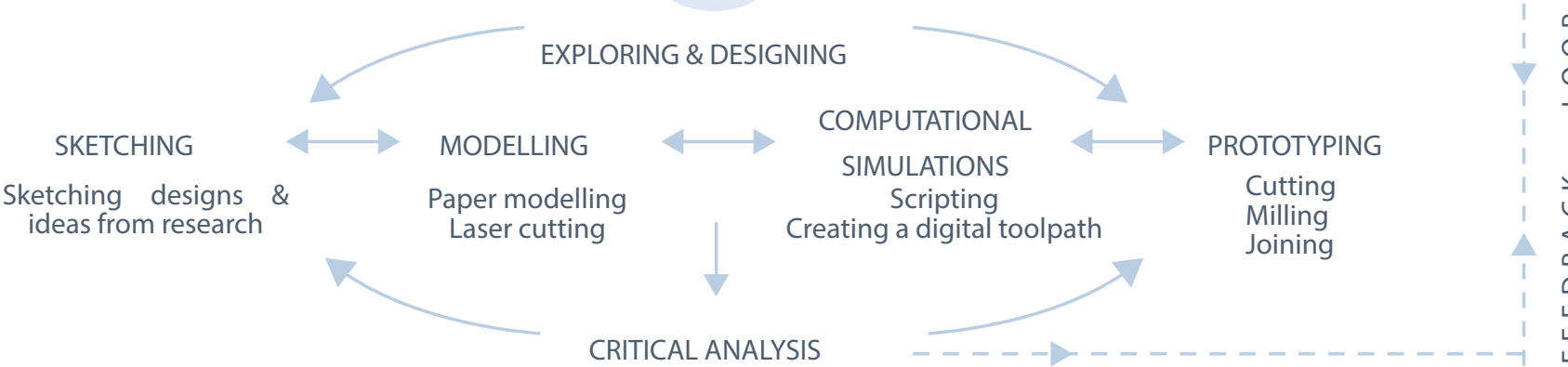

CRITICAL ANALYSIS

$$
\text { STAGE } 3
$$

FINAL PHYSICAL PROTOTPYE

Create part of a standing

tructure

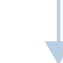

\section{- Identifying the strength an}

weaknesses

-Evaluating if what's be done is

successful and relates back to the aim

-Aiming to be able to move forward

into the next step

e process is clear or not.

- Resolve the issues found

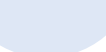

THESIS

\section{RESEARCH METHOD}

The key research method adopted in this thesis was design-led research focusing on computational simulations and iterative prototyping. These were chosen because they respond to the need for experimentation to understand where to move forward. An advantage of computational simulation is that it allows for an iterative process to examine which design will work best for the environment it has been placed in. In the paper, Simulation research methods, Dooley claims that "Simulation enables studies of more complex systems because it creates observations by 'moving forward' into the future, whereas other research methods attempt to look back across history to determine what happened and how" (Dooley, 2002 ,p.2). This is relevant to this study as computational simulations highlighted the design possibilities and captured the behaviour of the panels. The iterative process means differen outputs occurred depending on what rules were given to the code. The iterations were built on previous simulations which allowed the outputs to be compared. These simulations are also important because they acted as a substitute for the physical prototyping which minimised the time needed to achieve it. Furthermore, simulations educated and helped with the understanding of how the complex pane system worked. However, some limitations that occurred with this research method were that multiple parameters existed within the computational simulations. This allowed for an unlimited amount of times that the simulation can be run, which always gave the 'what if' question each time a simulation ended. Although this allows for multiple possibilities, a stop point was called to allow us to move forward with this research.

Stage one of this research consisted of collecting data through literature reviews, case studies and theory. The literature review enabled us to find the ideas behind the sheet materials, the robotic arm and digital design processes. This was crucial to understand the constraints risen. Case studies helped identify how sheet materials have been used in construction, using real-world examples to analyse what's been done and contributed to provoking new ideas. The theory was important to investigate into computation and parametric thinking.

Stage two began with computational simulations, then followed with prototyping. These simulations captured the behaviour of the system and analysed the issues before the digital design became physical design. Computational simulations is a research method used by all the precedents looked at, which was attributable to their successful outcomes. Prototypes allowed for the experimental testing of the panels to determine what types of cut and connections were required for the prototype to structurally support itself. These prototypes were evaluated and analysed, providing feedback and information that developed the self-supporting structure.

Stage three involved a final physical prototype to be analysed using the criteria established, which involved testing its strength, rigidity, ease of assembly and understanding the amount of steps required to fabricate the panels. A prototype was created using parametric design methods whilst implementing the robotic arm as a tool. The joints designed held the panels together without needing additional support and can give an insight to what a full-scale prototype could be. This challenged the way conventional methods are used with sheet materials.

Stage 4 created a final thesis outcome, which was the workflow to create a self -supporting structure Understanding the issues that occurred in this process to reach this final outcome was an important part of this thesis, as future research can benefit from these issues. Part of a self-supporting structure was created to demonstrate how the workflow worked.

After each stage, a critical analysis was completed to identify the outcomes, strengths and weaknesses. This was important to see what areas needed to be improved. Each stage had a feedback loop, where once evaluated, they helped further refine the previous stages. A key criteria was established based on the literature to define the success of each prototype. 


\section{INTRODUCTION}

This chapter looks into literature that helps inform this research. These include

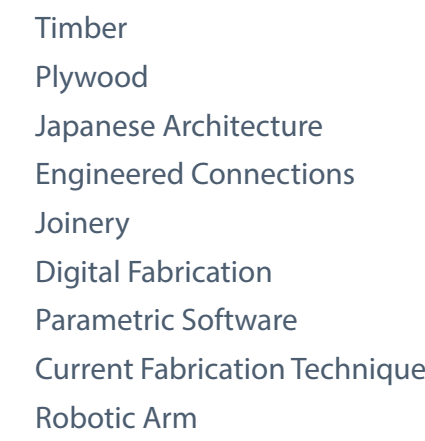

A range of precedent projects related to these topics were researched to understand the strengths, weaknesses and limitations of them. This helped further inform the areas that need to be targeted to develop a design that can resolve weaknesses found in the literature review.

\section{CHAPTER}


Plywood: $\quad$ First engineered wood product, made from sheets of cross laminated veneer and bonded under head and pressure with moisture resistant adhesives.

Oriented Strand Board (OSB)

First engineered wood product, made from sheets of cross laminated veneer and bonded under head and pressure with moisture resistant adhesives.

Medium-Density A smooth surface with no knots or grains. Consists of wood Fibreboard (MDF) fibres mixed with resin and wax and then formed into panels through compression and high heat pressure.
For many centuries wood has been the single most important building resource. Up until the 18th century, over $80 \%$ of the buildings were timber structures. However, its role gradually declined in the early twentieth century with the production of steel and concrete (Steurer, 2006). Currently, the timber industry has experienced a significant growth within the last decade, mainly due to the increase in engineered timber products such as cross-laminated timber (CLT), laminated veneer lumber (LVL), plywood and many more (Hough, 2019).

Current unsustainable practices of timber-based construction have destroyed forests and decreased timber resources. This has led many people to believe that wood-based construction is not environmentally friendly. However, timber is a significant grown building material and the only resource that does not require primary energy in its formative phase (Steurer, 2006). It is a natural material with good strength and stiffness to weight ratios similarly equal to steel (Chilton \& Tang, 2017). Even with the transition into new production methods such as the use of steel, wood still remains a practicality in people's lives (Steurer, 2006).

Timber is an aesthetic material that can be altered in a variety of ways, allowing it to be a multi-functional material. Timber has a low carbon footprint as well as a low level of embodied energy. "The production of a panel in a given compressive strength in wood requires 500 times less energy than steel" (Menges, Schwinn, \& Kreig, 2017, p.2). This is important because when addressing environmental concerns such as climate change, timber is a renewable source that should be used regularly. The environmental impact of the construction industry is unsustainably high, with the choice of building material being a large contributor. The iron and steel industry accounts for between $6-7 \%$ of global $\mathrm{CO}_{2}$ emissions (Hough, 2019). Whilst concrete, the widest used construction material, uses between $5-8 \%$ of global $\mathrm{CO}_{2}$ emissions (Green \& Taggart, 2017). The Green Building Council has said the built environment was responsible for about $20 \%$ of New Zealand's carbon emissions. Half of this comes from the manufacture and construction of its building and materials (Steeman, 2019). To persuade the common use of timber it needs to be made more compelling. Therefore, a multitude of ways to work with timber needs to be explored to give more variety in timber designs.

"Wood is no longer disregarded as outmoded, somewhat nostalgic and rooted in the past, but ncreasingly understood as one of the most promising building materials for the future." (Menges, 2012, p.37) 


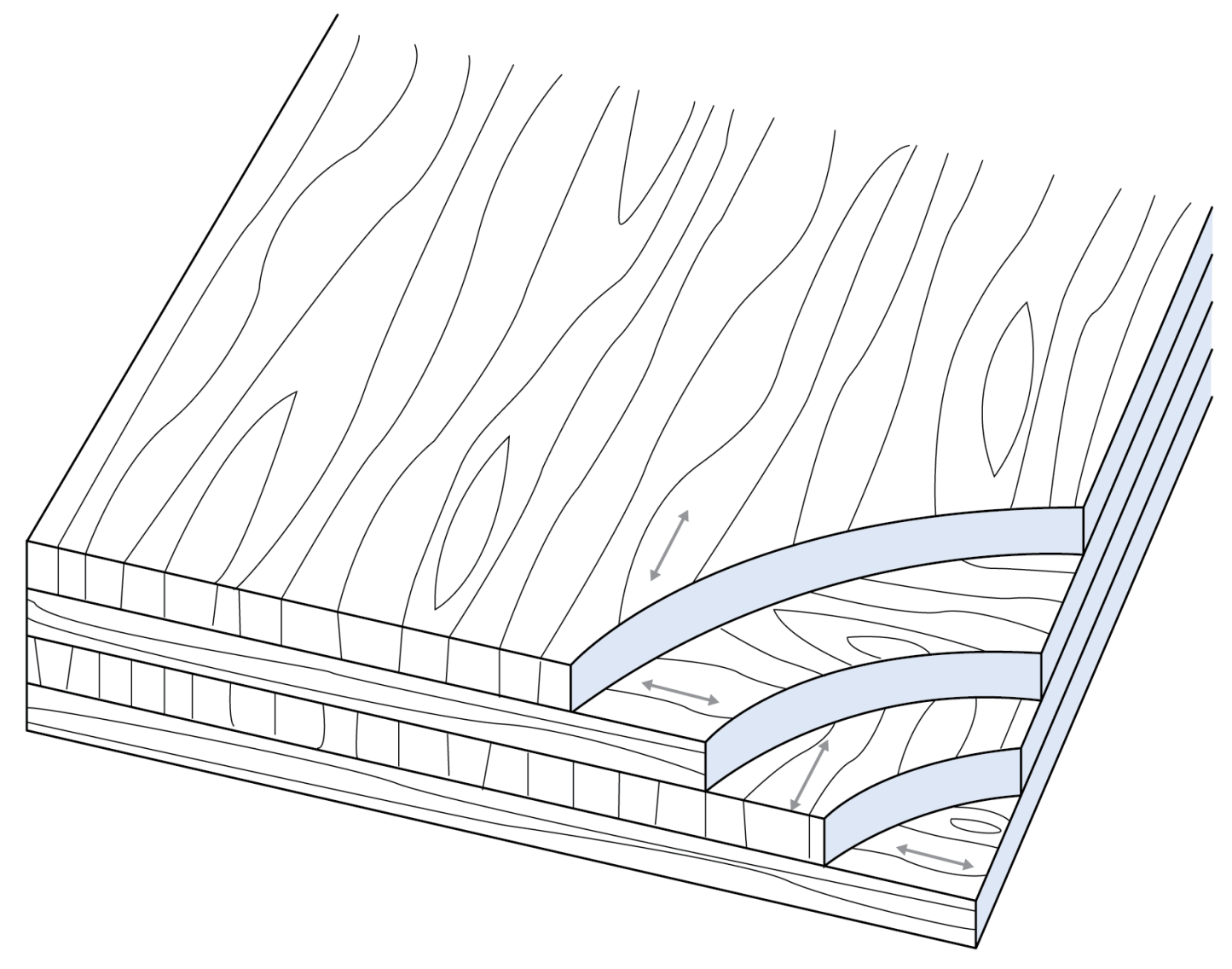

The shift from steel and concrete to engineered timber needs to be considered in the construction industry, not only for sustainable advantages but also for its seismic strength. This is shown in the Kaikoura Civic Building, where the surrounding buildings were damaged in the 2016 Kaikoura Earthquake, and the building itself remained undamaged. The building was constructed mainly from prefabricated engineered timber, including beams, columns and wall panels (Smith, 2019).

Engineered timber is manufactured by bonding together wood strands, veneers, small sections of solid umber or other forms of wood fibre to produce a product that is stronger and stiffer than wood alone (Green \& Taggart, 2017). Material that makes up this product can come from smaller trees which enables a larger percentage of the tree to be used rather than solid lumber itself (Green \& Taggart, 2017). This reduces wastage and encourages timber to be recycled and reused.

Plywood is a type of engineered timber, also known as man-made wood. In 1905, part owner and plant manager of Portland Manufacturing Company, Gustav Carlson, laminated wood panels from range of Pacific Northwest softwoods (APA Wood, 2018). House jacks were used as wood presses and paint brushes were used to spread the glue. This product was called '3-ply veneer work', this led to the production of 420 panels a day and the plywood industry commenced (APA Wood, 2018). Current plywood is made from thin layers of wood veneer and is glued together with their wood grain rotated up to 90 degrees, alternating with each layer. This method is called cross-lamination and is beneficial as it reduces the chances of the wood splitting when nailed, reduces expansion and shrinkage and most importantly, it distributes the load consistently across the panel (EWPAA, 2018). Therefore, creating a material that is stronger than solid wood.

Plywood is highly relevant in architecture and plywood these days are used for roof lining, walls and flooring. Plywood is most commonly available in $1220 \times 2440 \mathrm{~mm}$. It is a popular construction choice due to its low cost, however, this causes many surfaces in construction to be flat and looking the same as one another. This is because plywood is a material that was created for mass production which allows it to quickly produced and assembled on site. The design potentials with plywood are unlimited, they just need to be researched to develop new design potentials. 
During the Asuka Period (593-710 AD), Buddhism was introduced into Japan, which had a deep influence on Japanese architecture (Sadler, 2009). The Horyu-Ji Buddhist pagoda was built in 670AD with a height of 32.55 meters and is the world's oldest standing wooden structure (Hisatoku, Nakahar, Nagase, \& Takahashi, 2000). The temple is an example that reflects the Japanese adaption to architectural forms introduced into Japan. In China, pagodas were traditionally built from stone, however, due to Japan's high seismic activity and higher annual rainfall, stone was not a safe option to progress with (Tarantola, 2011). Therefore, Japanese builders adapted to the climate and used timber in their construction, as it is more capable of withstanding earthquakes compared to stone or brick construction. Japan's native timber is naturally resistant to attack by fungi and bacteria which made it a preferred building materia choice (Ding, 2015).

Traditional Japanese buildings are notable for the fine craftsmanship of their timber structures, especially the complex joinery (Locher, Simmons, \& Kuma, 2010). The Japanese tradition of woodworking spans over 2000 years, and they did not rely on any other building material except for solely timber. Japanese wood joinery is based on a bracketing system where each member is joined together without the application of non-wood based fasteners. These components were crafted from wood using prethe connections themselves. The wooden Japanese joints function as shock absorbers and show a great level of intricacy (Locher et al., 2010). Japanese carpentry requires years of practice and understanding of the properties of timber. The skill was passed down generations through an apprenticeship system. Japanese carpenters at the time worked as both the construction worker and the architect. The Horyu-j emple has been struck by 7.0 and higher magnitude earthquake 46 times and yet still stands (Tarantola, 2011). This results as an admirable exemplar that showcases the success of wood to wood joinery techniques in buildings. 


\section{ENGINEERED CONNECTIONS}

Engineered timber connections today tend to rely on fasteners, which faces many challenges ranging from the behaviour of the materials to the point of recycling (Schwinn, Krieg, \& Menges, 2013). Current timber building designs lacks a sustainable design approach, as many timber construction methods produce a lot of waste and disregard how the timber in buildings can be reused. Alternative methods of construction can be implemented than the ones that are currently used today. Timber is an above average insulator compared to other inorganic building materials. Due to metal fasteners being a good conductor of heat, issues arise when the fasteners are inserted into the timber. This is because metal cools faster than timber when there is a change in temperature. Therefore, condensation occurs on the metal causing the metal fasteners where their galvanised coating has been damaged due to abrasion from penetrating the timber. Furthermore timber surrounding the fasteners tend to wood preservatives are used. Therefore, in buildings with wood to wood joints, these chemica wood preservatives would not be needed (Graubner, 1992). Joints are made where supporting and supported elements meet, where timber must be spliced, supported or braced together. Therefore looking into traditional Japanese joinery techniques can help lead to a sustainable design approach. 

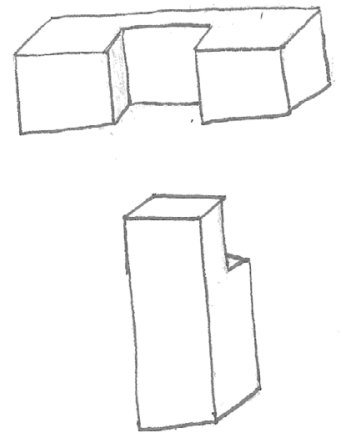

HALVED T JOINT

Made by halving the depth of the timber away to connect 2 pieces together

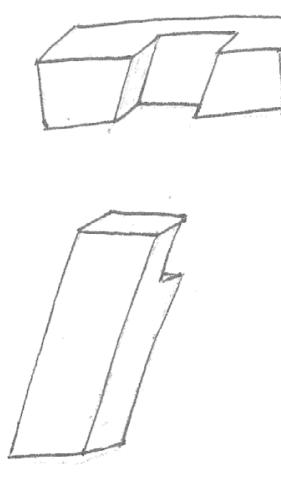

OBLIQUE HALVING

Used in positions for

strengthening framing

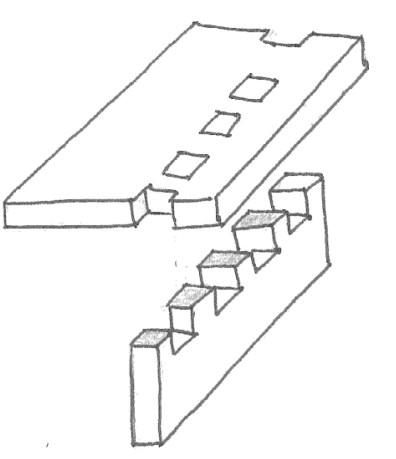

PINNING

Projecting a piece of timber into another piece

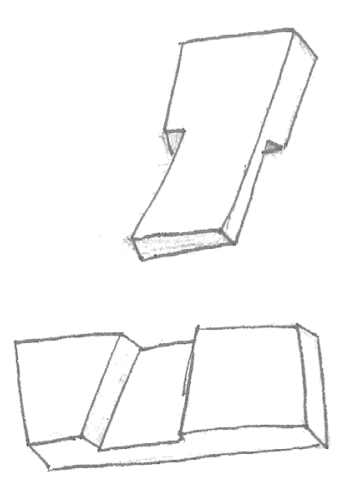

OBLIQUE DOVETAIL HALVING

Used to prevent racking/tilting in

framing. Often used as a cross

brace to framing

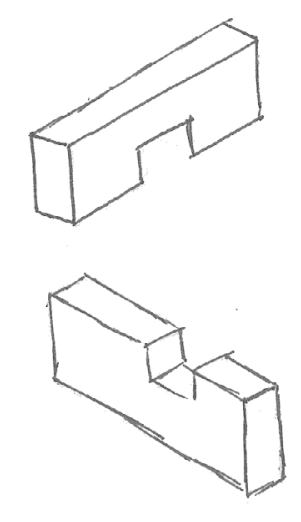

CROSS HALVING JOINT

EDGEWAYS

Each piece runs through each other

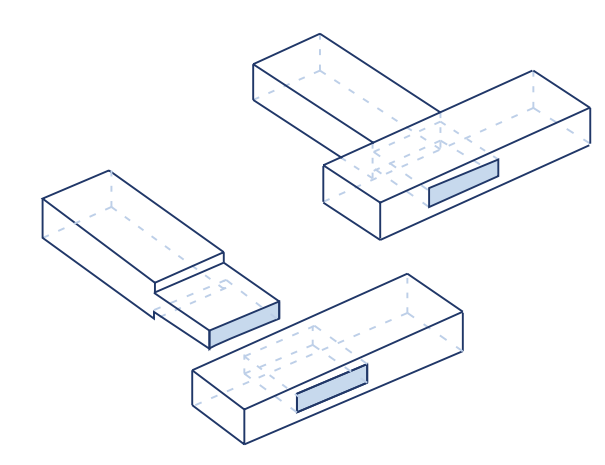

MORTISE \& TENON

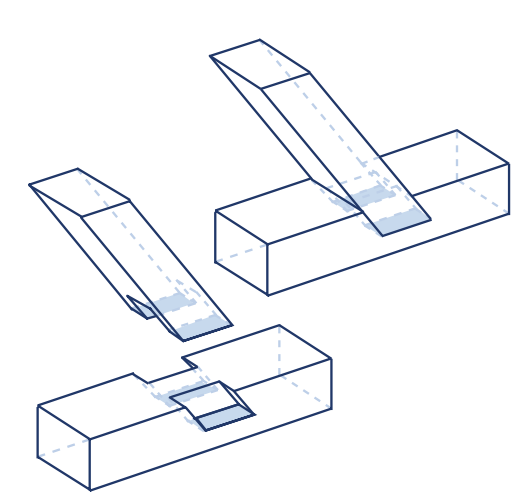

BRIDLE JOINT

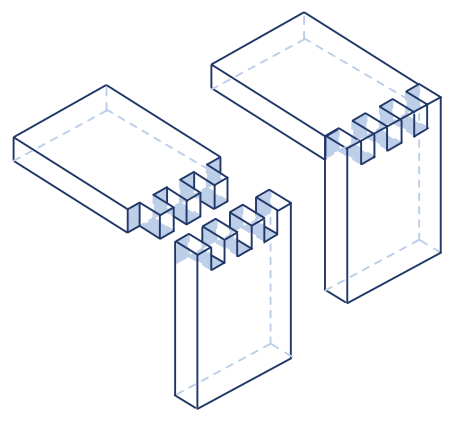

FINGER JOINT

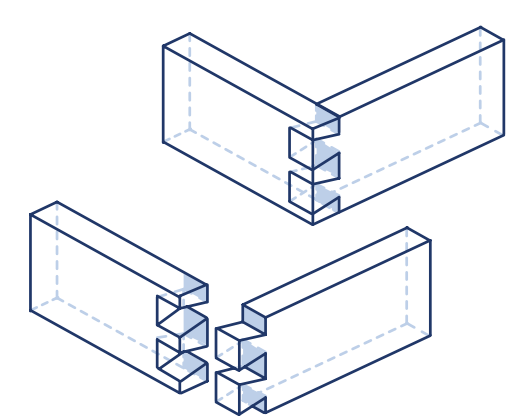

DOVETAIL JOINT 


\section{DIGITAL FABRICATION}

Digital technologies are changing the way architecture is practised and opening up new possibilities. Advances in computer-aided design (CAD) and computer-aided manufacturing (CAM) are creating a strong impact in the architectural design process (Kolarevic, 2003). "Computational design, once thought to be a special skill reserved only for those who were mathematically inclined, is now within the grasp of most designers" (Doscher, 2012, p.206). They have allowed the production and construction of complex forms that were until recently, challenging and expensive to design, fabricate and assemble using traditional construction methods.

In the early 1990s very few architectural practices used computers other than for administrative tasks such as accounting. Manual drawing methods and physical modelling was the typical process used to design (Dunn, 2012). Currently, everything that has been designed all have some form of digital technology integrated into it. Although CAD/CAM software has only emerged in the architectural industry in the last two decades, CAD/CAM have been used in engineering and industrial design for more than 50 years, aiding the development of cars, aeroplanes and the consumer product industry (Dunn, 2012). The architectural industry has always looked outside of their own discipline to learn about the processes and methods used. This has helped advance the architectural industry by broadening the range of techniques and opening up opportunities which changes the method of traditional architectural practice.

A strong link can be formed between the design and construction phase using CAD and CAM echnologies. (Kolarevic, 2003). This means digital fabrication is allowing the decrease of the gap between computational design and physical fabrication. "The logics of digital workflows in architecture have begun to structure the way that architects design, the way that builders build, and the way that industry is reorganising" (Marble, 2012, p.8). Computational design are extending the capabilities of conventional design by generating outputs from inputs determined from a workflow. Later on in projects, this workflow can incorporate more information such as structural and energy performance to result in a feedback loop of valuable design criteria (Doscher, 2012). Designing and building are no longer separate tasks, instead they are one thorough process creating efficiency in the advancing architectura industry.

\section{PARAMETRIC SOFTWARE}

Parametric software is a growing tool used in architecture, however not many of the unique designs created in the software are not built due to construction limitations. Parametric modelling represents change and design is change (Woodbury, 2010). Parametric software creates systems defined by linkages and constraints between geometry. They do not have a specific solution, but they are able to provide range of possibilities (Beorkam, 2013). Parametric design is beneficial in scenarios where there is complexity, and this method is useful as different components can be integrated into one database an manipulated (Dunn, 2012). Designing in architecture is nearly always an iterative process. Solutions are created and then refined to create a new idea. The word iteration indicates that a set of steps are reiterated through using the same rules (Jabi, 2013). This is the same as parametric design, where variations are created using the same set of rules. Examples of this can be changing the dimensions of the same design, or changing the angles of the same design. A clear advantage of a parametric approach is the ability to achieve complex solutions with simple systems (Scheurer, 2012). However, this still requires human thinking to find a clear solution to control the parametric tools, as computers are just there to store the information.

Rhinoceros 3D (Rhino) is a computer-aided design and 3D computer graphics software that many architects and designers are familiar with. Grasshopper is parametric software add on for Rhino which uses a visual scripting language. These two programmes combined, provides a way to give prompt feedback and generate designs rapidly through the iteration of many possibilities based on set parameters. This is a key benefit and an efficient way to generate computational designs and simulations, as quick visual eedback can indicate what is working and what is not. By assigning different values to the parameters, different objects or configurations can be created. This opens up the opportunity of mass customisation. Mass production in construction has occurred since the second industrial revolution in the mid-nineteenth century (Riggs, 2015). Copies of the same prototype can be produced rapidly by factories, now with parametric software, each object can be manufactured to be unique to one another. However, with thes customisable new designs, new workflows need to be developed since standard building materials come in flat sheets or straight strips. Digital fabrication tools can allow these designs to be feasible, such as CNC machines, the robotic arm or laser cutter, giving multiple degrees of design freedom. Therefore, parametric software used in conjunction with digital fabrication tools, can facilitate with the generation of complex outputs, making it a key tool for the creation of automated workflows. 
Common digital fabrication techniques use the laser cutter, or the three-axis Computer Numerically Controlled (CNC) milling and routing machine.

The first numerically controlled machine dates back to 1952 where researchers at the Massachusetts Institute of Technology (MIT) wired an early digital computer to a milling machine (Gershenfeld, 2012). This led to the introduction of many tools that have been attached to computer-controlled machines that can cut out materials. The key benefit of this technology is that designs can be sent anywhere in the world which fully eliminates shipping costs, creating a seamless integration of design directly to fabrication. which fully eliminates shipping costs, creating a seamless integration of design directly to fabrication.
Complex geometries have been an important driver for the development of CNC machine, due to the need to respond to material, manufacturing and cost constraints.

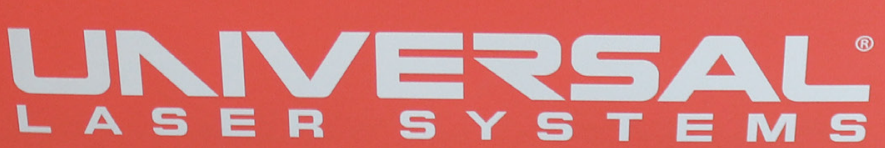

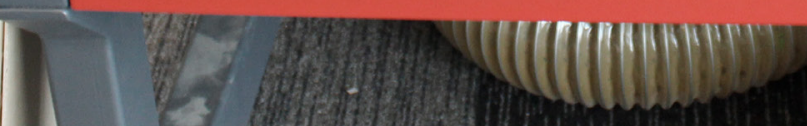

\section{CNC MACHINE}

The three-axis CNC machine is a subtractive process which removes material through a milling or routing process. Precision, size, and production are the advantages of these machines. Large elements can be made from these machines in a shorter production timeline, allowing it to be an economical option. Lower tolerances are needed allowing the elements fabricated to be more accurate. The gantry type three-axis CNC machine is the most common type. It has either a fixed or moving work table where the material is mounted on, however, this causes there to be constraints on the size of material that can be used. Two-axis milling moves along the $\mathrm{X}$ and $\mathrm{Y}$ axis whereas a three-axis milling machine also moves up and down on the Z-axis. Although the three-axis CNC machine is common, there are still many limitations on what it can do.

LASER CUTTER

The laser cutter is an accessible form of digital fabrication and is used in many design practices, architecture schools and workshops. It is only used with sheet materials up to $20 \mathrm{~mm}$ thick (Dunn, 2012). It cuts with a high degree of accuracy and can be used with a range of materials such as plastic, paper, card, wood and many more. The laser cutter is useful for small-scale models as it can cut or inscribe very small details and patterns on the component. Although the laser cutter is successful with displaying aesthetic information due to the ability to control the power of the laser, the size of the component fabricated is limiting. Therefore, it is not useful for thick or large sheet materials.

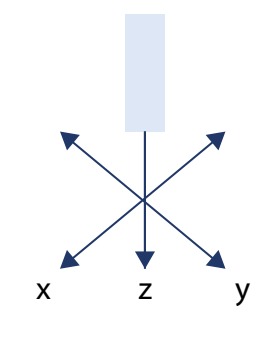

3 Axis

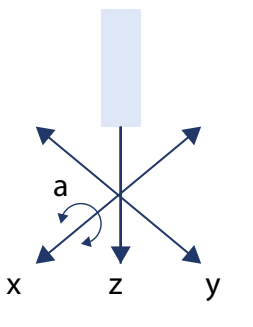

4 Axis

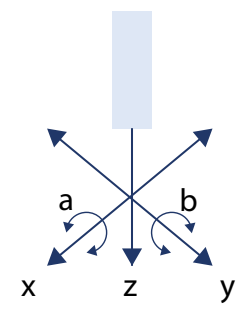

5 Axis 


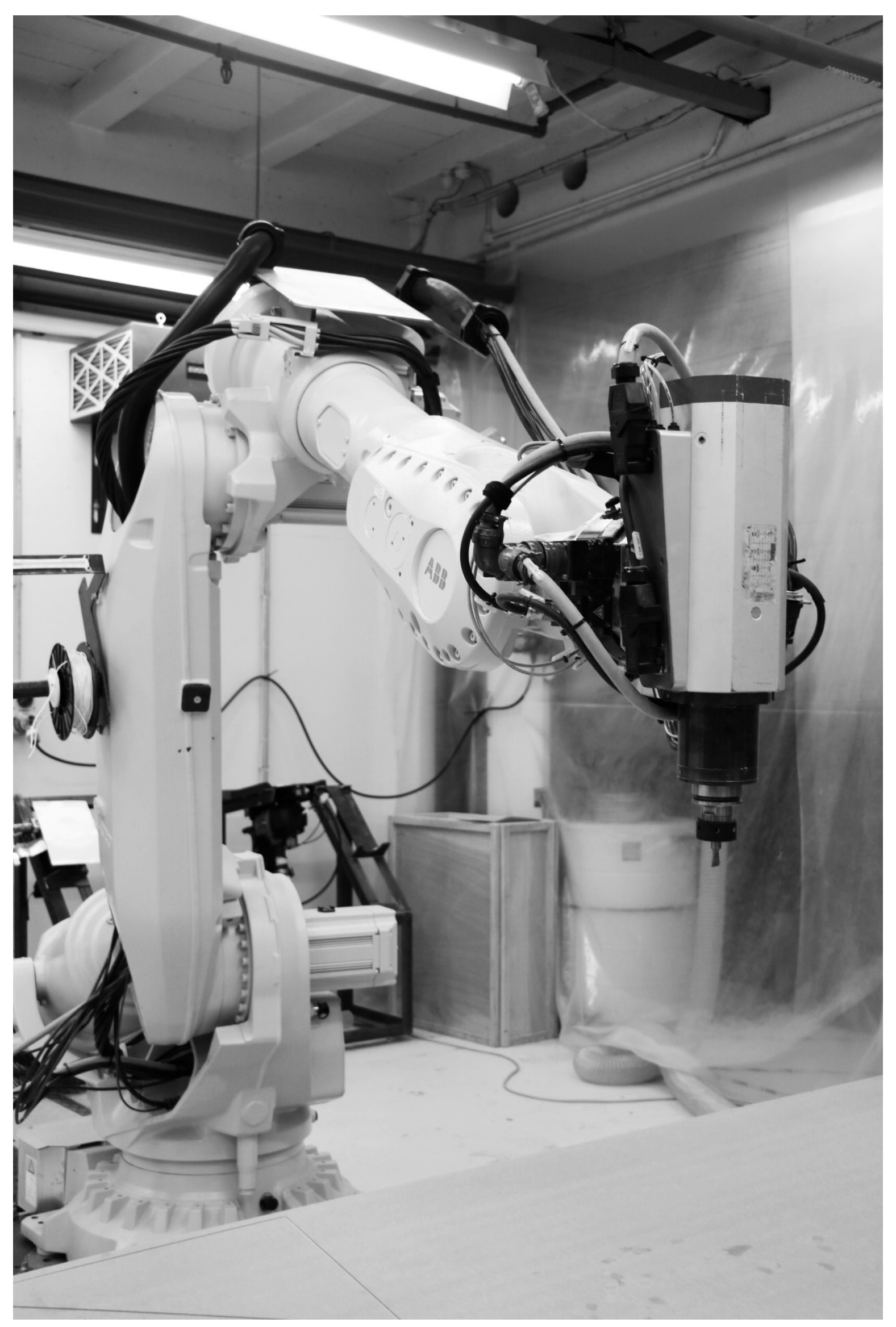

The robotic arm is a tool that is not restricted to a particular application or optimised for a specific disciplinary focus, however, it is a tool that is becoming relevant in architecture. The difference between contemporary industrial robots and their industrial predecessors and other computer controlled devices is their versatility (Willma, Block, Hutter, Byrne, \& Schork, 2018). The robotic arm is an efficient machine that can achieve a variety of tasks dependent on the tool that is attached to it. Some examples include milling, 3D printing, picking up objects and cutting (Owen-Hill, 2018). In order for these manoeuvres to occur, a toolpath created from visual programming software such as Grasshopper is sent as a code to the robotic arm. "The powerful opportunities afforded by robotic systems and the closely-related intelligent technology network are changing the relationship between the virtual world and the real one" (Yuan 2017, p61). This gives architects more freedom in the process of design and fabrication. The versatility of the robotic arm allows it to be programmed to achieve a wide range of specific tasks both at a smal and large scale.

Grasshopper has made robotic fabrication accessible to architects and designers as it can fabricate parametric components easily. Despite being an accessible programme, a lot of testing and checking needs to be done to ensure it makes no mistakes with the robotic arm. This process can take up more time compared to setting it up on CAM software which is used by traditional CNC machines (Dunn, 2012). The main advantage of the robotic arm compared to other fabrication machines is that the down and around a three-dimensional object prevails over conventional machines. This advantage gives the opportunity to showcase how the robotic arm can give designers the freedom to design outside the scope of conventional designs.

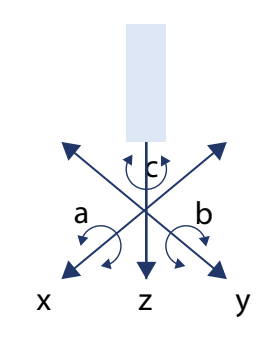

6 Axis

"The powerful opportunities afforded by robotic systems and the closely-related intelligent technology network are changing the relationship between the virtual world and the real one" - (Yuan, 2017,p.61) 

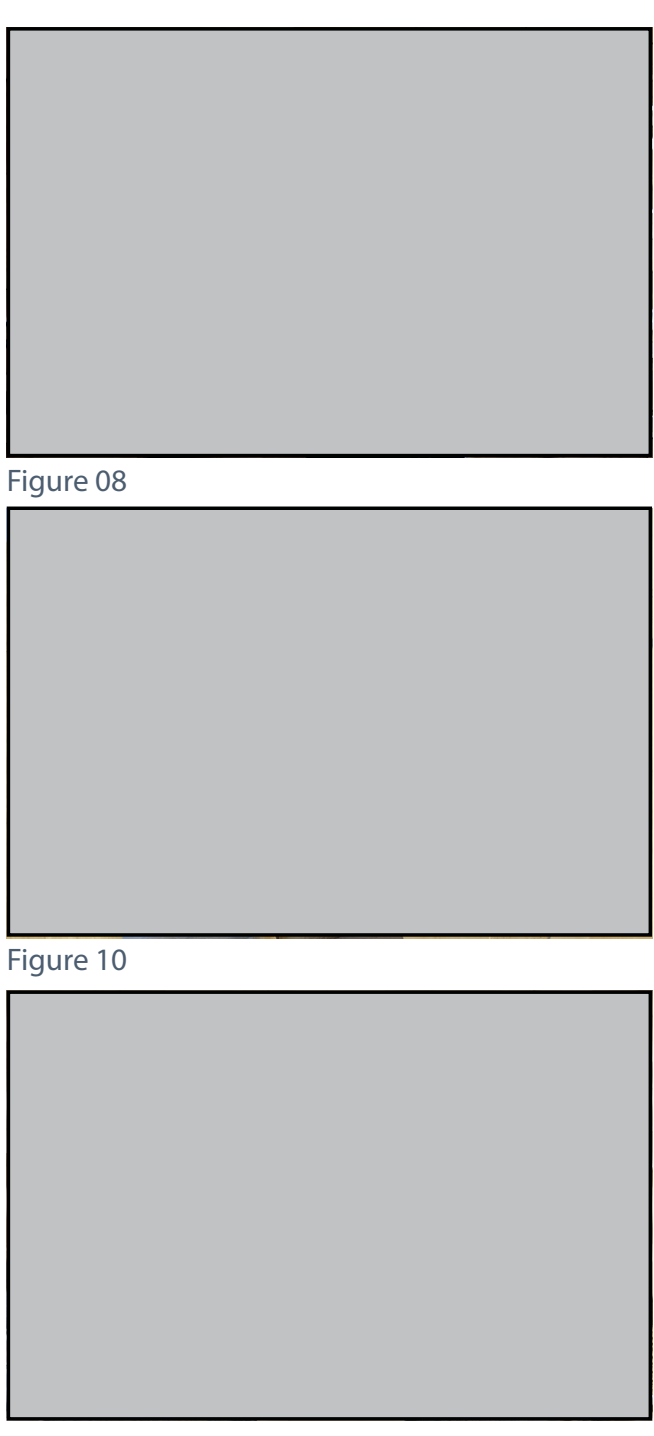

Figure 12
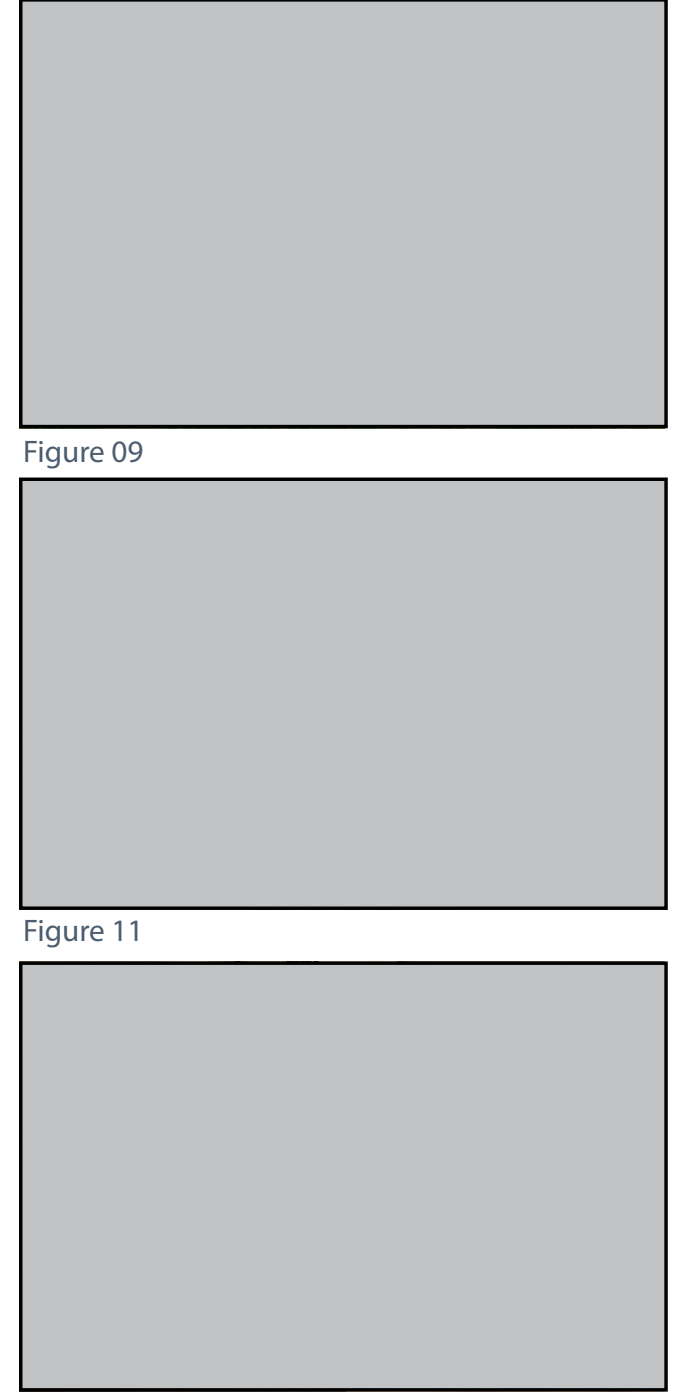

Figure 13
Figure 08: Acoustic Environments / AREA and Electrotexture Lab

Created from evolutionary algorithms tha search the optimum form and reflective environment for electronic music within the context of Aalborg's harbour front. (Alison Furuto, 2011).

Figure 10: Winnipeg Skating Shelters The form of the shelter is a resultant of this process of stressing/deforming and then releasing stress. The overall form resembles Buffalo's huddling together to brace from the wind. (Laylin, 2011)

Figure 12: Fabricwood

The form was inspired by Herman Miller

chairs, which use moulded plywood and elastic mesh to create an ergonomic, frame less

structure. The structure is comprised from slits in the surface, allowing the wood to bend. It is then stitched together with cable ties (Baranyk 2017)
Figure 09: 2011 matR Project: "The Passage" The initial form was created from Rhinoceros and Grasshopper definitions as a waffle structure of 24 horizontal struts and 26 vertical ribs. (Pagnotta, 2011)

Figure 11: The Porthole

The Porthole has an anamorphic nature The shape of the pavilion changes depending on the angle the viewer is looking at. " "The PortHole / TOMA!," 2015)

\section{Figure 13: TWIST Installation}

The form is primarily composed of two plywood strip elements, the 'ribs' and the 'wings'. The rib elements are working to trigger the inherent properties of the thin wings creating sinusoidal curves on the surface. (Oh, 
Robotic Wood Tectonics was a project from the 2016 DigitalFUTURE exhibition in Shanghai. It explored the combination of robotic wire cutting technologies and traditional woodcraft to produce geometrically complex wooden elements without the immense material consumption of a CNC milling production process. The capacity of current CNC-milling-based non-linear wood component fabrication methods, which not only consume a lot of time but also produce a lot of material waste, is falling out of line with the rapid development of digital design technology (Schwinn et al., 2013). This project employed a mortise and tenon joint system using the robotic arm which simplified the assembly process as the timber beams could easily be slotted in place.

Plugins, Rhinovault and Millipede were used as form finding tools used to find a compression only structure. The initial geometry was then translated into a grid-beam system. Glue laminated timber with four cuts at a speed or 5-8m per hour. The bandsaw has the smallest kerf compared to other wood cutting methods which ensure the process saved material compared to the traditional CNC process. Using a 24,000 rpm spindle on the same robot, slots on the beam were milled using the same bandsaw cutting process (Yuan, 2017). The fabrication of the 16 beams was completed in three weeks with high degree of accuracy and efficiency. This project presents robust robotic wood tectonics capable of full-scale wood component fabrication and explores the entire process from form finding to component drilling, cutting, slotting and positioning. This resulted in a technologically and aesthetically successful prototype displaying the design possibilities of technology.

This precedent showcases robotic milling and connections through using joints similar to what this thesis aimed to achieve. However, the assembly of the project required 5 workers, therefore a design was created that can be assembled by a smaller amount of people. 
A key precedent was the Landesgartenschau Exhibition Hall. It showcased the opportunities of timber structures that lie outside of the scope of conventional timber designs. The project integrated knowledge from a range of disciplines such as structural engineering, architectural design and robotic fabrication. The hall is a lightweight timber plate fult-scale prototype that is enclosed and fully insulated. Its primery

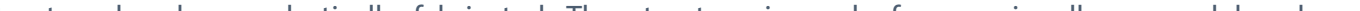
imber whose trees also surrounds the building. "The use of regional materials, i.e. a decentralised production with short transportation routes from harvesting and processing of wood to fabrication and construction, contributes to timber architecture unique potentials for low embodied energy, and therefore, constituted a key premise in the construction of the shell" (Schwinn, 2017, p.114). Sourcing locally is beneficial for the environment and gives a chance to encourage the support of using timber over other merials. New Zealand is a country with a thriving timber industry which needs to be taken advantage of and use this precedent as an inspiration.

The entire shell was assembled only by three workers over a period of three weeks. It was beneficia using prefabrication as a construction method and with the ease of lightweight components, construction times were reduced compared to labour intensive on-site fabrication. The robotic arm was used to cut the panels due to its capability of cutting on six-axis The robot was also used to mill the timber to cieate segmented shells provide the opportunity to reconsider the economic and ecological constraints of shell structures and re-take advantage of their structural and architectural benefits" (Schwinn, 2017, p.118). This shows that many unique designs can be created using the robotic arm and timber. Although this was a successful prototype, this precedent was not fully locked in as it still required many bolts and nails to hold it into place.

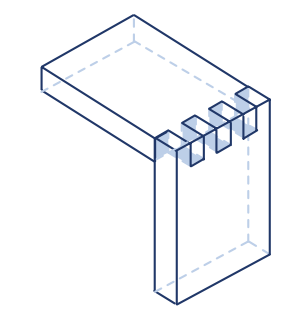

Jint Used: 7356 Finger Joint 
The pavilion investigates the potentials of robotically fabricated finger joints and plates to construct architectural scale plate structures informed by the capacity of biological structures. The sand dollar was analysed and its plate structure was integrated into the pavilion design. Three plate edges were always meeting together at one point which enables the transmission of normal and shear forces, but no bending moments between the joints (University of Stuttgart, 2011). This enables a bearing but deformable structure. Usually, load optimised shapes can be applied to traditional lightweight construction, however, this new principle can be applied to a variety of forms.

The finger joints were good in withstanding shear forces along the edge of the plates, however, on the other hand, they are weak in resisting bending moments or tension forces. A plate shell was able to be created through robotic fabrication and biomimetic rules. The $6.55 \mathrm{~mm}$ thin plywood plates were connected by 100,000 different robotically fabricated finger joints. This shell displays the structural capacity and architectural potential of a system (Menges, 2017). The research methods, design development computational design, simulations and structural design intertwine with each other, as (O) different components. The pavilion had one large interior space with a porous inner layer and a large opening and also had a smaller interior space that displays the constructive logic of the double layer shell (University of Stuttgart, 2011)

The research pavilion offered the opportunity to investigate methods of modular bionic construction using freeform surfaces representing different geometric characteristics whilst developing two distinct spatial entities: one large interior space with a porous inner layer and a big opening, facing the public square entities: one large interior space with a porous inner layer and a big opening, facing the public square
between the University's buildings, and a smaller interstitial space enveloped between the two layers that between the University's buildings, and a smaller inters
exhibits the constructive logic of the double layer shell.

This research is relevant to this thesis because $6.5 \mathrm{~mm}$ of thin plywood sheets were used to create this structure. This proves that no matter what thickness materials are used, structures are still able to be created through computational design and robotic fabrication. 


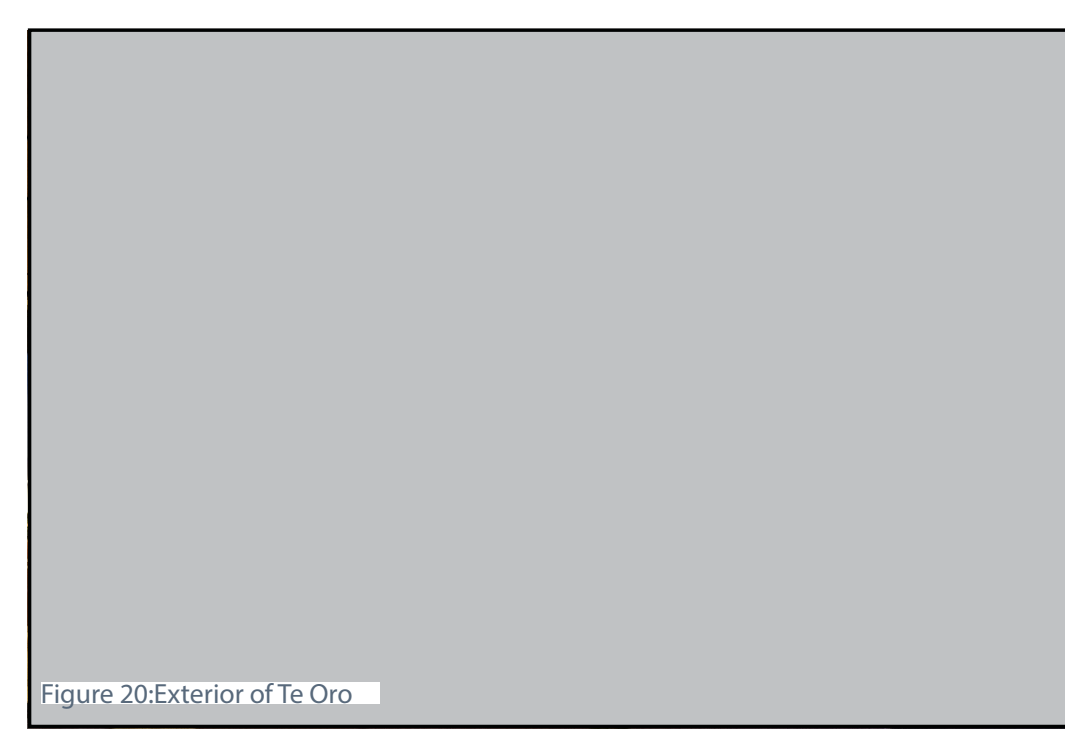

The exterior has a unique shape that

used computational tools to design the

structure. The interior uses laminated

timber and exposes the screws used to

hold the timber together (Brink, 2016). It

uses timber as its aesthetic quality.

Te Oro Community Center

Auckland, NZ

Archimedia

(Reynolds, 2015)

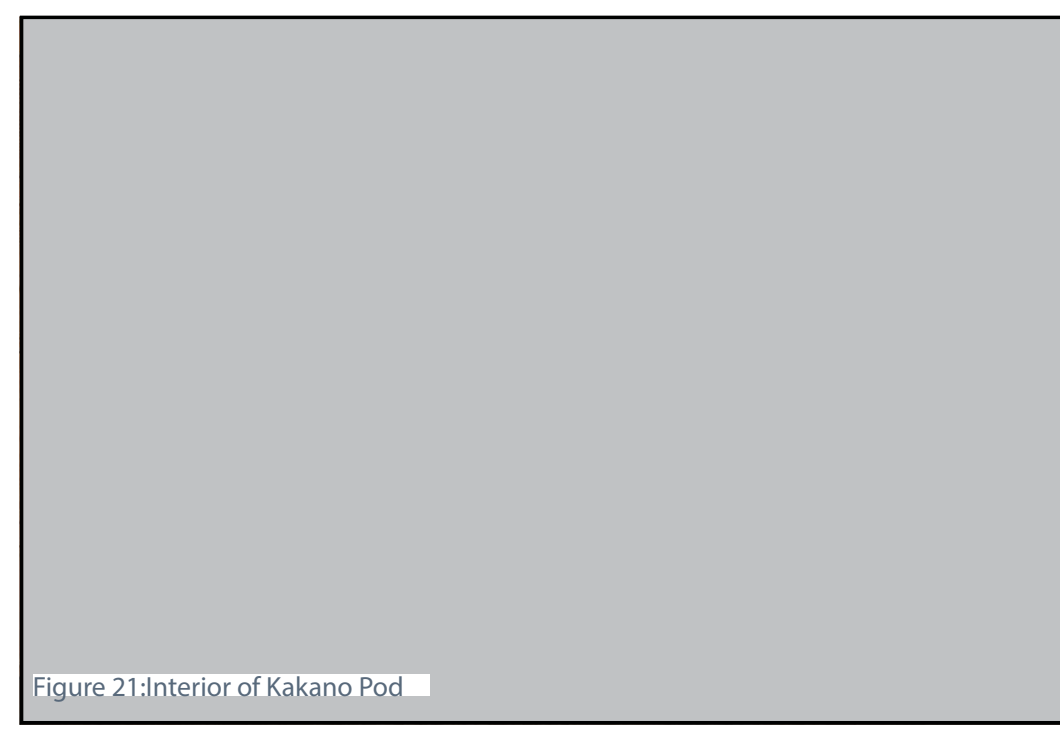

A structure located inside a building.

It is located at the entry point of the

atrium, providing a teaching and

reflective space, and allows for acoustic

isolation from the lively atrium. Created

from $18 \mathrm{~mm}$ plywood and screwed with

aluminium angles with a decorative outer

plywood skin (Tennant \& Brown, 2012).

Ngapurapura Kakano Pod

Otaki, NZ

Tennant + Brown Architects

(Mccredie, 2014)

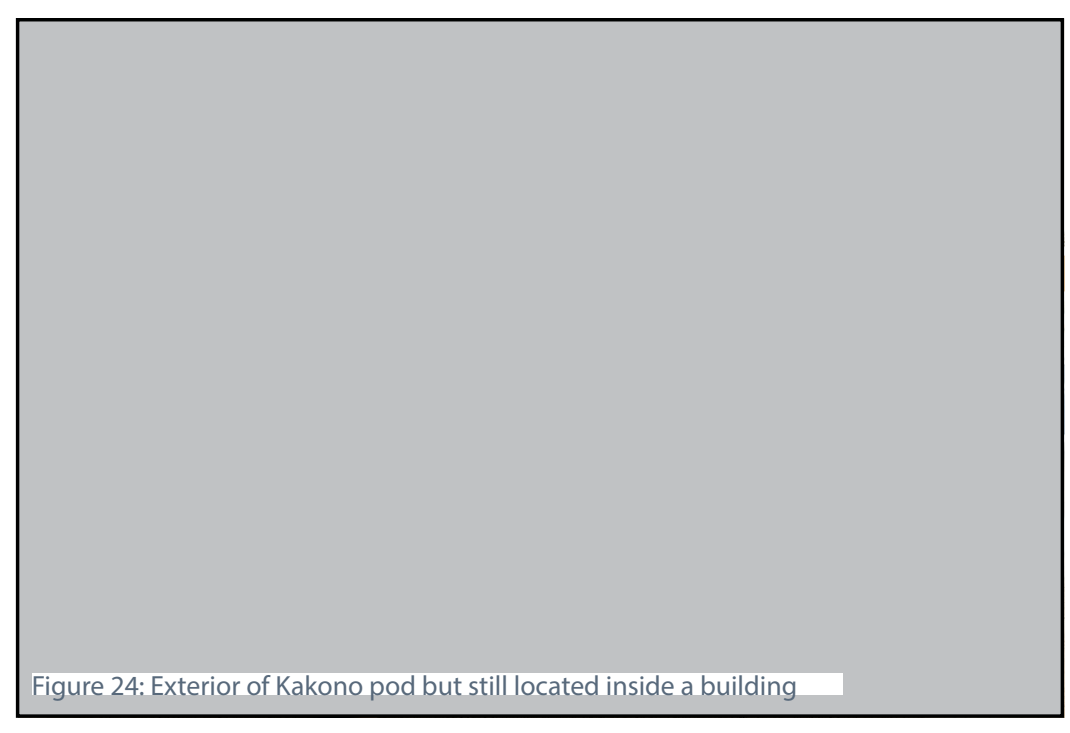

These three precedents are located in New Zealand. All three of these used computational tools to help design the structures, as well as a CNC machine to fabricate the structures. These were built within the last decade, showing that these tools combined are becoming more common in the design and more common in the design and
construction industry. However, they all still required metal fixings, showing that New Zealand structures have not tested wood to wood connections yet. Robotic fabrication was also not used, as it is not concept that the construction industry a concept hat the construction industry is familiar with yet. These precedents showcase that unique structures are starting to come into the industry,

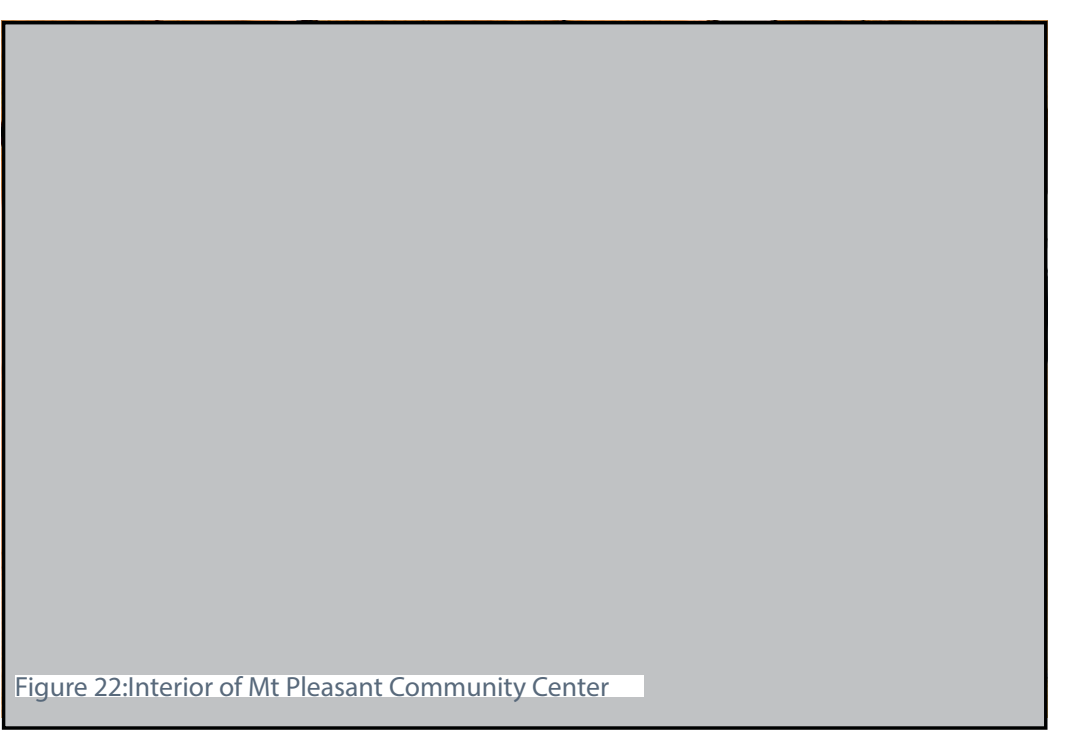

This project was created using a desig fabricate and assemble method. It was fabricated on a five-axis CNC router

using $45 \mathrm{~mm}$ thick laminated veneer

umber (Marriage, 2018). Features an angled timber interior.

Mt Pleasant Community Center

Christchurch, NZ

Chris Moller Architecture + Urbanism

(Radermacher, 2018)

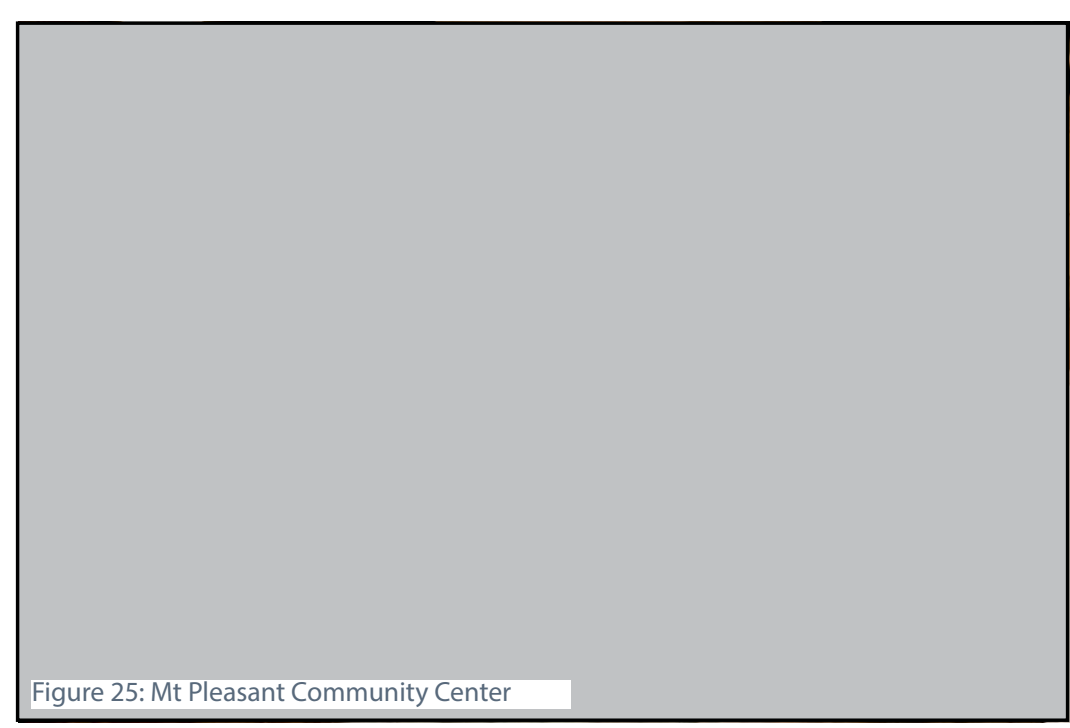

hever more tools needs to be tested

with it to speed up the workflow to

create these unique designs. 
The literature review gave an insight on the topics that are dealt with in this thesis. It helped inform on what has progressed in the last few years and also defined the gaps that are currently missing in the industry. It is clear that a more sustainable based construction is needed, as engineered connections are not contributing to a sustainable approach. Timber needs to be used more, as proven by alarming figures found on steel and concrete contributing to a large percentage of global greenhouse gas emissions.

Current precedents show that robotic fabrication combined with timber has created unique looking structures that can be customised using computational tools. However, all these precedents still use metal fixings to hold it together, which does not help lower the statistics on the contribution to greenhouse gas emissions. This showed a clear gap that needed to be explored to redefine how robotic fabrication can be used with timber without the need to use metal fixings.

Japanese timber connections have demonstrated its longevity, with buildings still standing that were created with these connections from hundreds of years ago. The advancing level of technology we have with robotic fabrication and computational tools can help create these connections faster than how they were originally crafted and can be used in buildings today.

This literature review has created a base for this thesis and defined what is needed to be explored. Which is creating a workflow using robotic fabrication and computational tools to create a unique structure without the need of metal fixings to join timber pieces together. 


\section{INTRODUCTION}

This chapter begins with tests using the CNC machine, laser cutter and paper folding. This chapter was important to understand how common machinery used in architecture works. Grasshopper, a parametric software was also explored in this chapter. This was done to understand the plugins available and identify the forms can be made with the software. The testing of the software created a form that was then able to be exported to create laser cut models with it. 

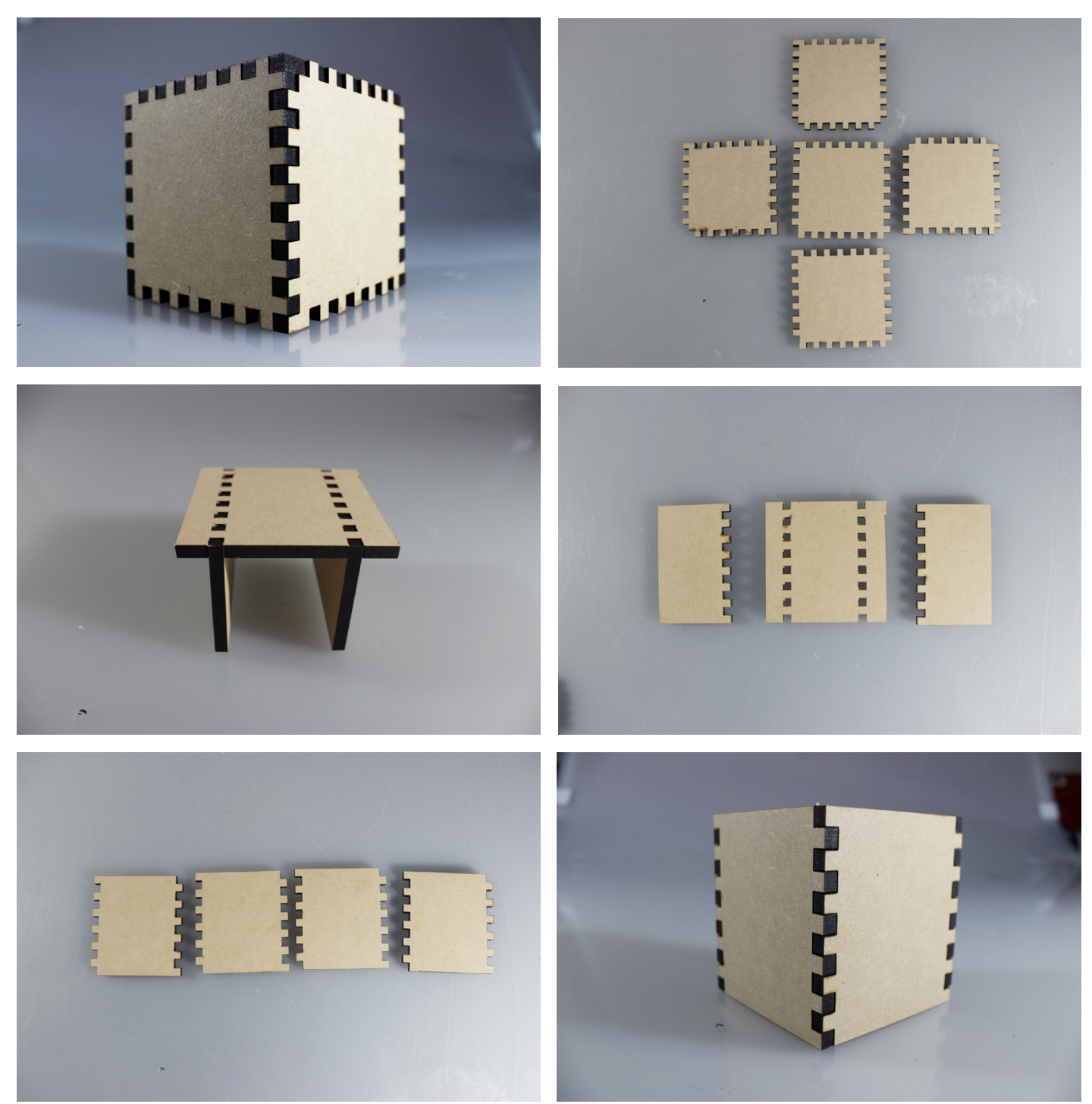

Figure 26: Laser Cut Models

A basic box was created on the laser cutter and joined together by finger joints. This did not require any glue to hold it together. The laser cutter only limited the cut to be a finger joint as it can only cut vertically through in one direction
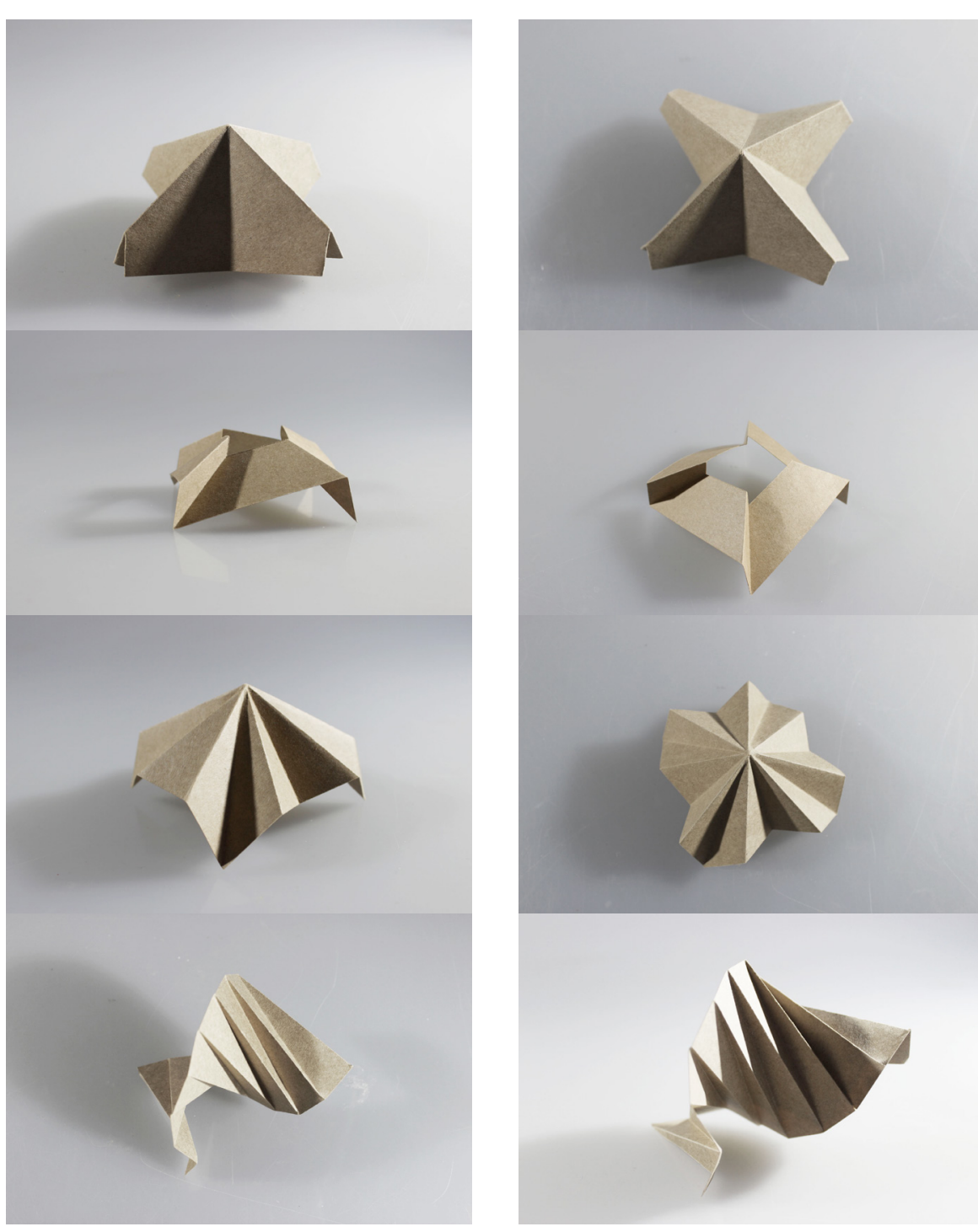

Figure 27: Paper Modes

Paper was folded to see what forms could be created with just manually folding. This process is a lot faster than modelling a form digitally. However, only simple forms could be created with manual folding. 

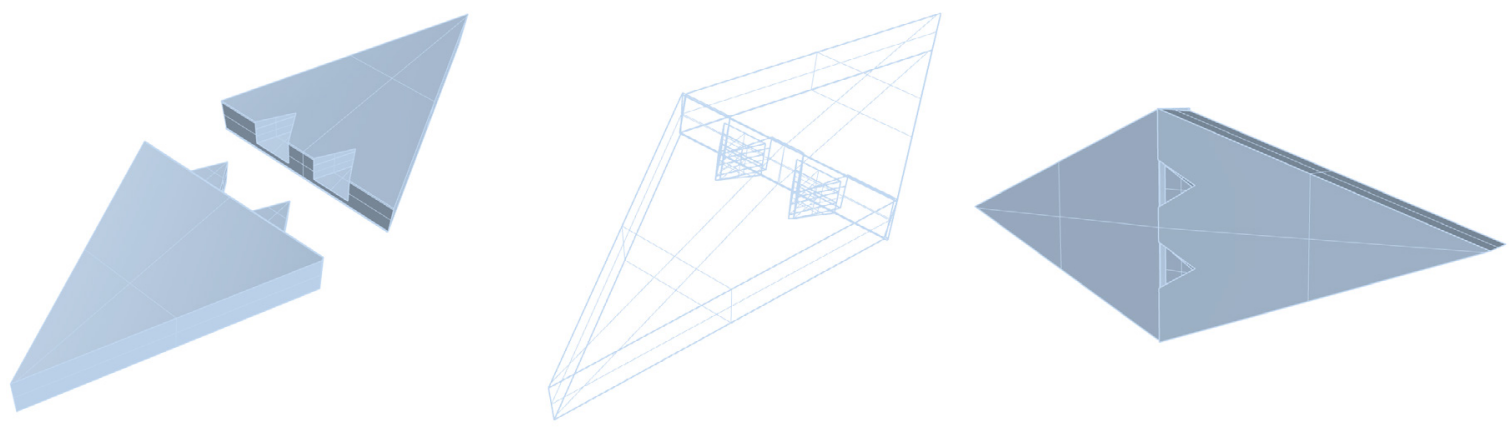

Pointed Finger Joint

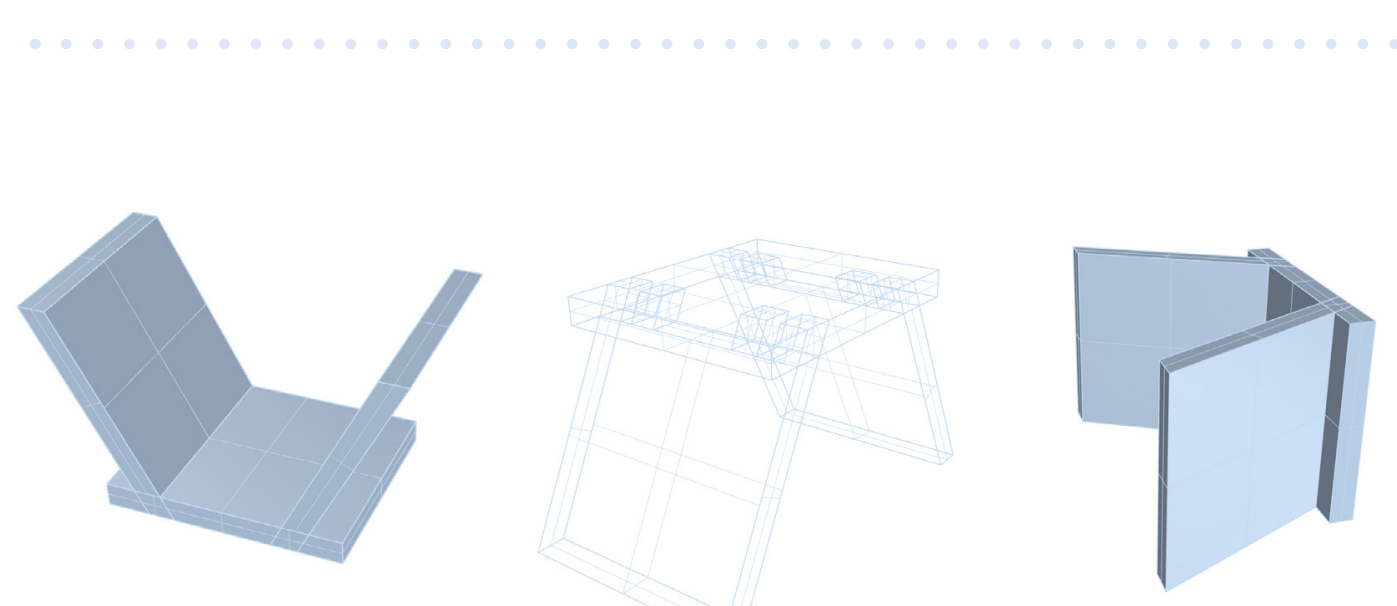

Bridle Joint
A pointed finger joint that wasn't fully cut through and a bridle joint was chosen to be cut with the CNC machine. These two were chosen due to the angle required to create these connections, even though they gave the impression that they were simple cuts. Due to the limitations of the CNC machine, the timber piece used to cut the bridle mortise joint had to be reversed halfway through the cut to achieve the correct angle. This caused the tenon to struggle to fit into the mortise This became an accuracy issue, as manul labour combined with the CNC machine was required to complete the cut. The pointed finger joint also struggled to fit itself into the gap, as not enough tolerance was given to the gap, therefore, it had to be heavily sanded down in order for it to fit. These were two very small-scaled cuts, and the process needed to achieve these for it to work was time consuming and not very practical when angles are needed to be cut with the CNC machine. Therefore, with larger angled cuts, it would take even longer and not work well with a structure.

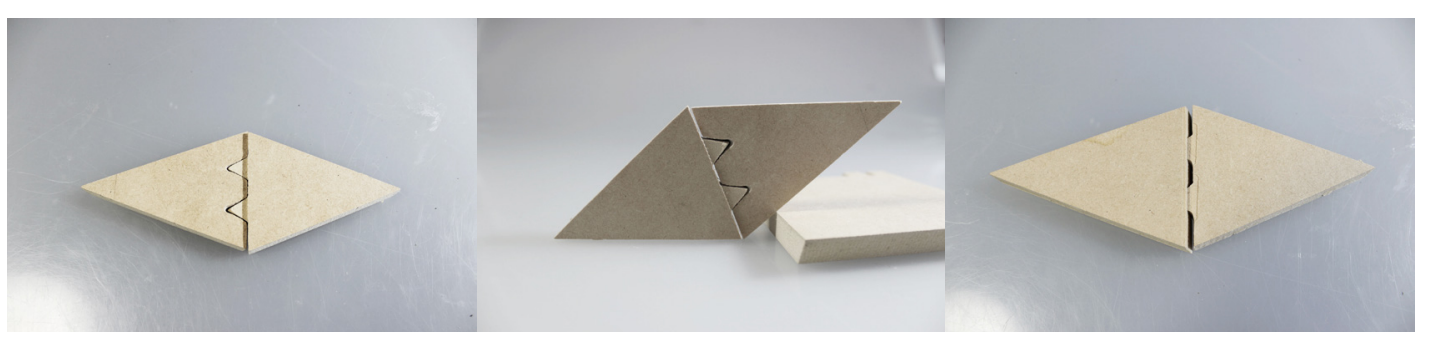

Figure 28: CNC Joint Model

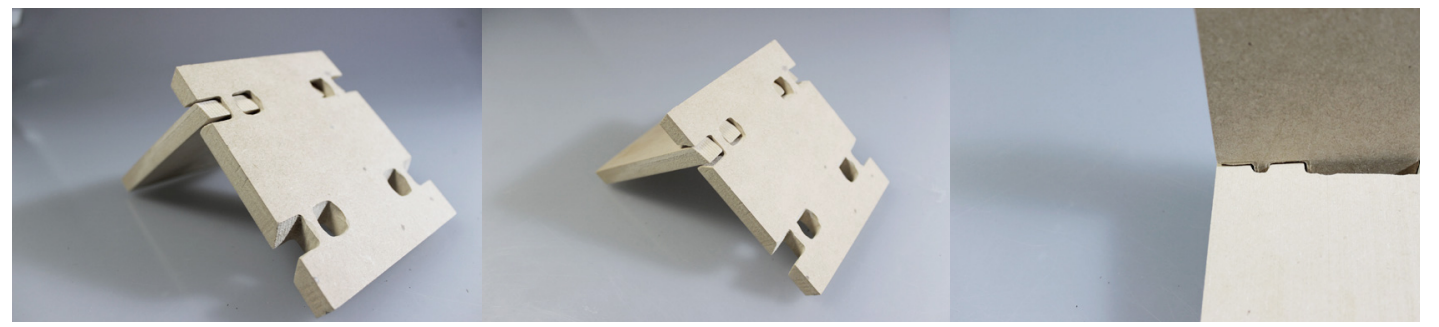

Figure 29: Bridle Joint Mode 


\section{PARAMETRIC FORMS}

3.4 .0
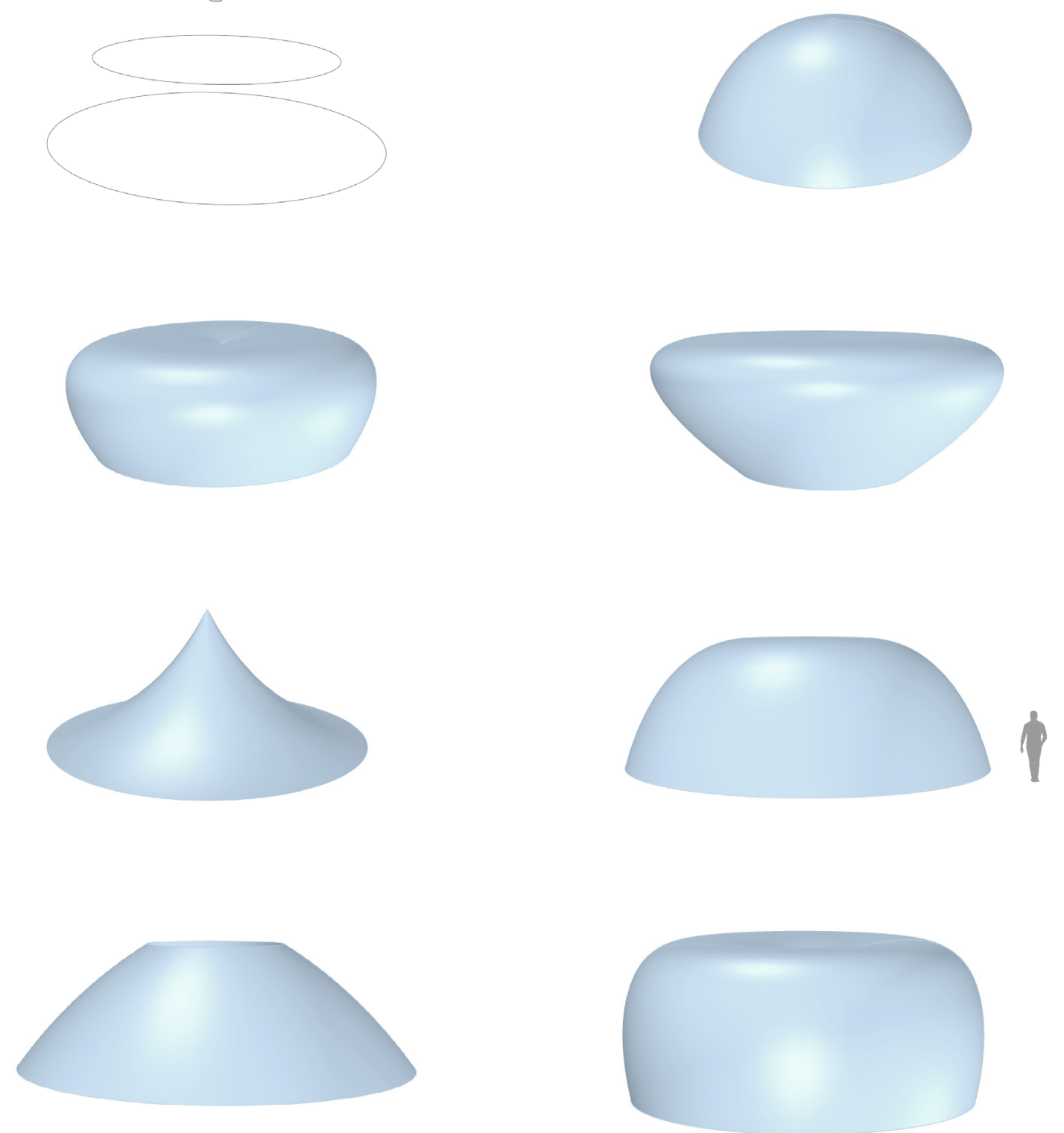

Figure 30: Parametric forms created digitally

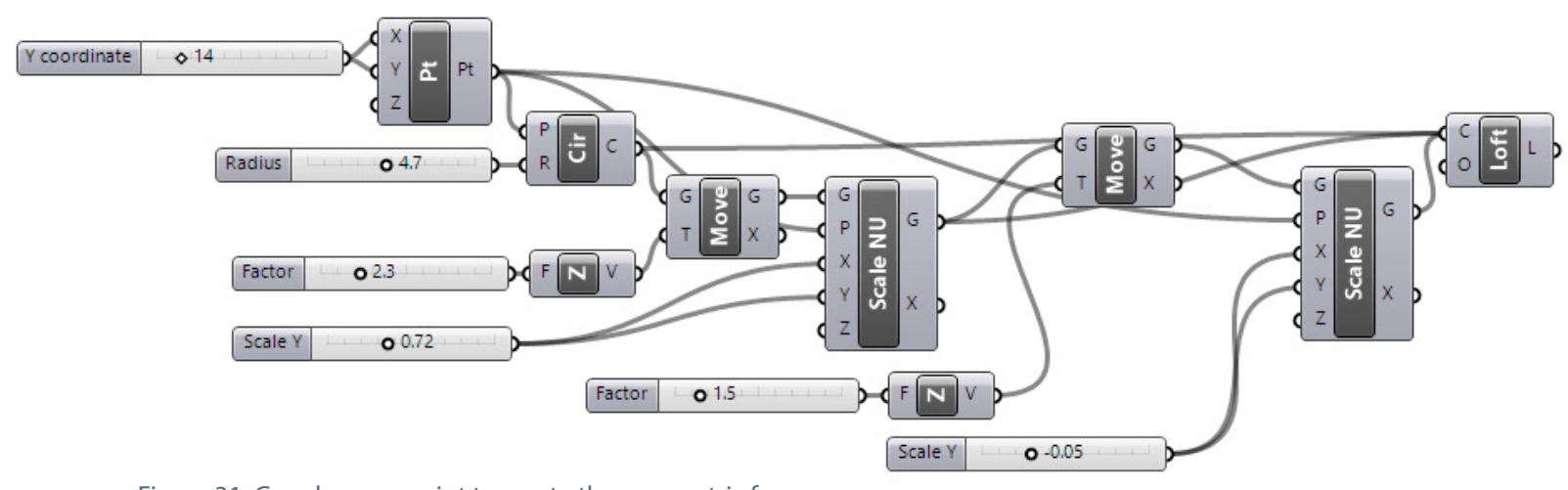

Figure 31:Grasshopper script to create the parametric forms

Grasshopper was used to create parametric forms. This first test began with creating a dome with three curves that can be adjusted with set parameters. This was important to have a basic understanding of Grasshopper and understand the limitations of it.

\section{PATTERN FINDING}

3.4 .1
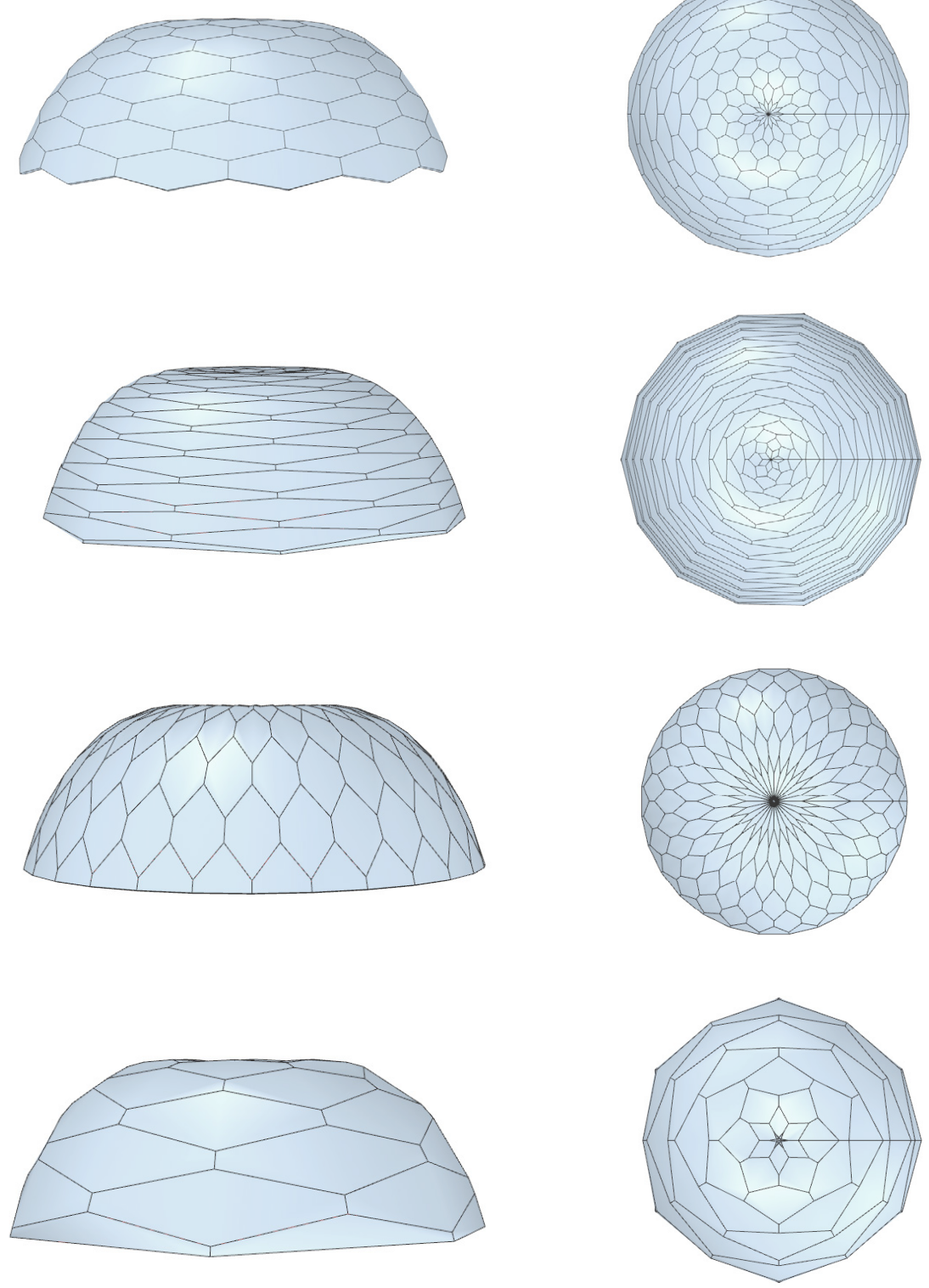

Figure 32: Pattern exploration

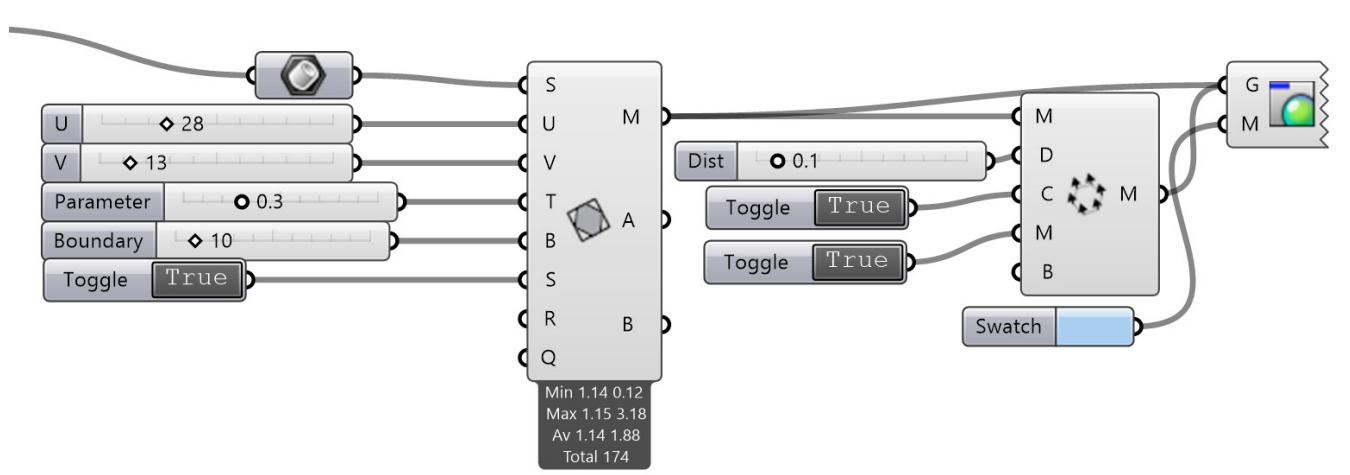

Plugins for grasshopper was used to create patterns on the forms created. Multiple patterns were created by changing the sliders on the parameters. This showed that an infinite number of patterns can be created on the forms, therefore certain criteria needs to be set to ensure which patterns will work in this research 

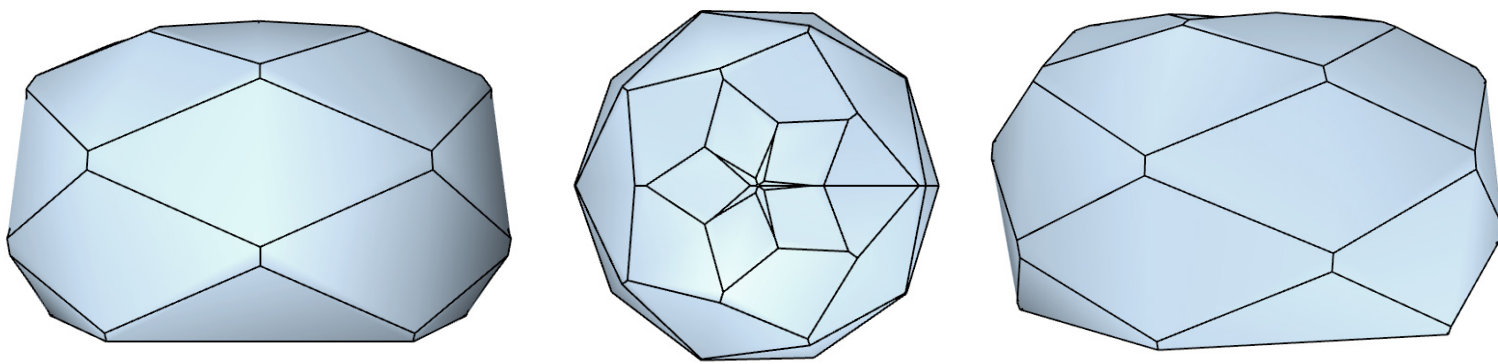

Figure 34: Curved panels
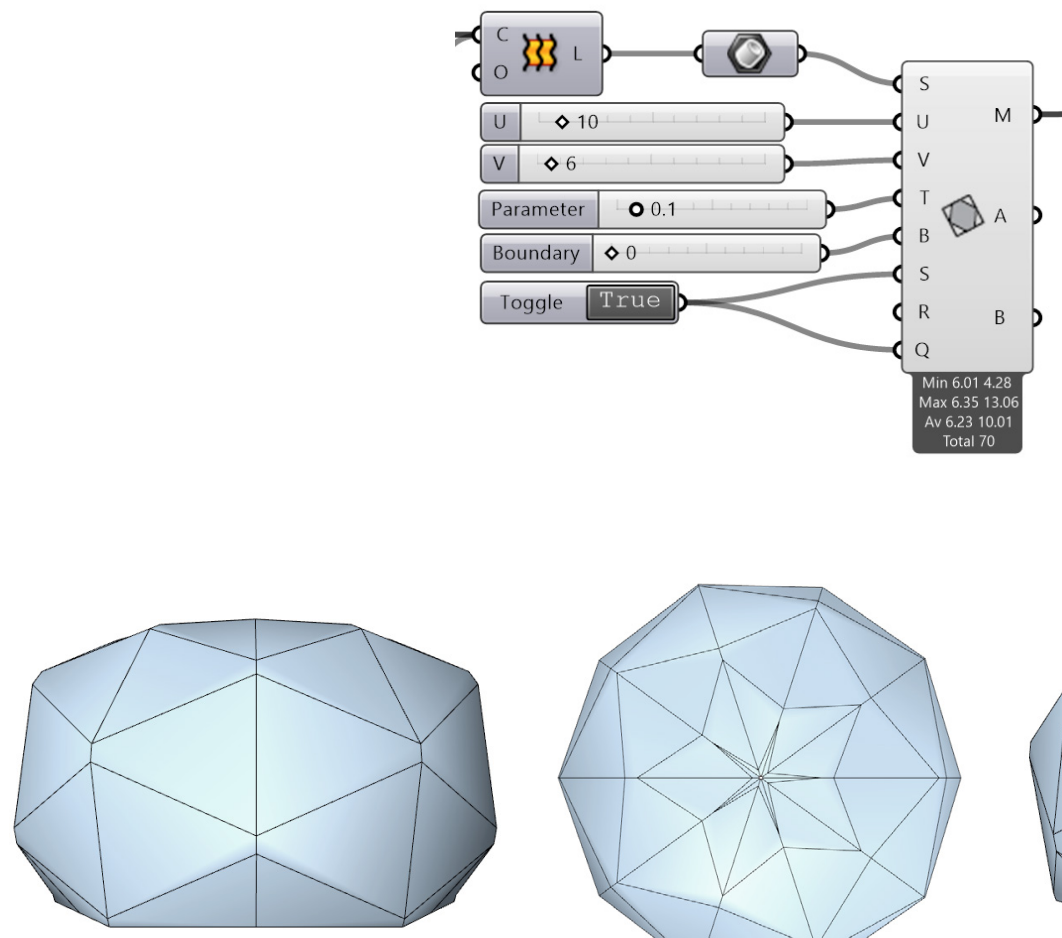

Figure 35: Straight panels
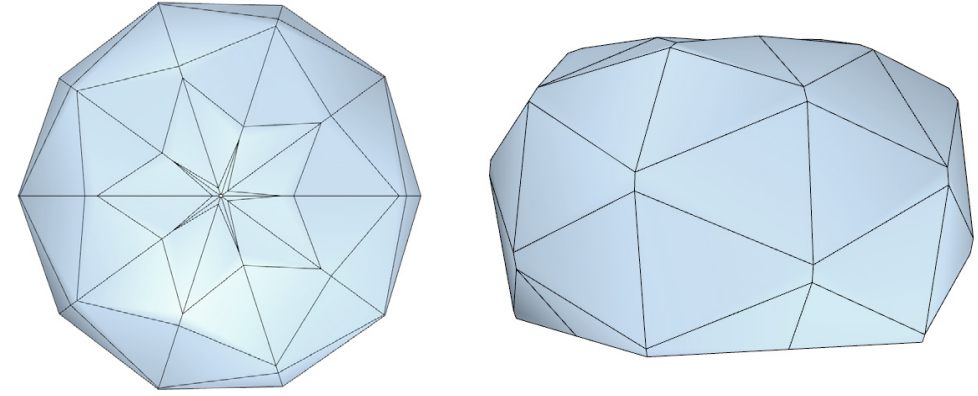

A criteria was set, which ensured the patterns generated had created flat panels. Straight edges was also part of the criteria to ensure the panels would be able to be fabricated and assembled. Therefore curved edges were disregarded in the parametric code.

A limitation with the first code was that the panels were not flat. This issue was noticed when using the plugin IVY to unfold the design, however the code kept failing because of the non-flat geometry. After further testing with the parametric software, the quandragualte function was used which created flat panels on the surface. A limitation of this is that it created more panels to overcome the non-flat issue. Therefore a way for the code to automatically generate flat panels will need to be experimented, as the way this code was set up was unsuccessfu

\section{EXPERIMENTATIONS}

3.4 .3
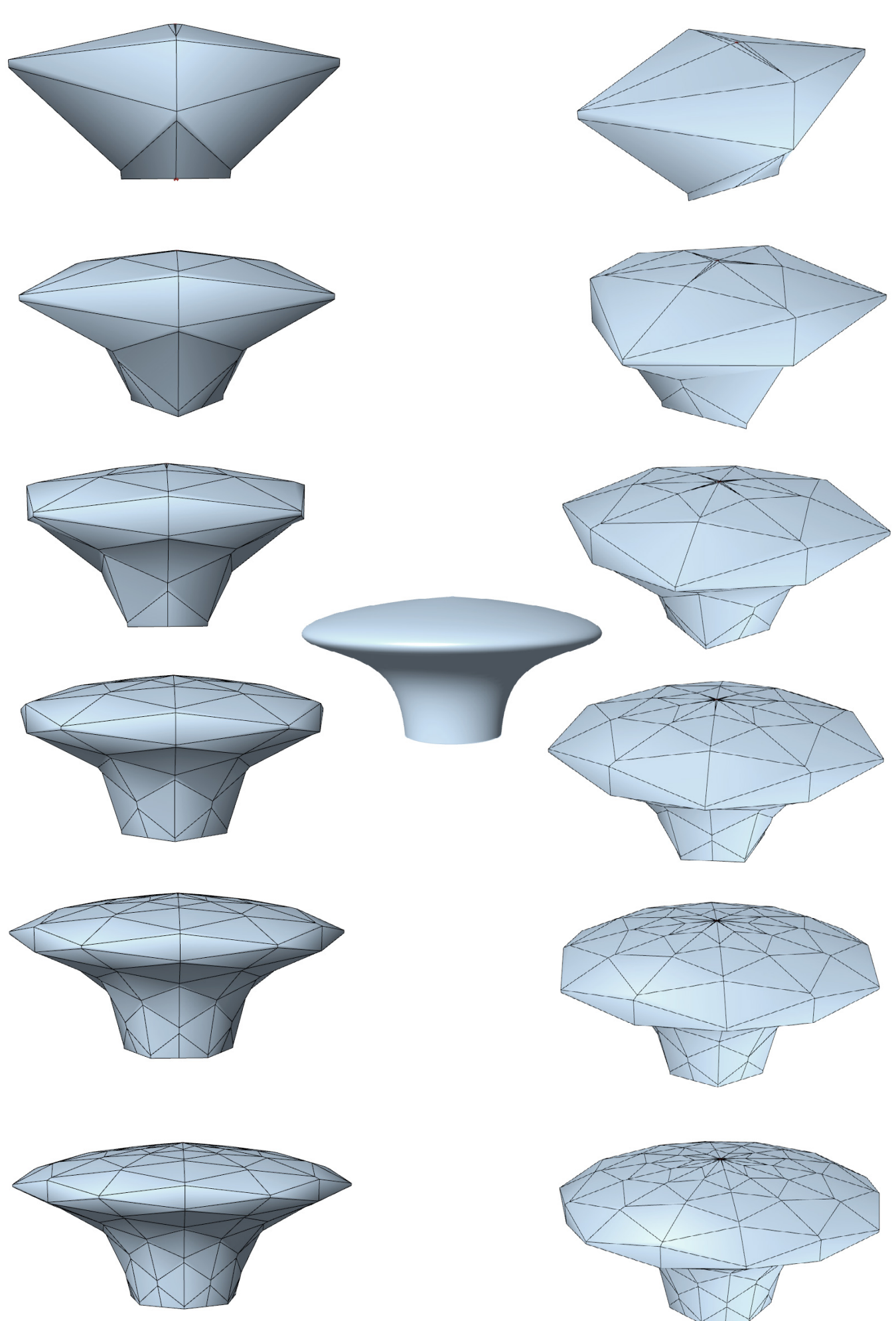

Experimenting with a different shape 

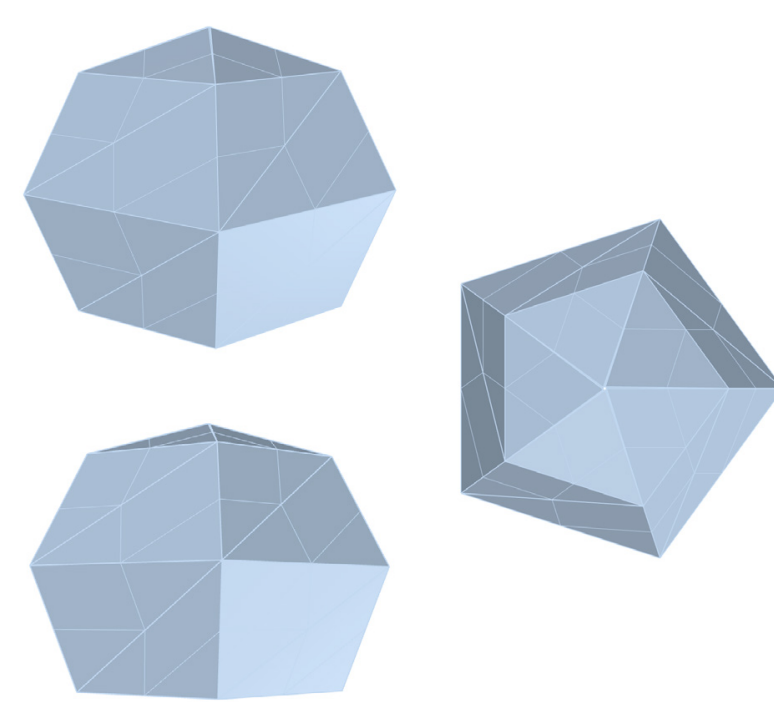

DESIGN

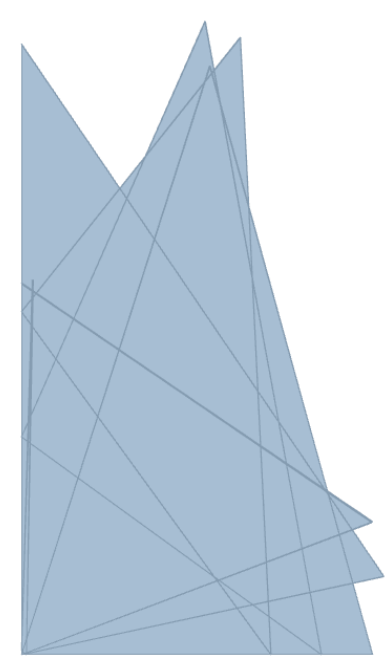

UNROLL

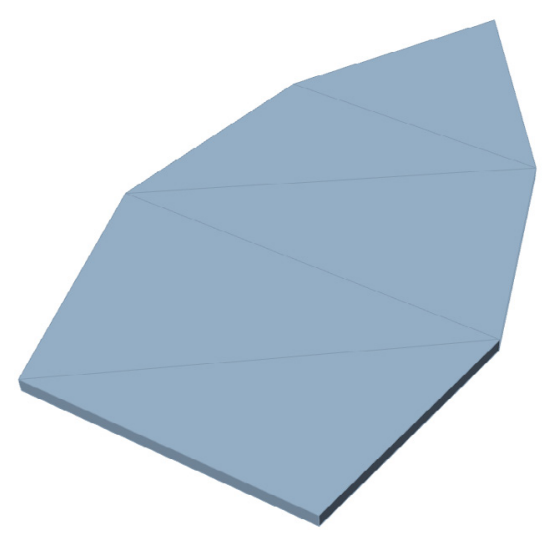

MOVE

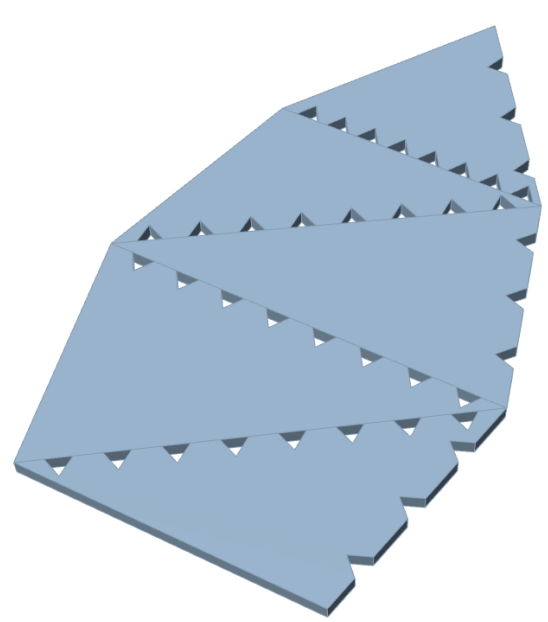

CREATE JOINT

$\checkmark$

1

$-$
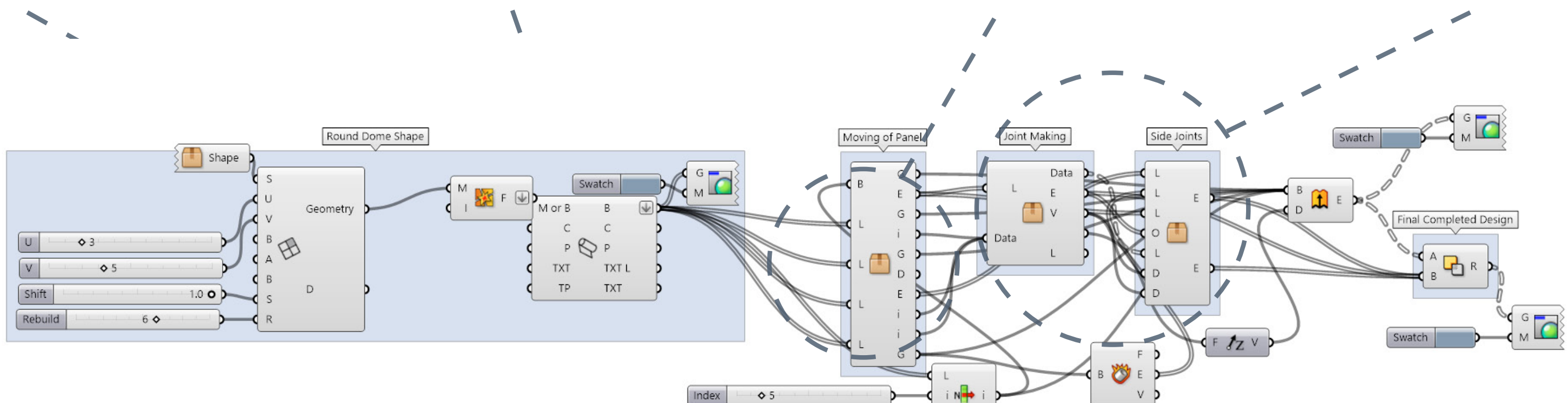

Index $05 \quad 0$ i ing $i$

A base form was created on Grasshopper to be transferred to the laser cutter to be cut. Joints was also created on Grasshopper, to allow brisk assembly of the model because it would not require glue due to the joints locking into each other. A code was created on Grasshopper that allowed a form to be created, then flattened in the software. This meant all the different panels used to create the form was automatically disassembled and all the outer faces of the panels were facing up in the $Z$ direction. Although the code was designed to automate the disassembly, it disassembled the panels all in the same area, therefore it overlapped each other. To resolve this issue, the code was adjusted, so the correct panels would move to the correct place where they fit each other. Following on, joints were created in 

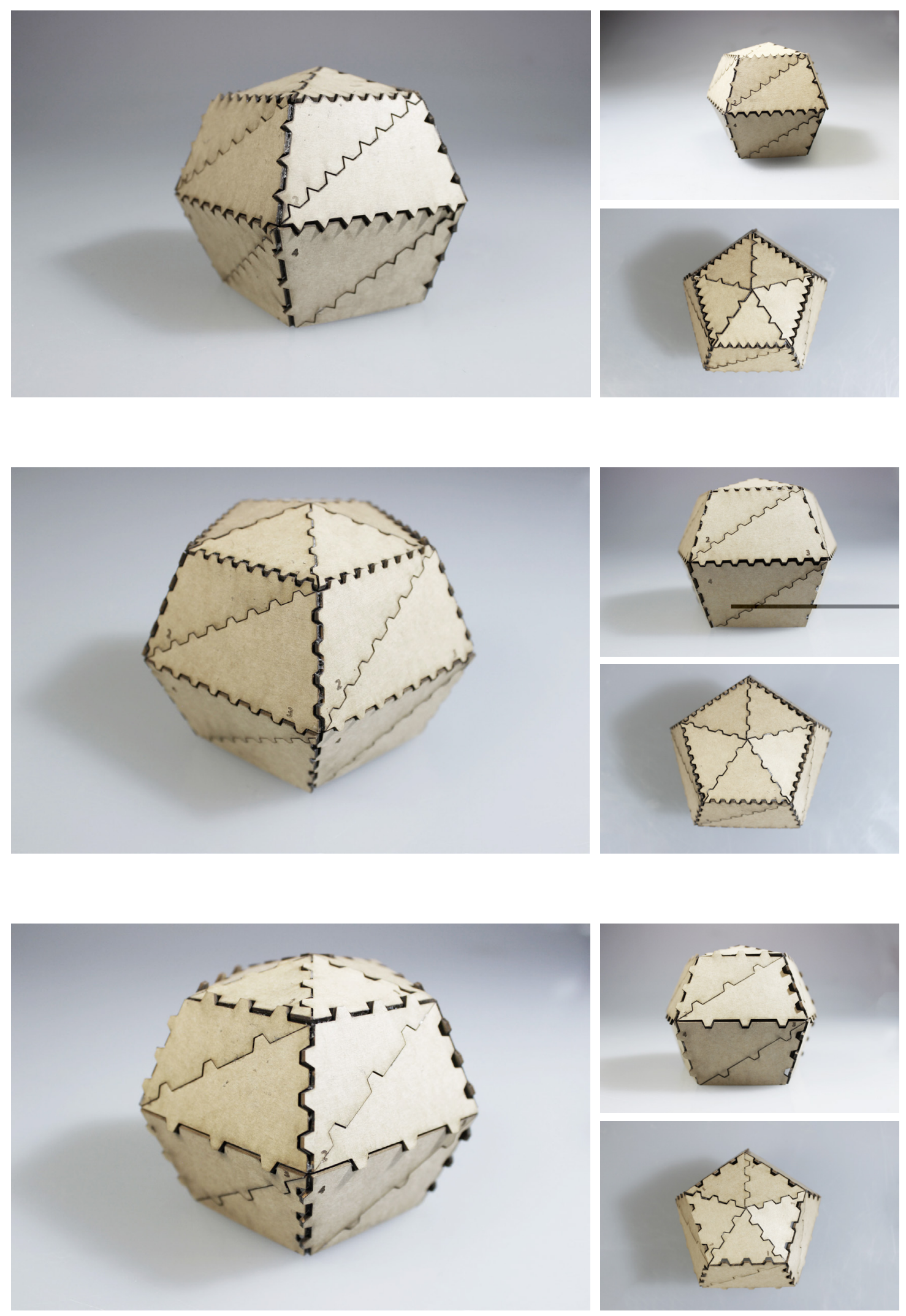
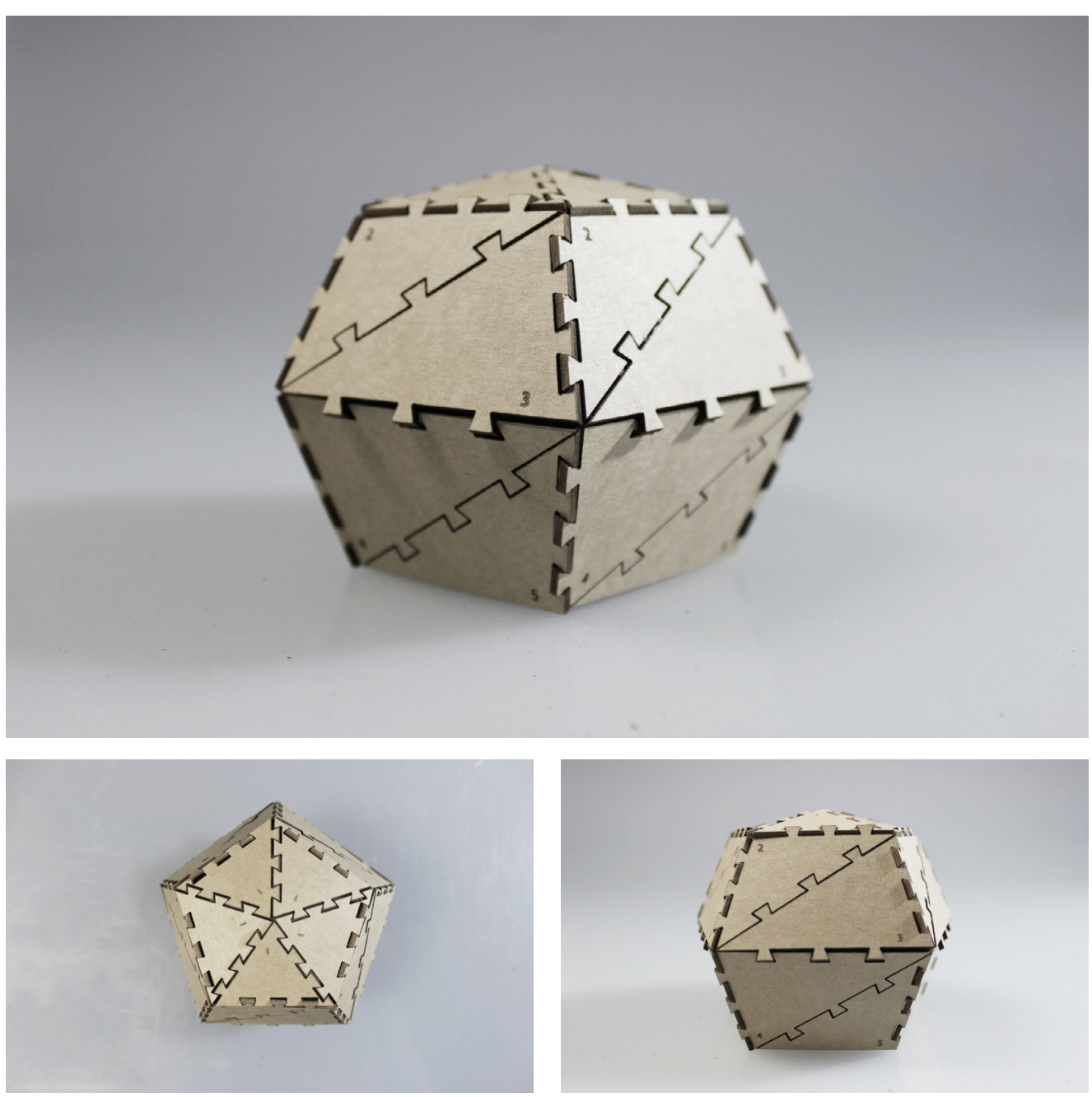

Several finger joint styled shapes were created in Grasshopper to be used with the laser cut models. The laser cut models used $1.5 \mathrm{~mm}$ thick brown card. From creating the first 3 models, they were struggling to hold itself together, as it required glue to hold itself together. Therefore, a different joint was needed to be explored as the finger joints was not working. A dovetail shaped joint was then experimented with the laser cutter. This was more successful as it allowed the card to hold itself together without needing glue. 


\section{REFLECTION}

This chapter was the beginnings of going from digital to physical. The experiments with the laser cutter and three-axis CNC machine showcased the limitations of the designs that can be created with them The exploration of Grasshopper led to many forms generated, however, few could be cut on the threeaxis CNC machine. This helped with the understanding of why a six-axis CNC machine would be more beneficial over current machinery used.

Finger joints tested on the laser cutter were unsuccessful except for the dovetail-shaped finger joint, as it did not require glue. Therefore, the dovetail-shaped finger joint was further tested on a form created in the following chapters.

Due to Grasshopper being a software that has many plugins, many of these plugins have infinite shortcuts or ways to generate forms. However, only certain plugins were tested, and although some did not create forms as efficient as others, the ones created were satisfactory enough to create flat panels. It is difficult to test all the possibilities each plugin can create as there are everlasting possibilities, therefore a stop point on form generation was called to ensure progression of this research. 


\section{INTRODUCTION}

This chapter focuses on creating a toolpath with the robotic arm. Due to there being no set software for robotic milling, toolpaths were created on Grasshopper, which is a visual scripting language add on for Rhinoceros 3D. HAL Robotics is a Grasshopper plugin that was used to create the toolpath. These programmes combined provided a way to view the toolpath as a 3D graphic in the Rhino interface. This was an efficient way to generate computational simulations with the toolpath, as visual feedback indicated where the toolpath would mill through the timber and show where the spindle would clash with it. This led to reworking the code until the toolpath was going in the right direction.

Prior to creating a toolpath, it was important to understand the workspace and analyse the router tool bits available. Analysis of the router bits was important, as when creating the toolpath, the diameter of the router bit needs to be taken into account, to ensure a precise cut in the correct area. The workspace was also important, as hazards and obstacles were identified to ensure the route the robotic arm takes to follow the tool path will not clash with the obstacles.

Creating the toolpaths involved many parameters such as speed, planes, router size and amount of passes to ensure it can be outputted correctly as the robotic arm's Rapid Code. The toolpath created in this process goes beyond the limitations of a traditional CNC machine's CAM toolpath generator. Customisation of the toolpath was a key benefit as it creates greater design freedom and allows the fabrication of bespoke designs.

\section{CHAPTER 0.4}


Spindle tool and controlling the router bit size

Creating passes, points and

turning the points into planes.

Also controlling the direction of

the planes

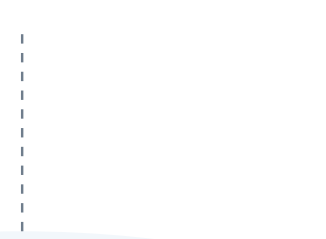

$3=$

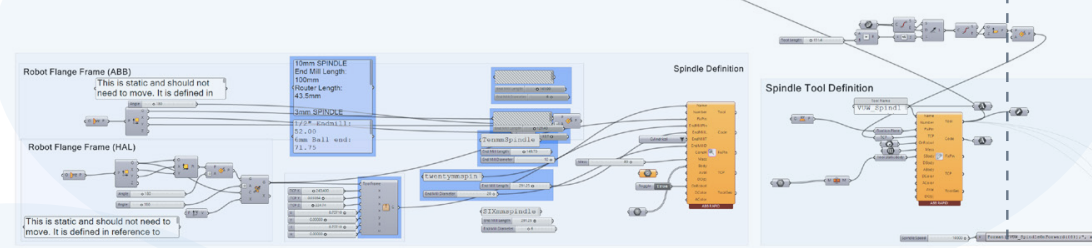

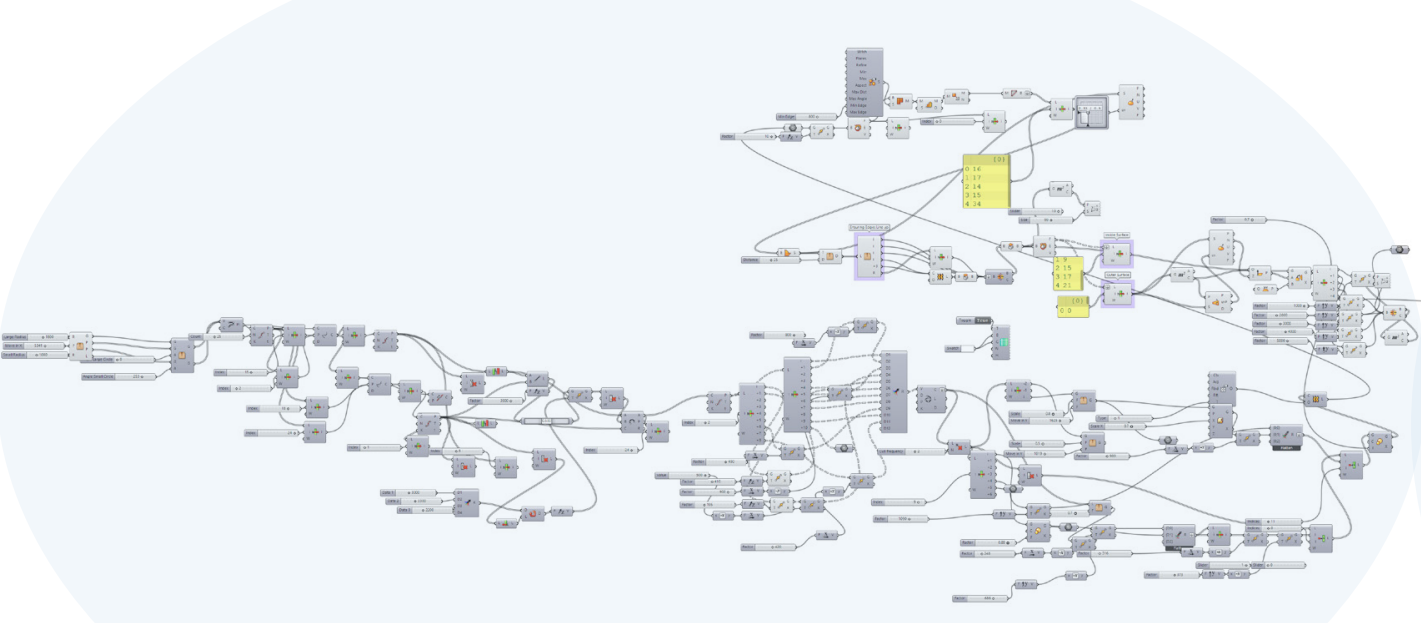

Creating the structure, and flattening out the panels

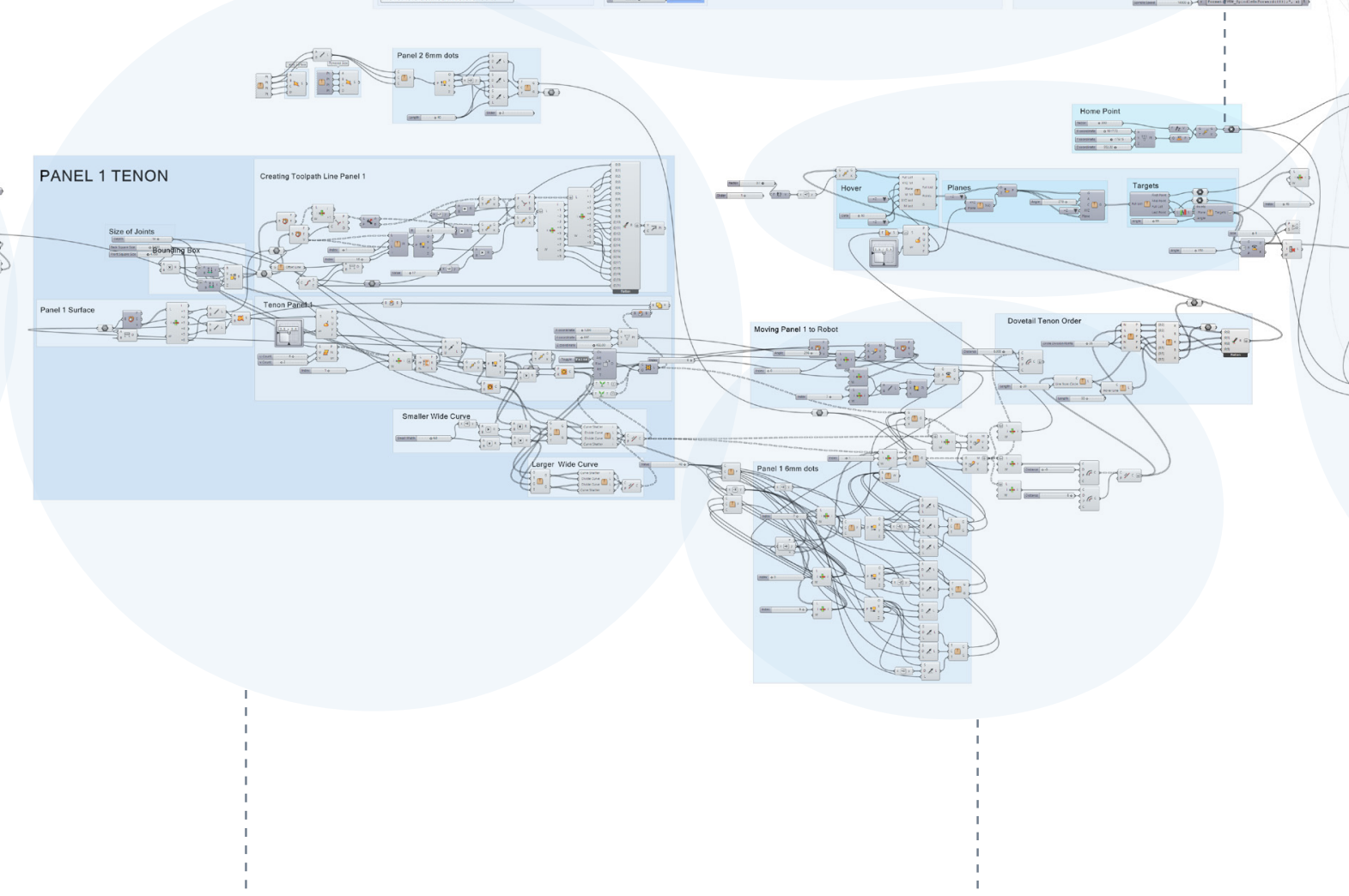

Creating joints on the panels

Moving panels and joints to the robotic arm table surface

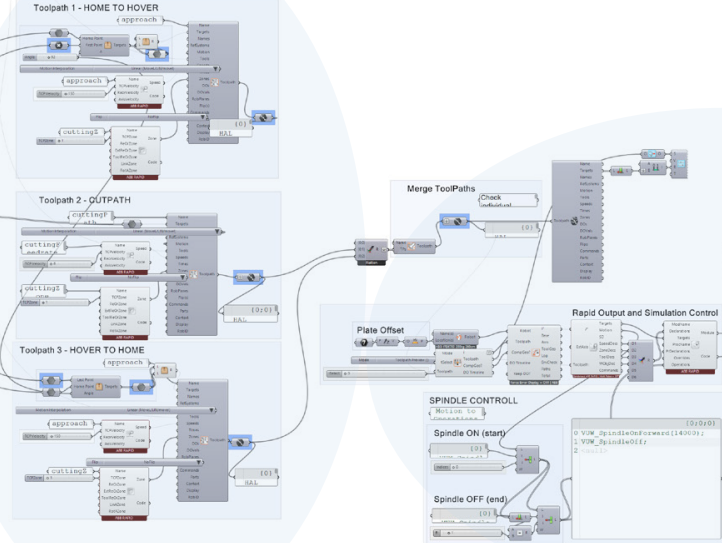

Controlling the speed of the router bit, and turning the planes into a toolpath
Turning the toolpath into a Rapid ode that the robotic arm ca 
1. Offset curve by $1 / 2$ the diameter of the router bit.

2. Array curve by certain amount of millimeter to create passes till the depth of the timber is cut.

3. Flip direction of every second curve, then join to create a continuous curve from start to end.

4. Create points along the continuous curve, so the robotic arm knows which target point to go to next.

5. Convert points to planes, so the robotic arm will know which direction to face.

Passes were created as the router bit cannot cut the whole depth of the cut in one go, otherwise, the router bit would break. Therefore, multiple passes were created, which would only cut the timber only a few millimetres at a time. The passes had many parameters that were controlled such as the depth of each pass and more passes were created dependent on the thickness of the timber the size of the router bit. The depth was decreased if there was a more detailed cut with a smaller router bit Larger router bits does not require smaller depths, as it can handle cutting deeper into the timber without the bit breaking.

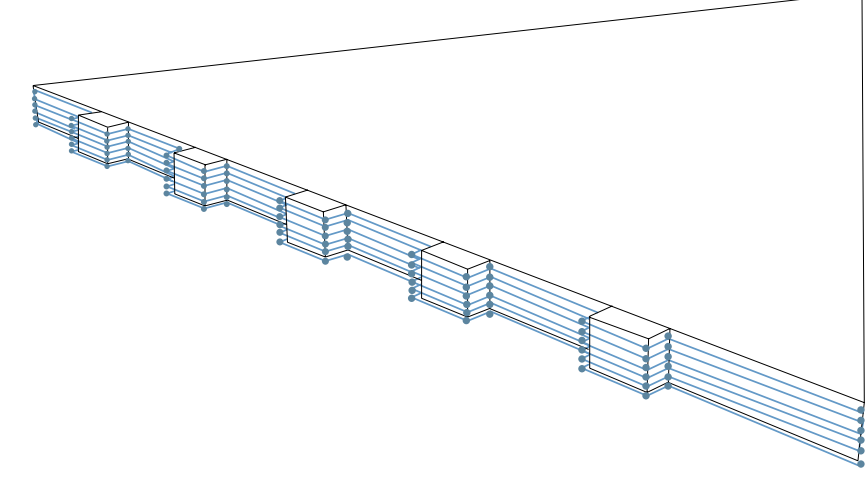



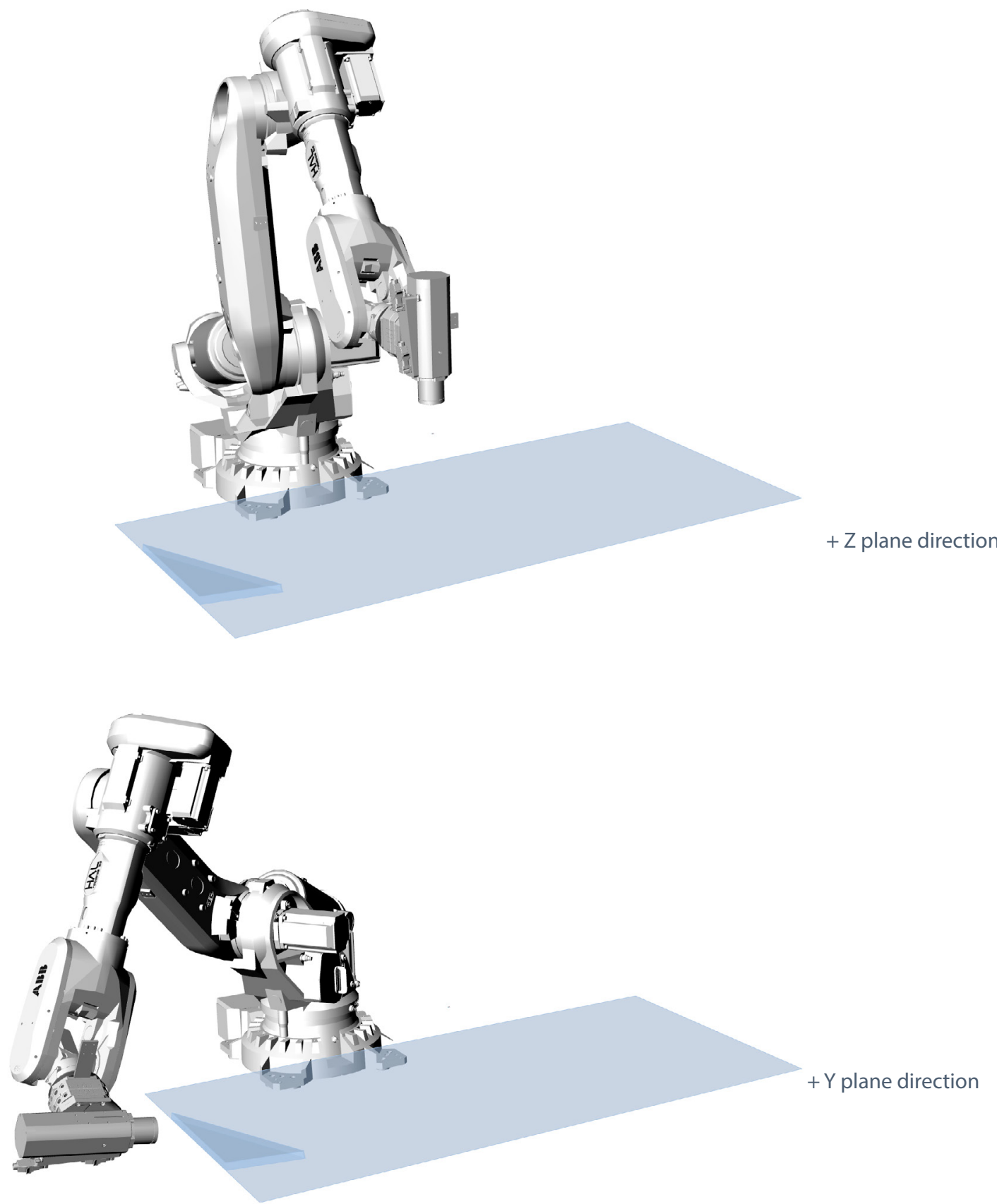

A script was created to convert points into planes on Grasshopper. This allowed the robot to approach the timber from the correct direction to cut. The $Z$ plane would allow the robot to approach the timber from directly above, the $Y$ plane would approach from the side and the $X$ plane would allow the robot from the other side. Angling the planes would also allow the robot to cut from a specified angle to achieve nonorthogonal cuts. The ability to control the planes enables customisation in the timber, as it was able to be pproached from any specified angle.

The digital simulation was important in this process as it displayed where the clashes would occur and would turn red when the robotic arm could over-rotate or reach unreachable positions. This decreased the risk of errors and increased itself in the simulation, the angle of the plane would be changed in the script to allow the robotic arm to approach the same cut from a different direction. The use of parametric software was particularly useful in this process, as small adaptations could be quickly made to ensure the simulation is successful and can be exported to be physically cut.

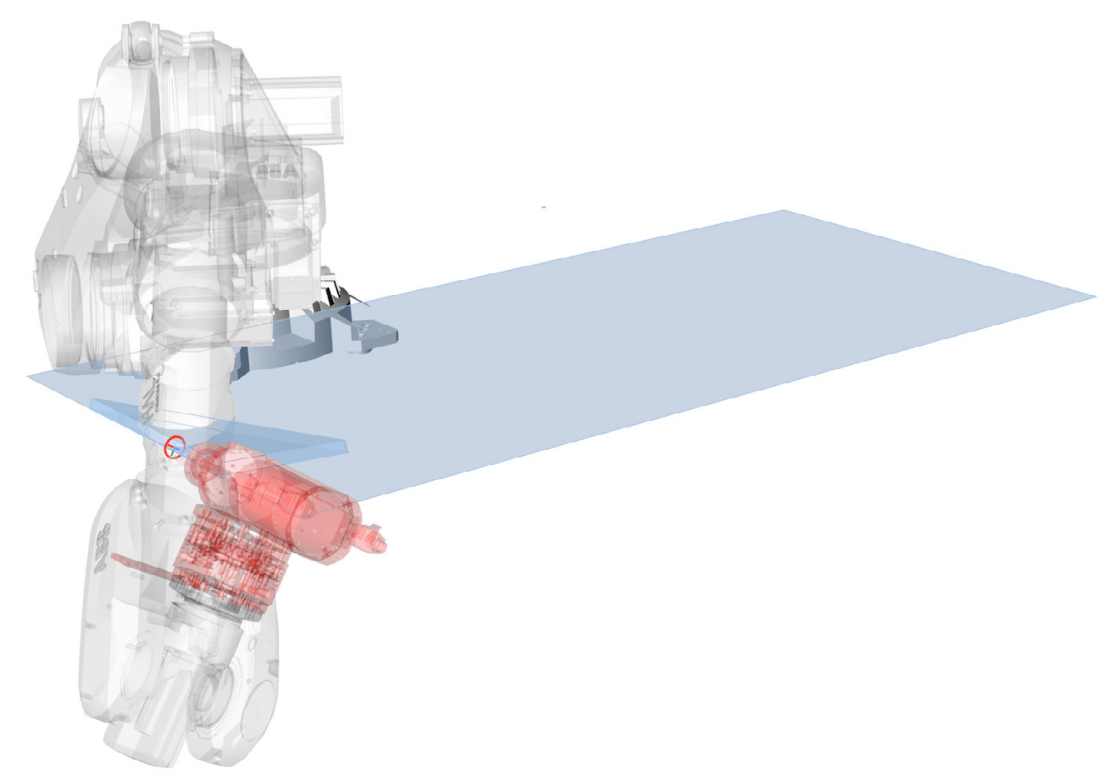




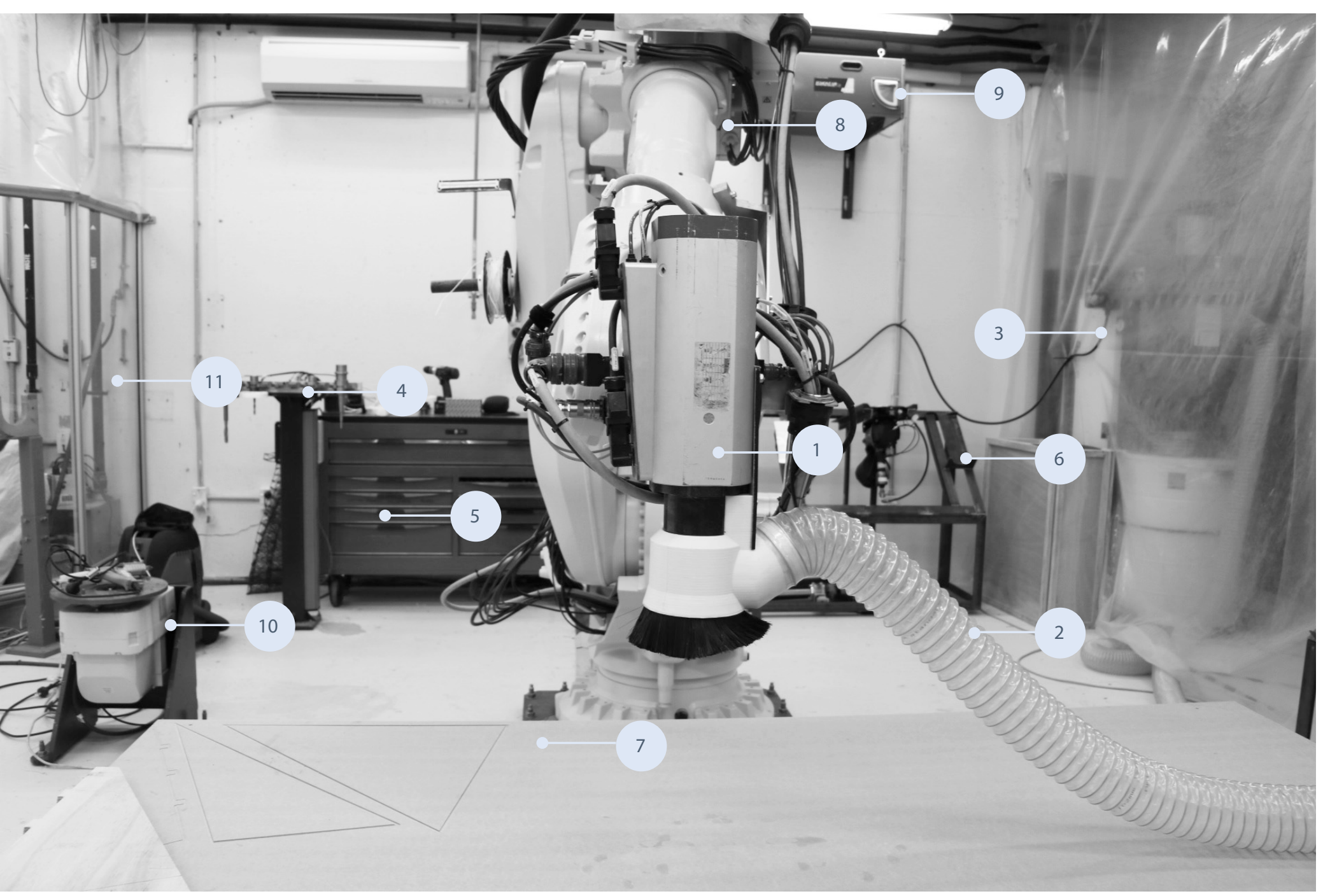

$1 \quad$ Spindle

2 Extraction Hose

$3 \quad$ Extractor

(4) Tool Rack

5 Tool Drawers

6 Spindle Rack

$7 \quad$ Work Table

8 ABB IRB 6700 Robotic Arm.

$9 \quad$ Air Filter

10 Rotary Table

(11) Clear Protective Wall 


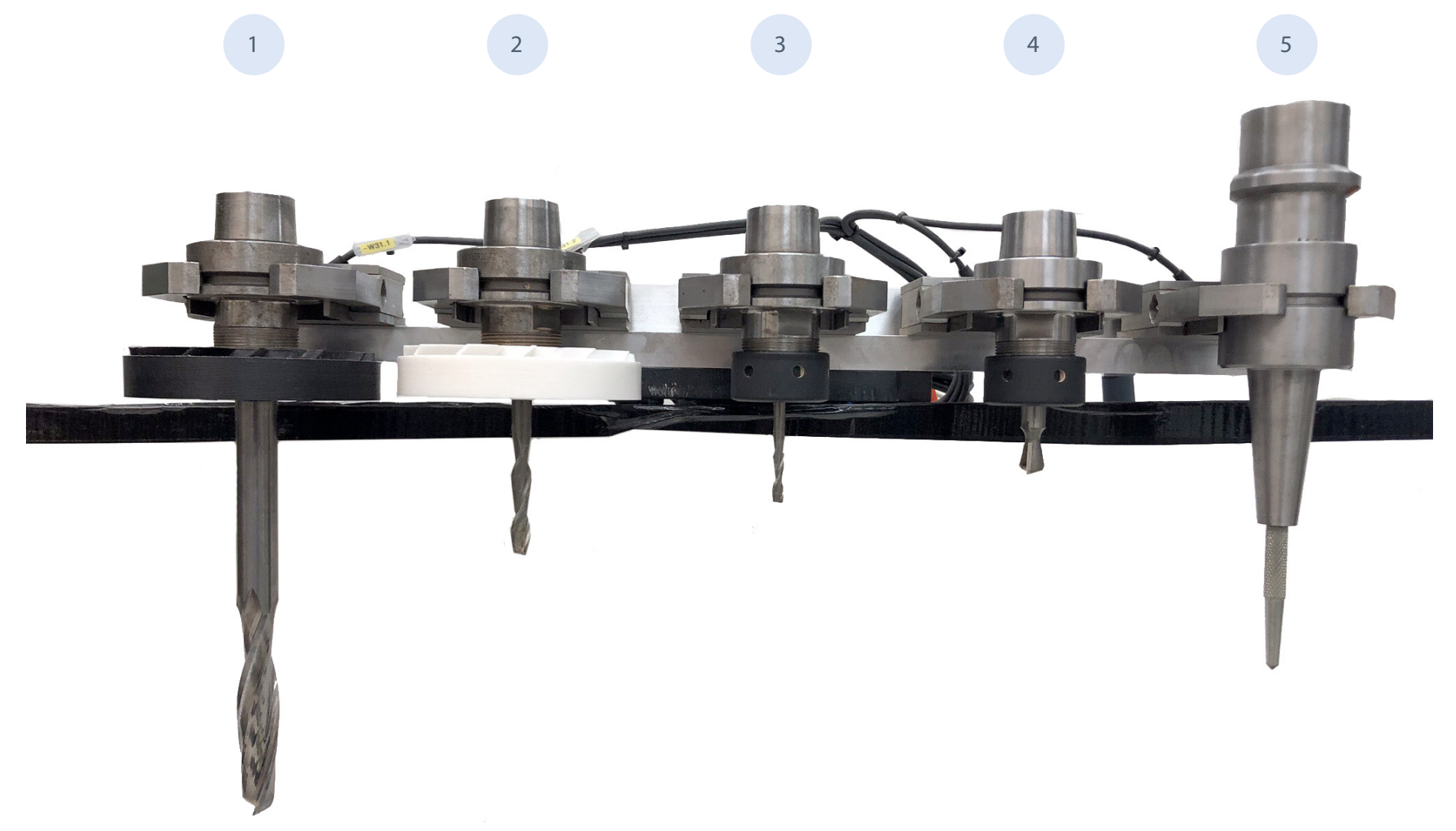

TOOL SIZES

$20 \mathrm{~mm}$ Straight Router

$10 \mathrm{~mm}$ Straight Router

$6 \mathrm{~mm}$ Straight Router

$16 \mathrm{~mm}$ Dovetail Router

5 TCPTool 


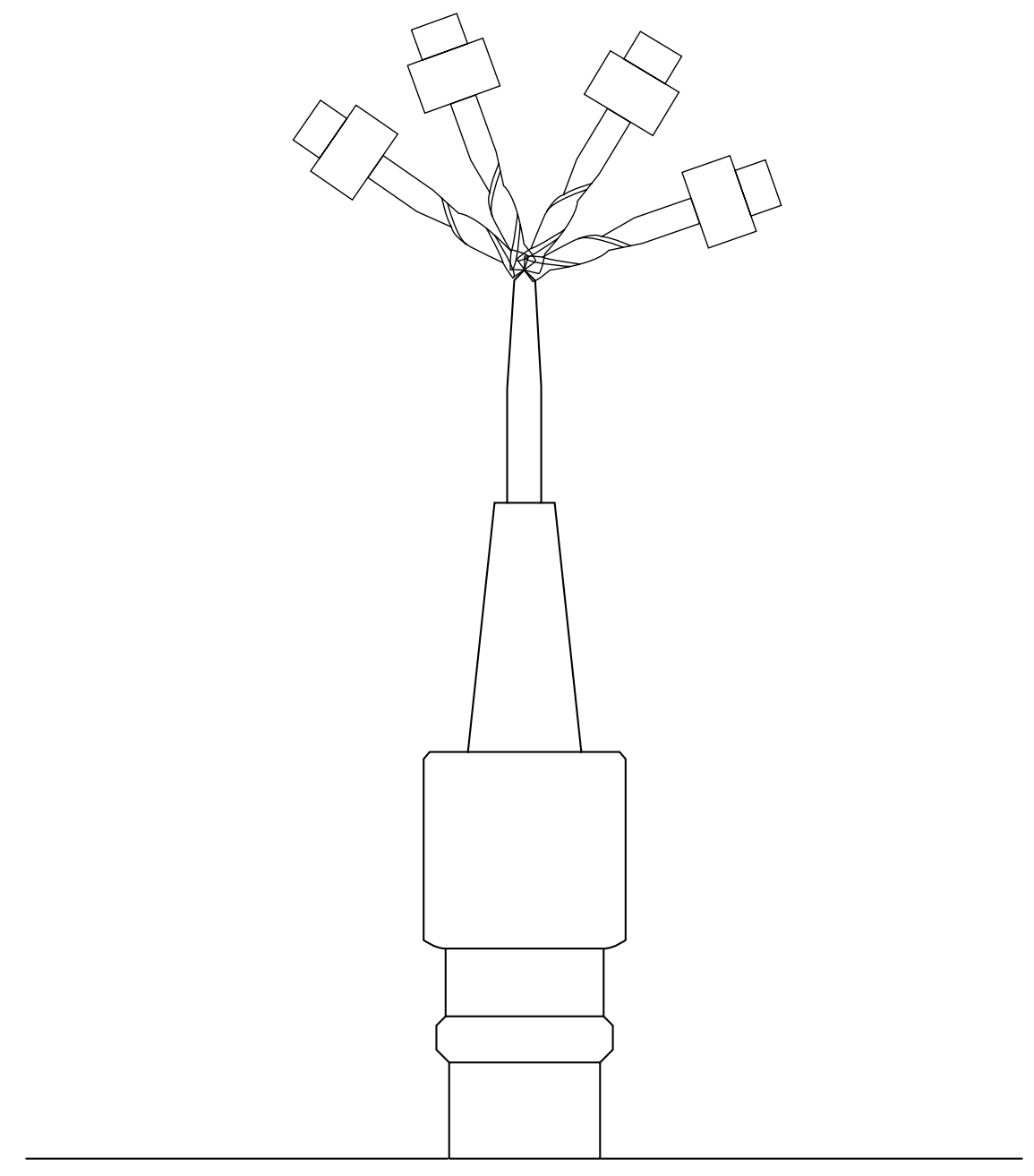

Figure 45: Diagram of initial method to measure TCP

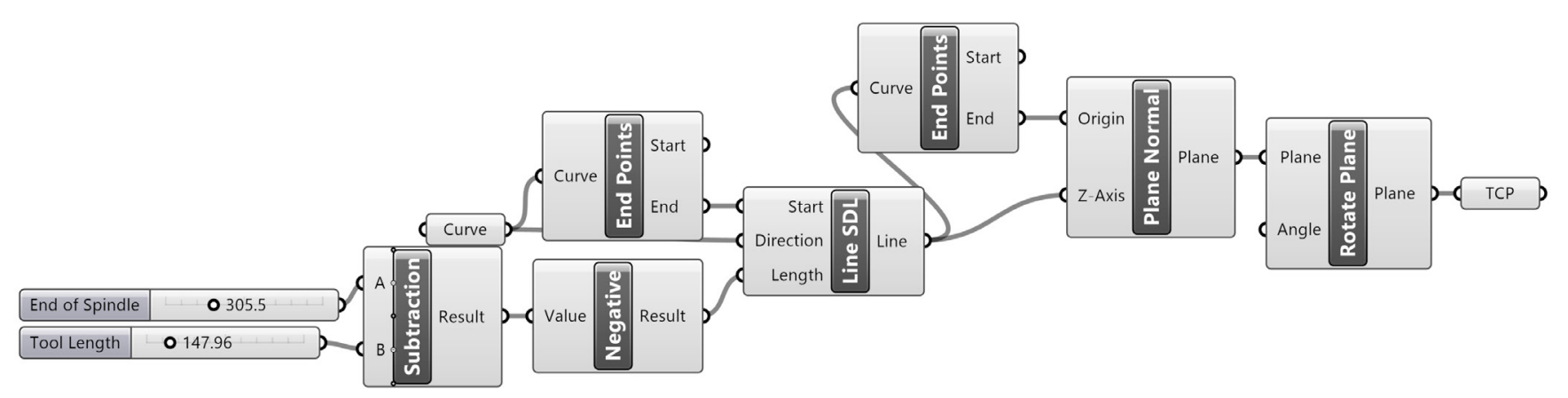

Figure 46: Script created showing new \& faster way to measure TCP
The robotic arm Tool Centre Point (TCP) is the point used to position the robot which involves points defined in the Cartesian space. The TCP tool was used when a new router bit was placed into the end of the spindle, which XYZ points, This process found the tool centre point The tool centre point is needed to ensure, the robotic arm knows the length of the router to allow it to cut exactly at the correct point. Finding the tool centre point was time consuming and during the first test cuts there were some inaccuracies as it would still be off by between $0.1-1.0$ of a millimeter, which impacted the cuts. This was due to the manual calibration to find the TCP. To solve these issues, a new script on Grasshopper was created, which subtracted the ond the plane allowed the robotic arm to know where the end point of the router bit is in the Cartesian space. This process was a lot faster, as every time a new router bit was used, the number subtracted on the code can be changed, which enabled a parametric process, rather than measuring the tool four times on four different angles to find the XYZ coordinates. 
The timber used was $25 \mathrm{~mm}$ plywood. This plywood thickness was chosen because the design required a locking system, where timber will connect with one another without the need for fasteners. Using peration of cuts into the side of the timber, which open 列 trength and lightness within the timber. 
Creating a toolpath to work with the robotic arm contributed to the workflow to aid in mass customisation. The tool path was created in Grasshopper which enabled many parameters to be explored and designed. Creating a customisable fabrication toolpath goes beyond the limits of current CAM software, used by CNC machines. However, there are still many benefits of CAM software that exceeds the method used

in this chapter to create a toolpath. The CAM software can automatically generate the tool path code, which allows for faster output and fabrication. This could be due to the robotic arm being a tool that is not restricted to a particular application, as it can achieve a variety of tasks dependent on the too attached to it. Therefore, there is no software specifically made yet for robotic fabrication. Robotic fabrication is also still a developing concept in the construction industry, therefore when it becomes more common, software specific tool path outputs could be created in the future. As for now, the technique of offsetting, arraying, creating points then converting to planes still works well to achieve customisable designs. 


\section{INTRODUCTION}

This chapter focuses on creating a base structure to allow the iterative process of the joint designs to have panel forms to work from. The structure will take the form of a pavilion. According to the Britannica Encyclopedia, in architecture a pavilion has several meanings. It can refer to a subsidiary building that is an attachment to the main building or can be positioned separately. It can also often function as an object of pleasure. This was important to allow the joints to have a purpose and showcase structures it can be applied to in the future.

\section{CHAPTER} 0 
Dovetail joints were used on the edge of three panels on Grasshopper. However, these were time consuming to create and were not parametric, as each angle on the edge of the panel had its own set of parameters to work with to create the finger joints. Therefore, a different locking system was needed to be explored for this research to continue further. A system that is parametric and able to lock neighbouring panels together will need to be designed. 
Number of Router Bits Needed: Some designs require different router bits to complete the cut.

Number of Passes: Designs will have different amount of passes to complete the cut, the more passes required, takes a longer amount of time to cut.

Strength: A scale based on how strong the connections are when joined together. The joints were pulled from side to side to assess if it breaks.

Rigidity: A scale based on how secure the joints are, by examining the sturdiness when picked up.

Assembly: A scale based on the ease of assembly of the structure with the joints.
The exploration of the dovetail joint contributed to the realisation that the strength of it was not strong enough to hold itself together. This led to the establishment of a criteria to determine the success of each joint designed to find the best one to be taken to be used with a self-supporting structure. The criteria is a qualitative measurement, creating a general evaluation of each design. The criteria are established on the adjacent page

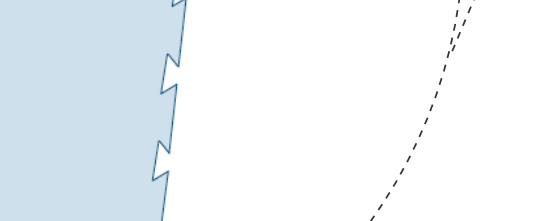


The current design of the structure is a simple dome shape to showcase the possible shape the form can be with this system. More designs were needed to be created to show the full potential of creating unconventional designs using sheet materials. However, due to the dovetail joint design not working, the ointing system needed to be first resolved before implementing into a bespoke form. Earlier evidence shown by the Landesgartenschau Exhibition Hall, should have been examined further, as the building used finger joints, but also needed a variety of nails to hold it in place. The use of nails reduces the sustainable quality of timber projects when other timber locking design do not need them, shown by ser this esearch but the issues that came out of it can be learned from. The establishment of the criteria was crucial to allow analysis of each design and to determine which connection can be used for the selfsupporting structure. 


\section{INTRODUCTION}

This chapter outlines the fabrication of the connections of the sheet materials using the robotic arm. The connections were first designed and iterated on Grasshopper. Following this, a digital tool path was created which was then exported to the robotic arm to be cut. The sliding mortise and tenon series was fabricated, and critically analysed with a certain criteria which was established. After each analysis, the design was developed to be stronger to be able to structurally support itself. 

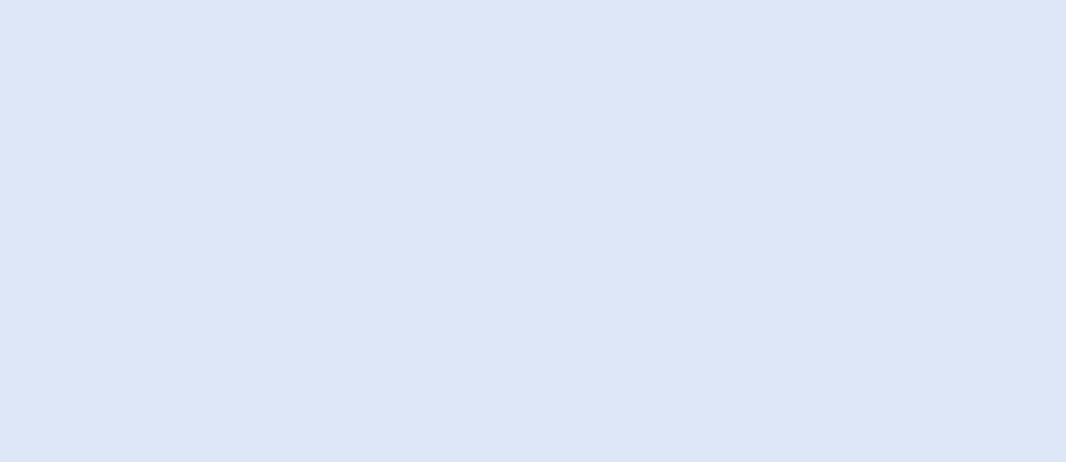

Figure 50: Mortise \& tenon joint
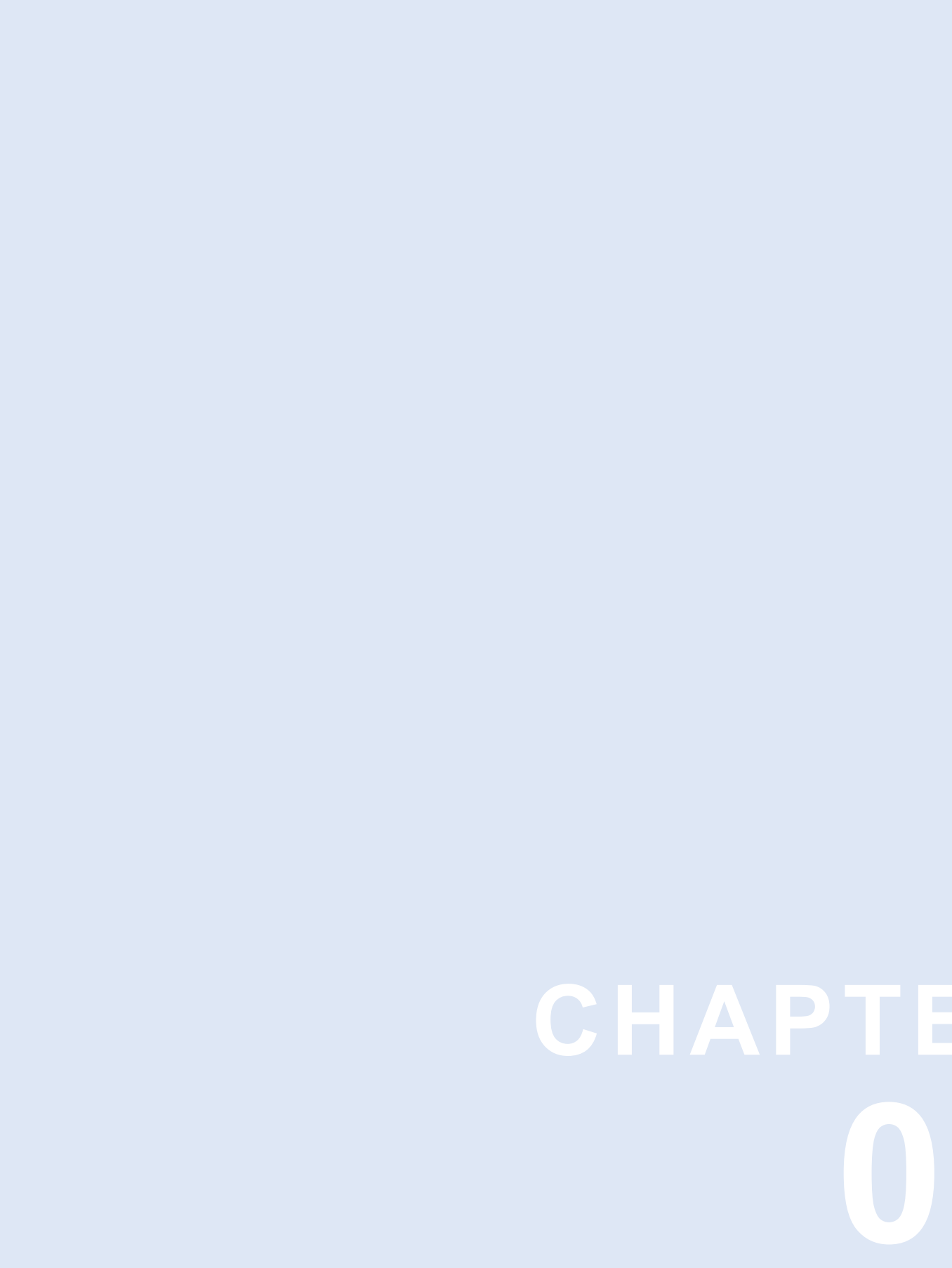

\section{SLIDING MORTISE \& TENON}

This connection is based on the traditional mortise and tenon joint system. Mortise and tenon joints have been widely used for centuries especially in building and furniture making (Tankut \& Tankut, 2004). It consists of two components, the mortise hole and the tenon tongue. The tenon is cut to fit perfectly into the mortise hole. An advantage of the mortise and tenon joint system is that it is a strong joint. The mortise and tenon are generally used when corner joints need a sturdy frame.

Iterations of this joint was designed to establish how the panel could hold itself together with just this connection. Therefore a sliding mortise and tenon joint system was established that locks in and preve it from falling apart. This new system allowed the model to be parametric and simplified the Grasshopper code, compared to figuring out each angle the finger joint needed on the surface. The finger joint was unsuccessful, as although it can fit into each other like a puzzle, in order for it to lock together, it still required many screws as shown by the Landesgartenschau Exhibition Hall Precedent. The implication with the use of these screws lowers the sustainable quality of the joint system and makes it difficult to take apart.

This sliding mortise and tenon system square system was first milled on gold foam to identify and resolve the issues found with the robotic arm environment, spindle tool and material used before continuing on with the milling of timber. This enabled a faster setup for the cuts following on from this first set. 


\section{Offset went in other
direction}

Even if the digital design has sharp

corners, the router used still
curved corner.

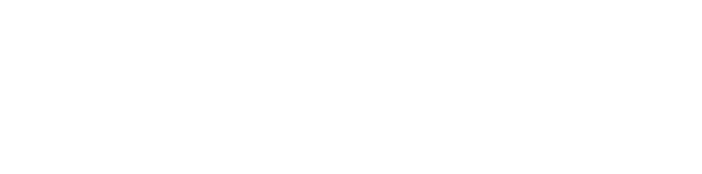

\section{.}




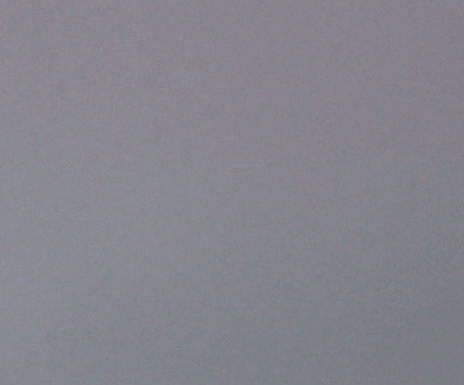

Cut 1

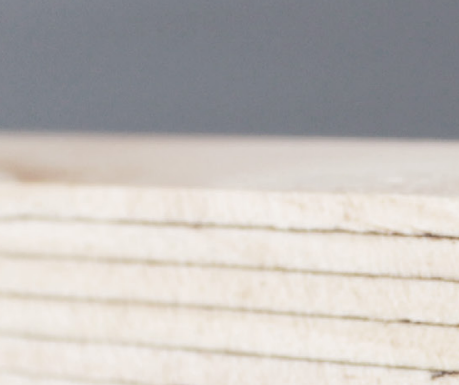

Cut 2

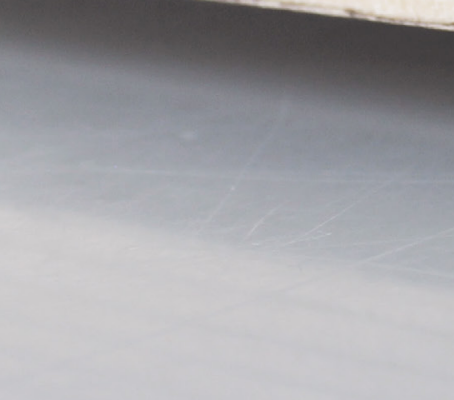

Cut 3

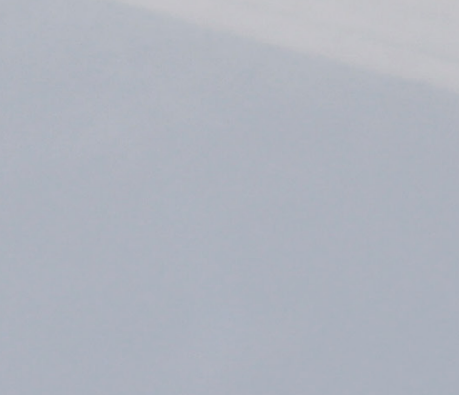

TOOL CHANGE

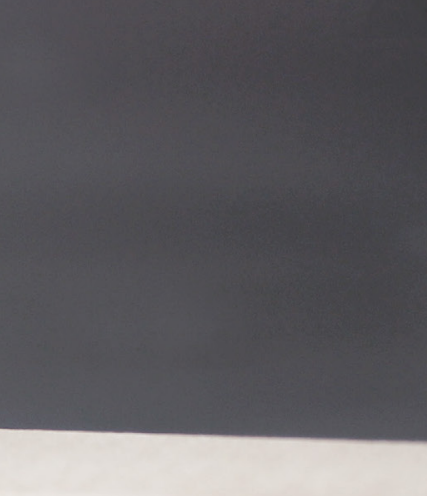

$6 \mathrm{~mm}$ Router Bit

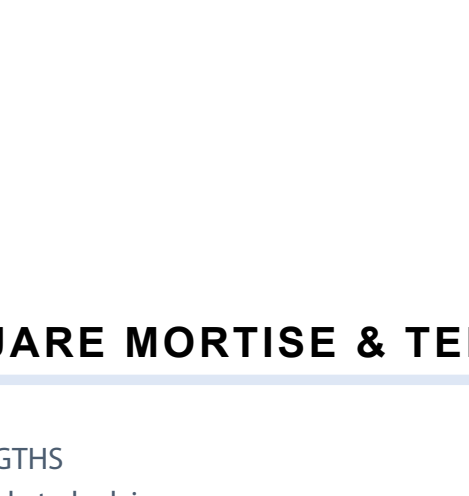

$3 \mathrm{~mm}$ Dovetail Router Bit
An issue with the first iteration of this series was that it could not have sharp corners due to the size of the router bit used. Many passes are required to cut the mortise out, as the $6 \mathrm{~mm}$ straight router tool cannot plunge deep into the timber in one go. It needs to go in a small $3 \mathrm{~mm}$ increments each time. Due to the number of passes required, the interior of the mortise is rough which caused some difficulty for the tenon to slide in smoothly This led to a rework in design to resolve the issues that were found from this design.

To solve this issue, the tool used was changed to a $13 \mathrm{~mm}$ dovetail tool that can be attached to the end of the spindle. This created a design change to best optimise the execution of the dovetail router. Which caused the shape of the mortise and tenon to be a circle instead of a square This allowed the dovetail tool to plunge itself straight into the plywood and move across and out. This was a beneficial decision because it allowed the Grasshopper code to be simpler, as now there is only one curve instead of four separate curves to create the square shape. This also ensured the cut was faster as the robotic arm only had to make two moves instead of making four moves each time and having to repeat the four moves each time it went deeper into the plywood. 
This design was more successful compared to the square design, as it was able to slide in smoothly to lock into place. However, an issue with this system is the dovetail router needs to be plunged in at a very slow speed as it is cutting it all out in one cut.

There were some issues when cutting the tenon out. The tenon was cut in 3 passes, which caused it to have grooves in it, which meant it wasn't as accurate as anticipated. The dovetail also didn't cut deep enough which left part of the tenon uncut. Therefore when the tenon slides into the mortise there was a small gap between the edges of the first set of panels.

To solve this issue, instead of cutting the tenon straight from the side in 3 passes, the dovetail router ended up coming in from the side and cut it out in one circle motion, which ensure the tenon was smooth. Although, this was successful, the joint was not strong enough, as the tenon was too small to support the weight of the panel.

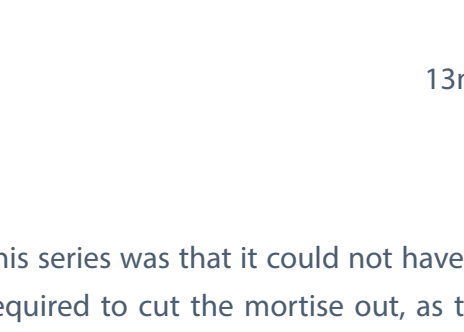

Using a $13 \mathrm{~mm}$ dovetail router bit
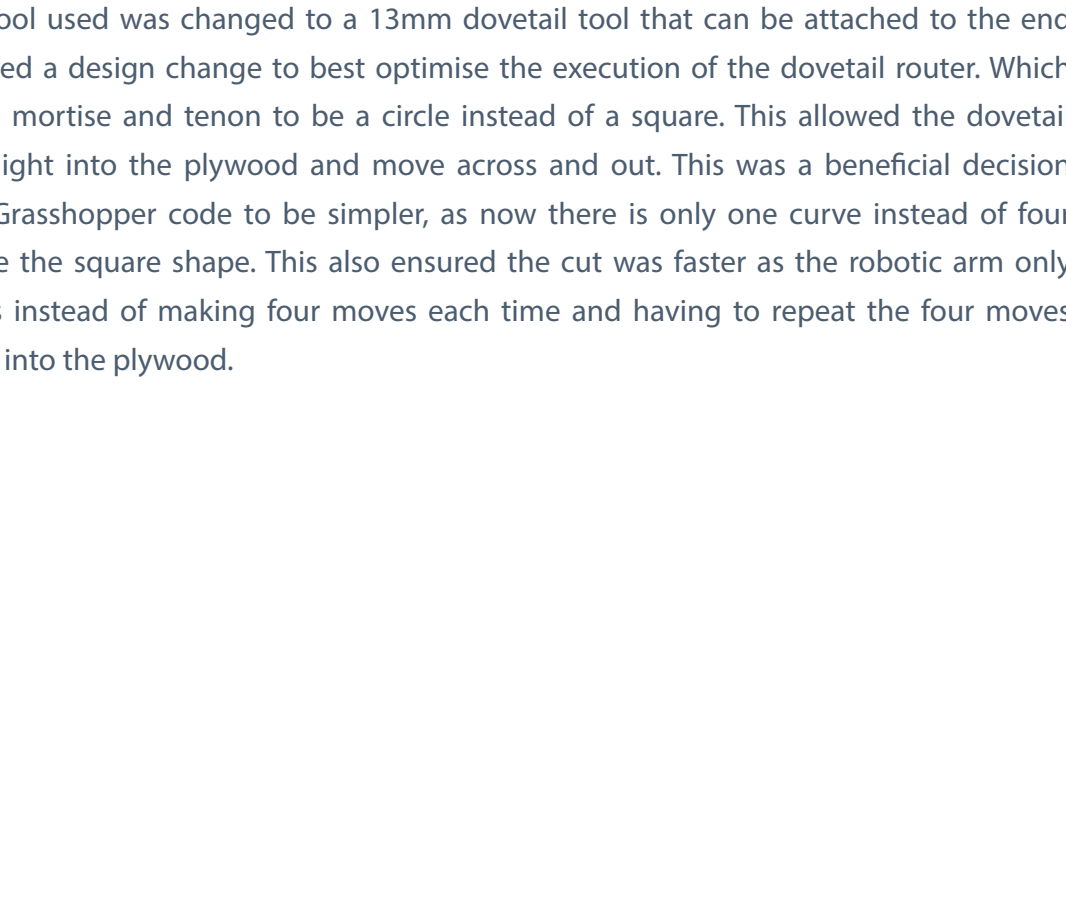

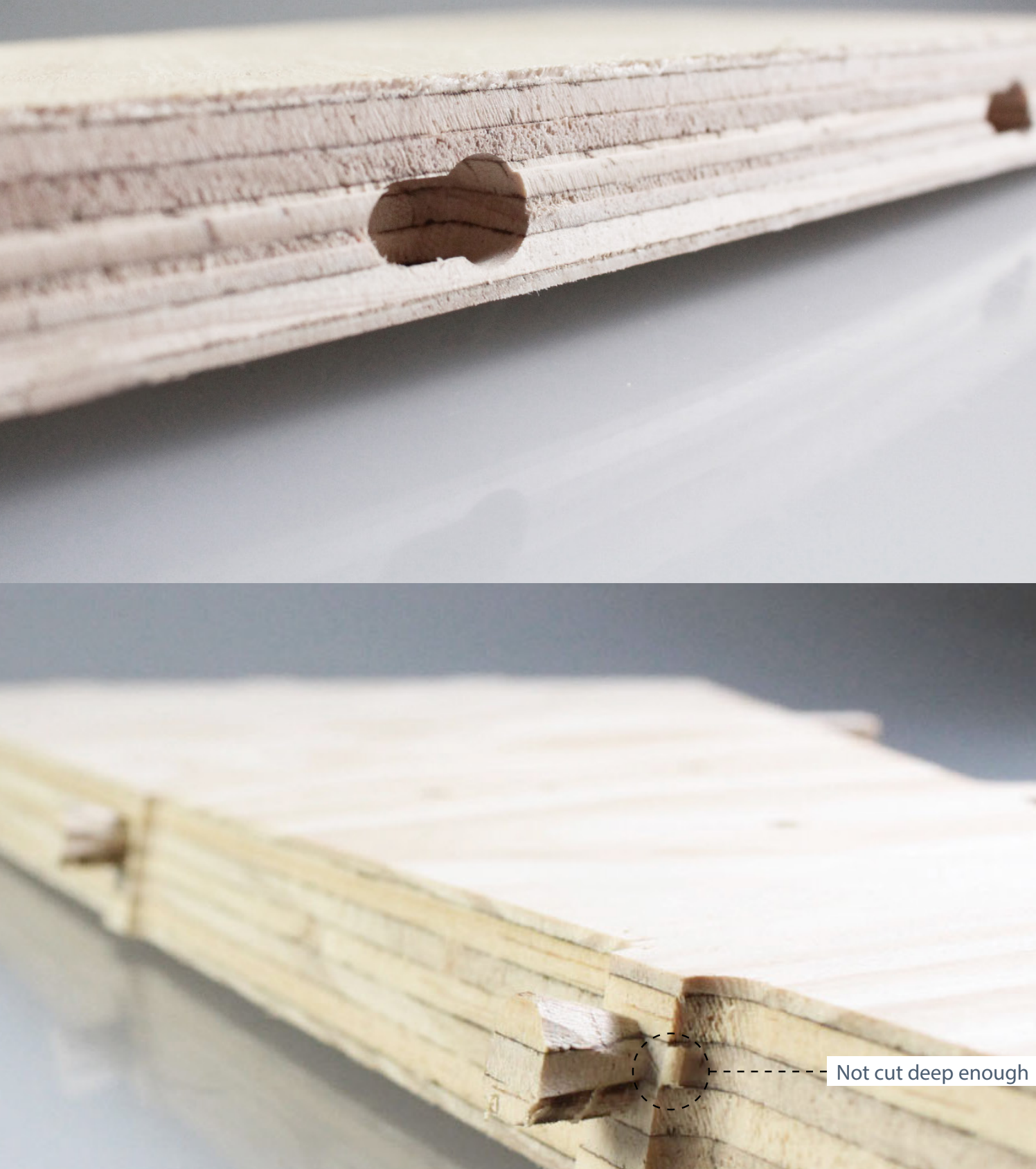

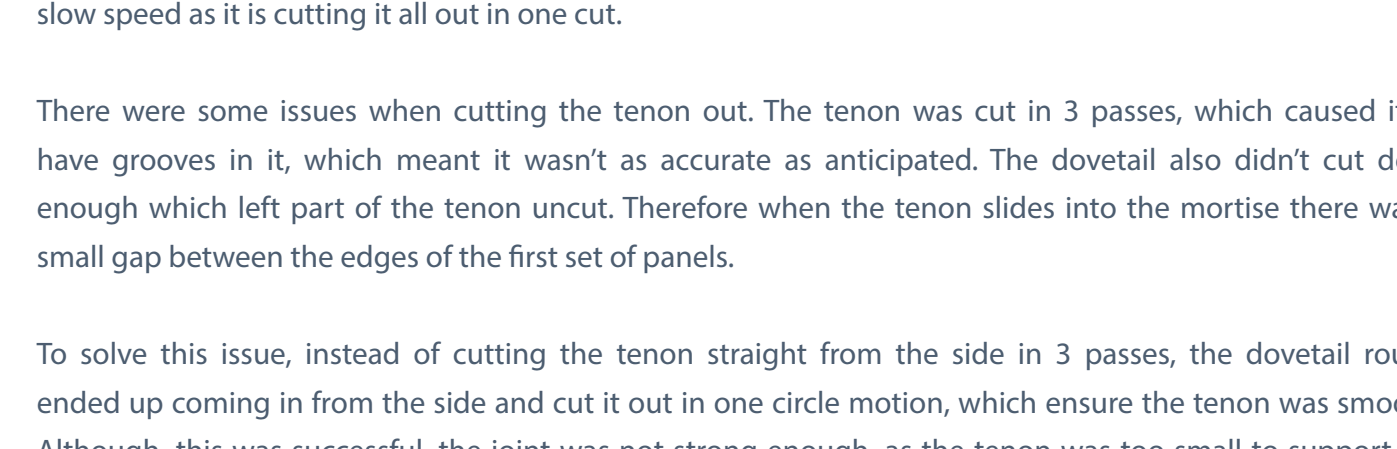

Initial direction the tenon was cut with the dovetail router. This method causes the tenon to be rough and not as accurate as anticipated.

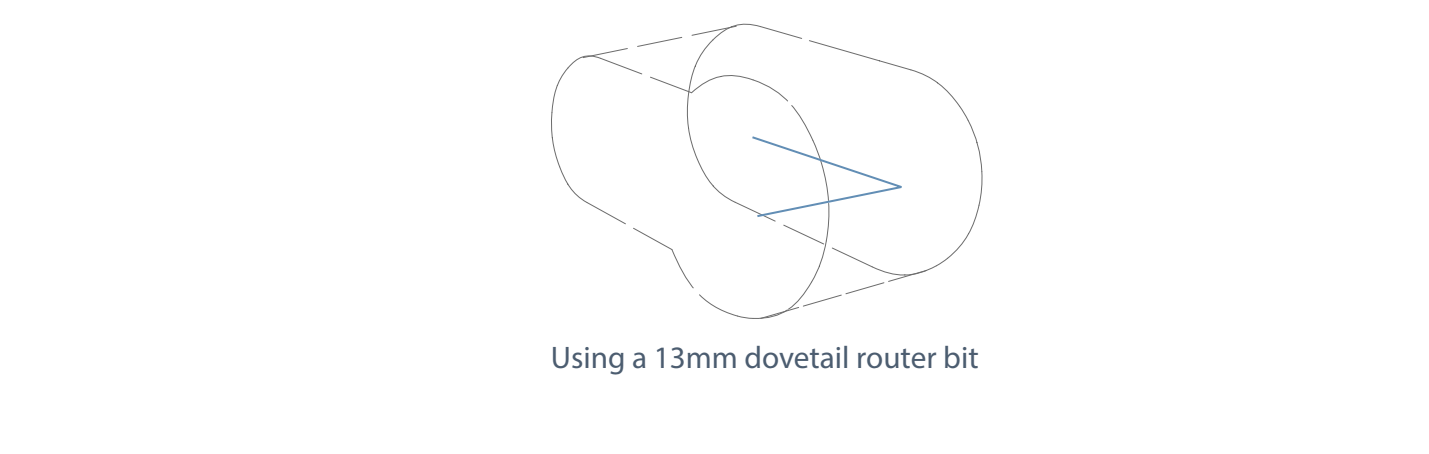

The way the tenon was cut was changed by creating a toolpath to come in from the side and

To create the tenon, a rectangle is first cut where the round tenon would be, then the dovetail router is able to go in to cut it out. However, for this set, the depth created with the rectangle was too large as it was offset by $3 \mathrm{~mm}$, as when cutting out the panel and rectangle, the $6 \mathrm{~mm}$ straight router was used. This meant all the edges were offset by $3 \mathrm{~mm}$. This caused the dovetail router to burn as $3 \mathrm{~mm}$ of the rectangle edge was not reached by the sharp part of the router, causing the timber to burn. To solve this issue moving forward, there was no offset created for the end edge of the rectangle. 

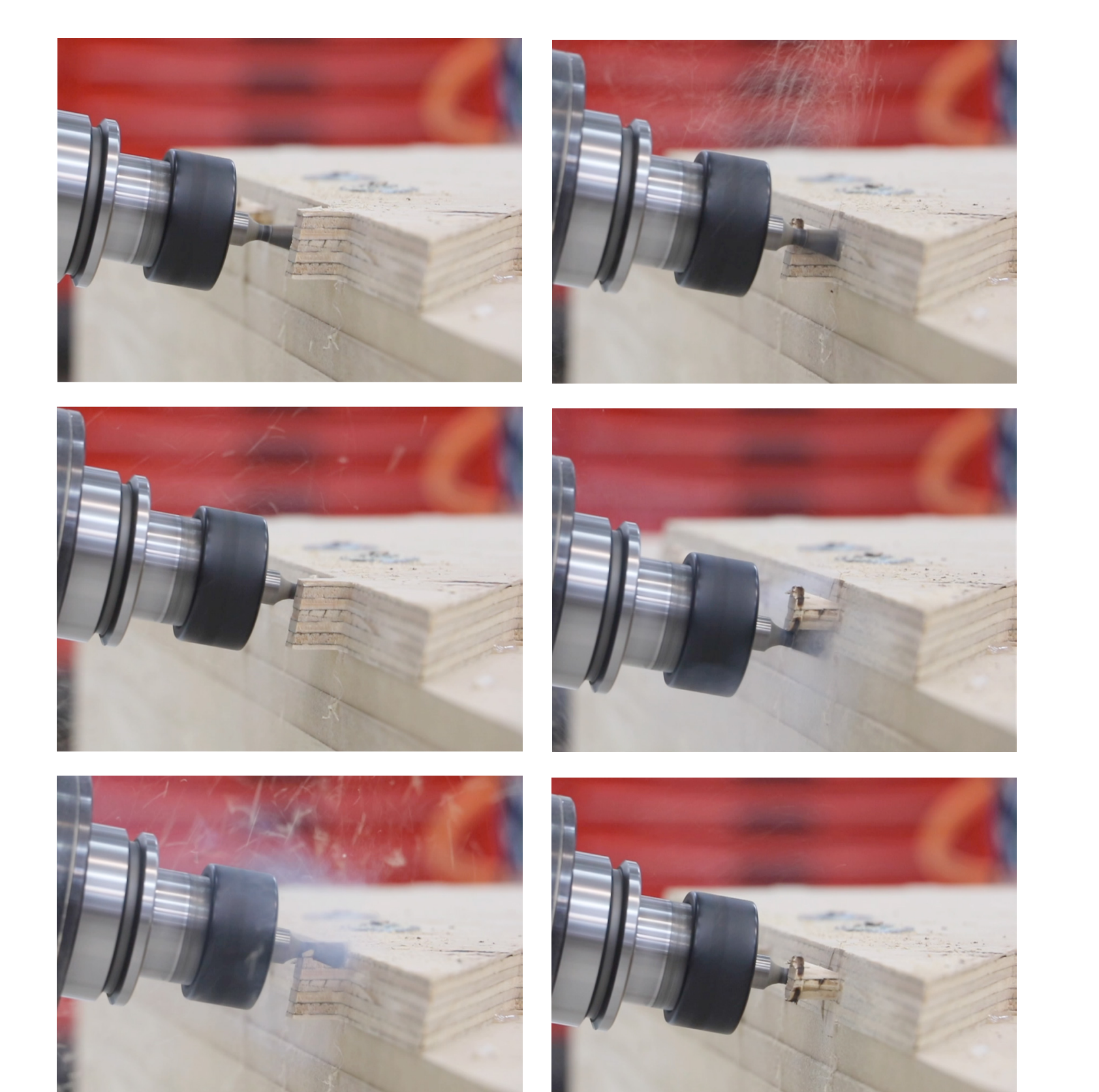

\section{MM DOVETAIL ROUTER BIT}

6.1 .5

From the first test using the $13 \mathrm{~mm}$ dovetail tool, the tenon was cut exactly at $13 \mathrm{~mm}$ and the mortise hole was also exactly a $13 \mathrm{~mm}$ diameter. This caused there to be some difficulty to allow the mortise to go in. Therefore tolerance was needed to be added into the tests. Tolerances in fabrication are accounted for the joints between the components providing a small space to accommodate for inaccuracies during the fabrication and assembly process. In this research, tolerance was important because the cuts cannot be fully precise due to the manual placement of the timber.

Router Bits: : $\quad 13 \mathrm{~mm}$ Dovetail Router Bit

No of Passes: $\quad \vdots \quad$ Mortise-1

Strength:

Rigidity:

Assembly:

Tenon- 1
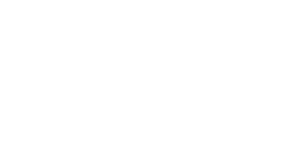
Due to the $13 \mathrm{~mm}$ tenon not being strong enough to hold the weight of the panel, the $16 \mathrm{~mm}$ dovetail router was tested on the spindle to examine whether it would be stronger. This enabled the tenon to be thicker. Instead of only having three tenons on the edge of the panel, a fourth one was also added to further increase the strength of the connection. The tenon was made to have a diameter of $15.8 \mathrm{~mm}$ which would give small bit of room for the tenon to slide in. The joint was tested on a scrap piece of The lo jovetail router was halfway cutting through the circular shape of the tenon. This indicated the joint was not strong enough and the cut should have been tested on plywood, as LVL timber is a type of timber where thin layers of wood are oriented together in the same direction. This caused the timber to initially be quite weak, and if tested on plywood where adjacent layers are rotated up to 90 degrees, it may not have broken off as it would have been stronger. Regardless, he joint still needed to be stronger to ensure it would not break of

Router Bits: No of Passes: $16 \mathrm{~mm}$ Dovetail Router Bit

Strength:

Rigidity:

Assembly:

Tenon- 1
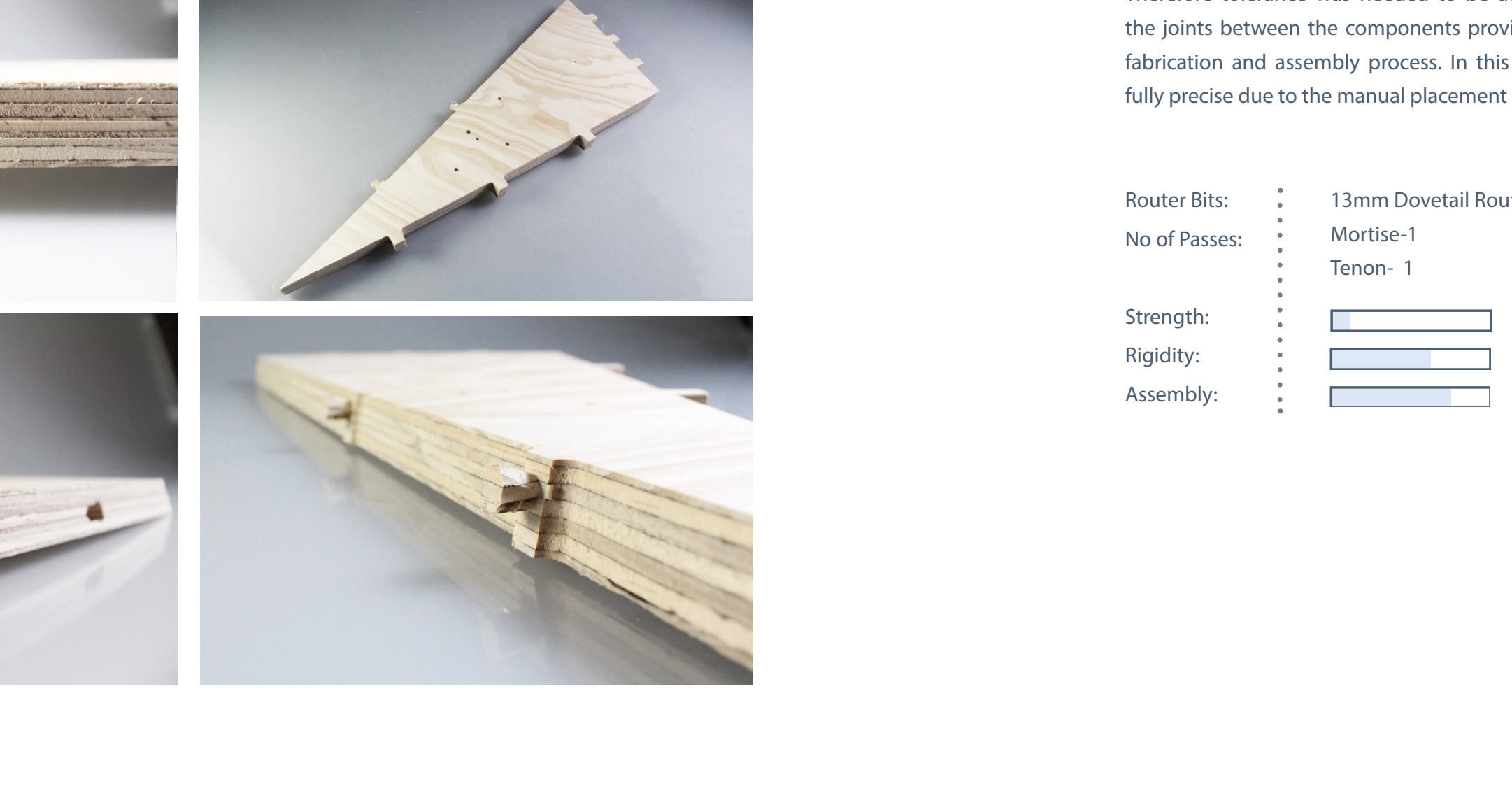
The same joints were tested on $25 \mathrm{~mm}$ plywood to examine whether it would break off during the cutting process. It successfully didn't break off. Once the joints were cut, the panels were able to slide in and hold itself together. Only three panels with joints were first cut, to analyse whether it could join together. This reduces wastage of plywood, as this was not the final set and was only cut to analyse the strength and success of the connection. This set was not successful because two out of the three joints on one edge eventually broke off after sliding it in and out a few times. This led to a redesign of the joints to ensure it can hold itself together without snapping off. 



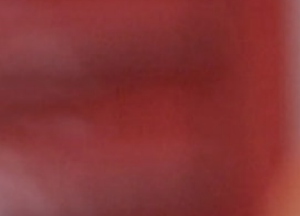

$28.8 \mathrm{~mm}$

Current Joint

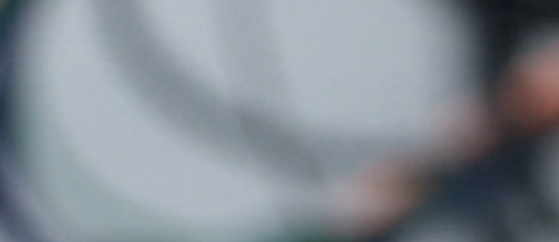

Proposed Joint

Although the current joint created that fit in the panels were strong, it could still be made stronger Therefore the joints were widened even more to ensure maximum strength. The current joint so far was $28.8 \mathrm{~mm}$ wide at the widest point. Due to the parametric script created, sliders could be adjusted to widen the joint easily. This was increased to $53.2 \mathrm{~mm}$, which helped the joints become stronger.

To create the joints, it started with grabbing the surface of the side of the panel the joints would be on and dividing it by a number dependent on how many joints are needed on each edge. The image on the adjacent page is divided by 4 , therefore the surface created four centre points. A circle using each of the centre points were created and then moved out by a depth of $15.9 \mathrm{~mm}$. This depth was used because the dovetail router bit was $16 \mathrm{~mm}$, therefore it gave $0.1 \mathrm{~mm}$ of tolerance. The centre point was then moved both in the $X$ and negative $X$ direction by 186 , which gave the new distance of the centre points to be $37.2 \mathrm{~mm}$. The radius of the two new circles were 8 , which gave the total distance of the joint to be $53.2 \mathrm{~mm}$. This parametric quality allows for quick customisation without needing to rethink a whole new process to work with the changes. The increase of the width of the joint was important to showcas the parametric capabilities of the script created, and that it can be adjusted for any length of timber or router bit used.

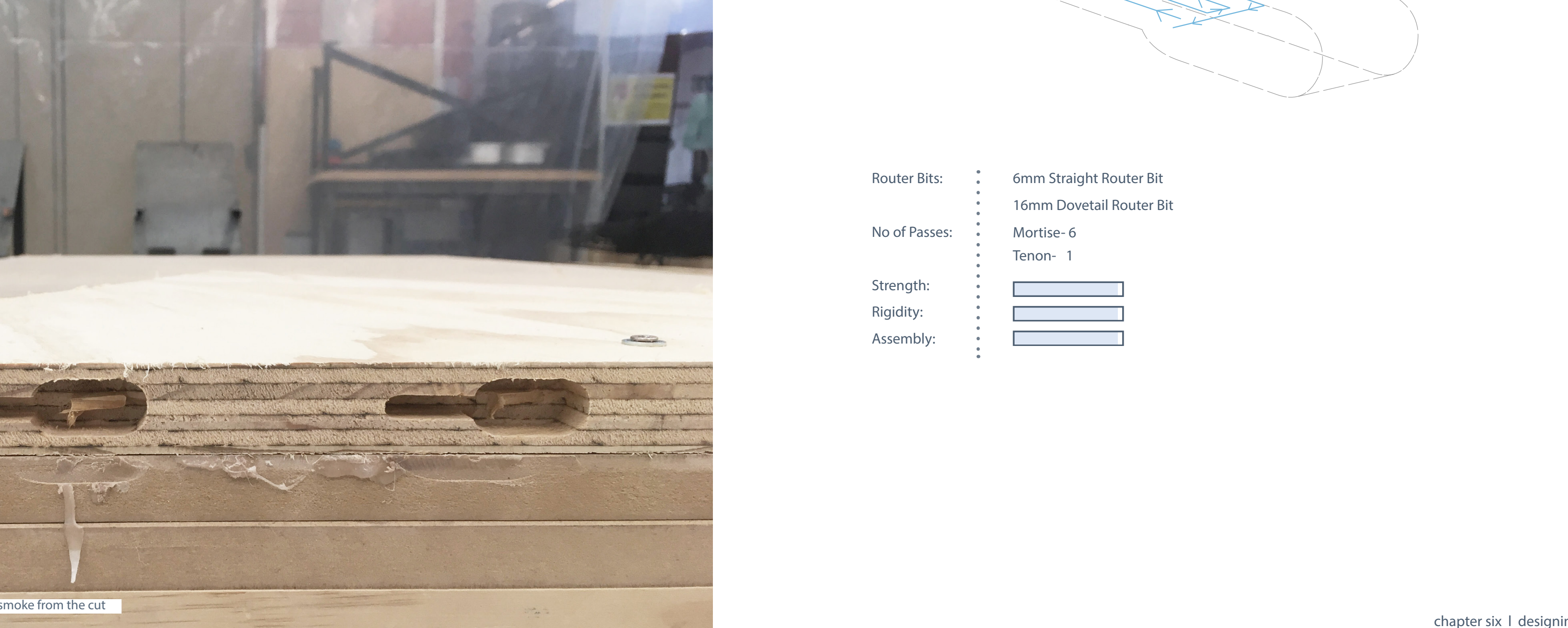




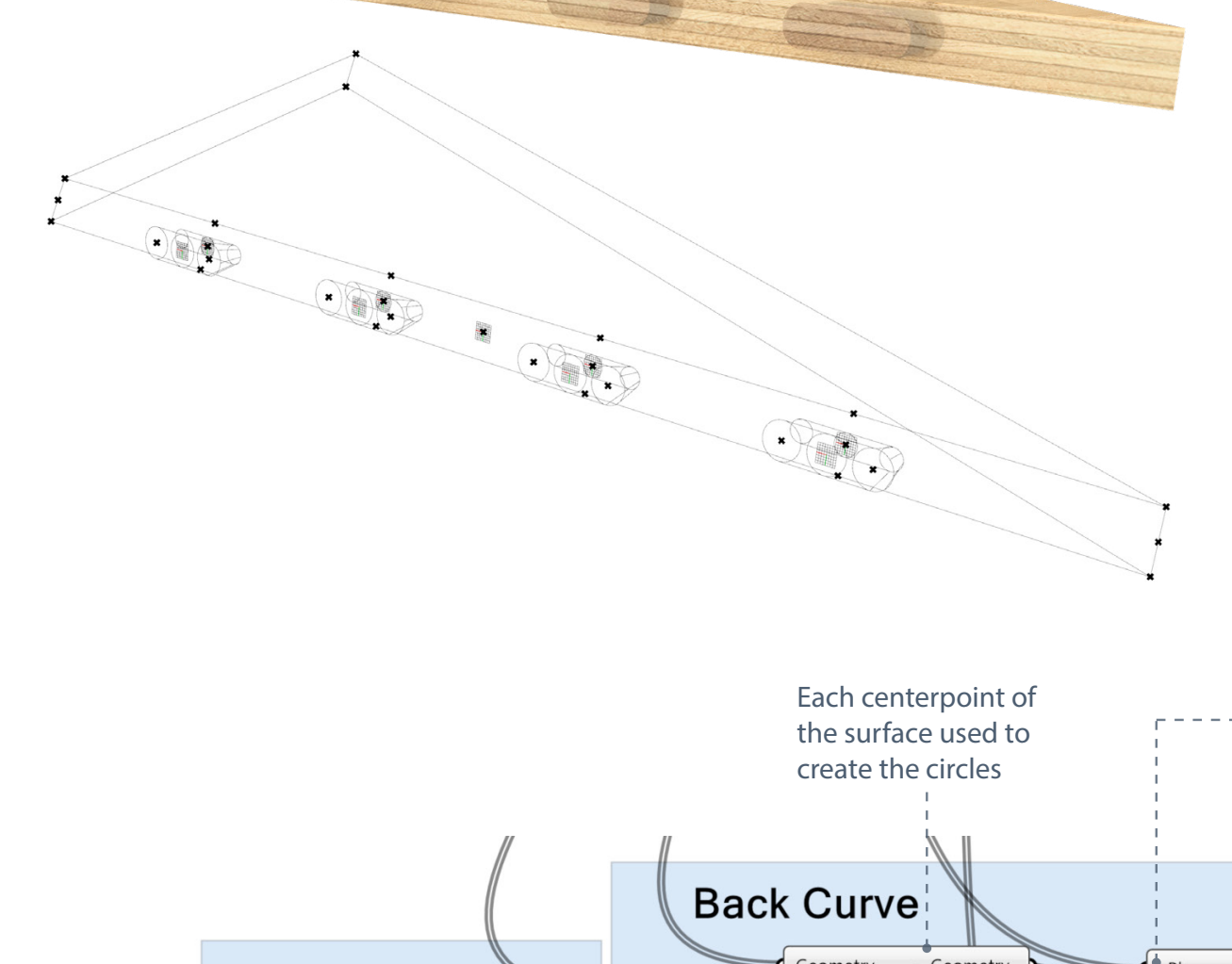

SLIDING MORTISE

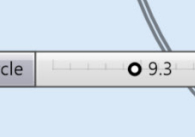

SLIDING TENON

$\square$

N NON-SLIDING TENON

NON-SLIDING MORTISE

\section{BUILD SEQUENCE}

6.2.0

An issue with the sliding system was that not every panel was able to slide in to create the structure therefore a build sequence was established for the base form. Once a certain point was reached, the sliding method became impossible and a new method was needed to be explored to fit in the remaining pieces. This meant that some panels had a sliding mortise and tenon joint and some other panels would just be a mortise and tenon that does not slide and instead slot into place and hold itself together. This allowed the panels to still be able to be slotted into the difficult positions. Openings can be created, to enable more panels to use the sliding system and help aid in the construction of the structure. One single wide tenon and mortise will be created on one edge to ensure the system will be able to fit in. The non sliding mortise and tenons needs to be surrounded by panels that use the sliding system to ensure it will hold itself into place.

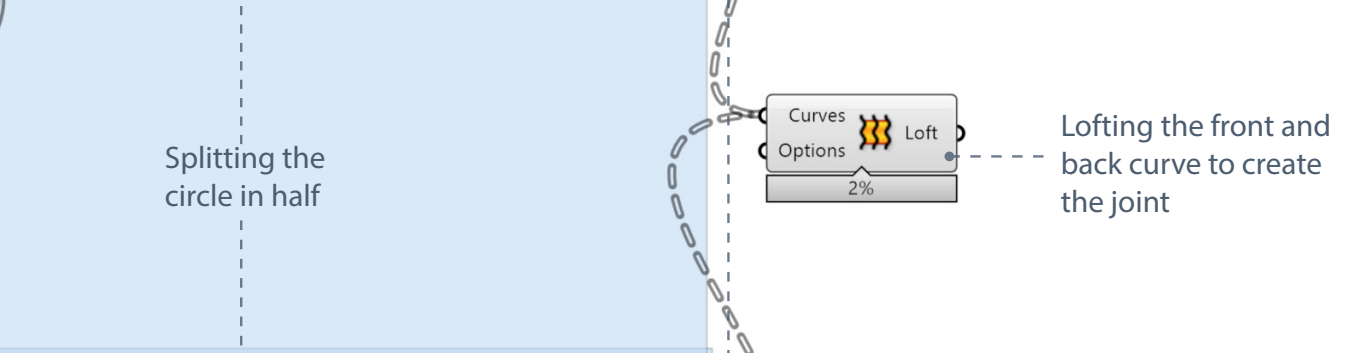



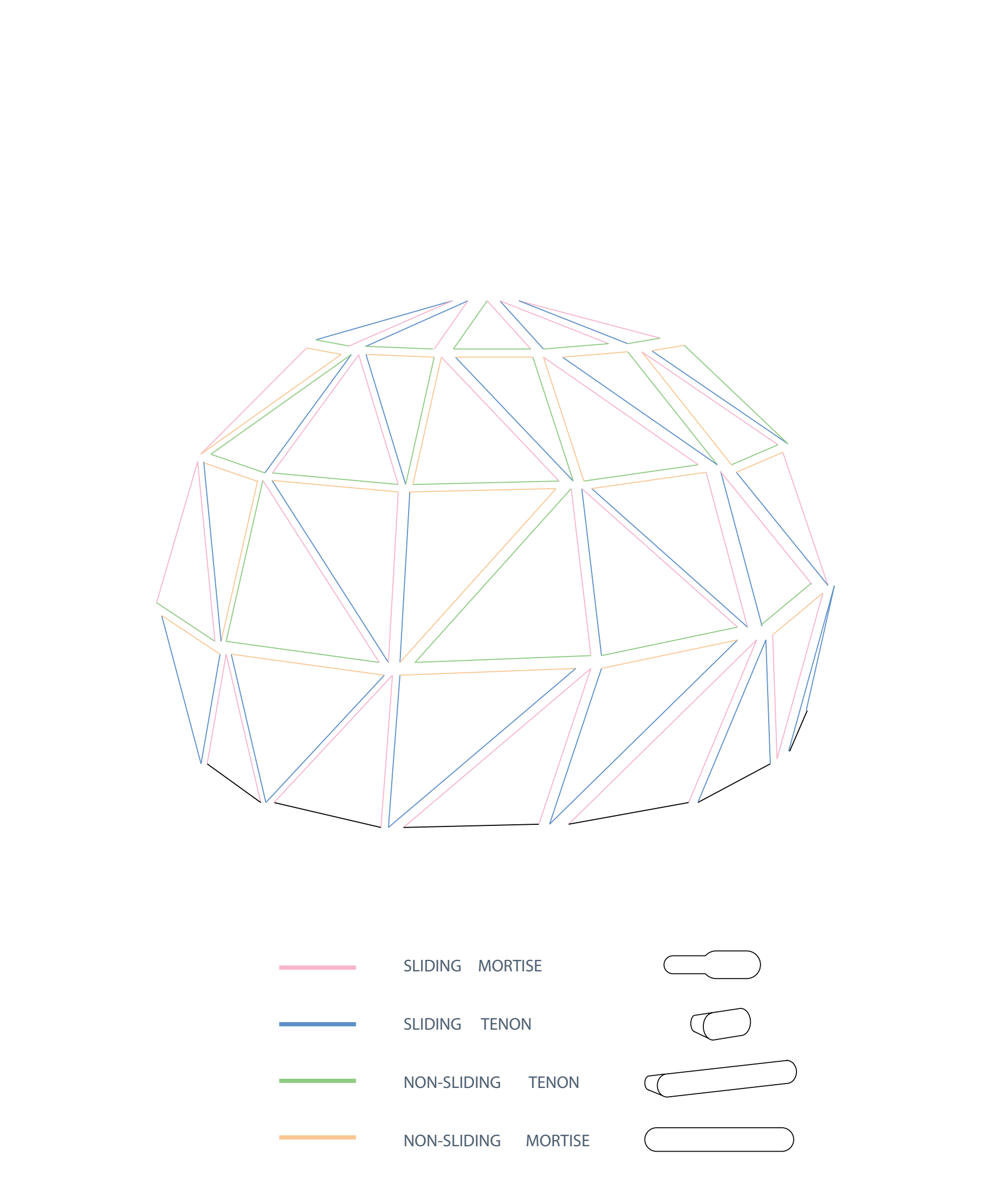

\section{CUTTING PROCESS}

When using the robotic arm, a cutting process was established to ensure the fabrication would be precise The cutting process started with two holes that were drilled $40 \mathrm{~mm}$ apart and spaced $40 \mathrm{~mm}$ from the edge of the table. The same holes were drilled $40 \mathrm{~mm}$ from the centre of each edge of each panel that would be cut. This was done to ensure when the panels were once cut, they were able to be manually lined up with the two holes drilled into the edge of the table. Lining the holes up to the centre of the table surface allowed the mortise and tenon to be cut precisely from the $y$ axis. There were some issues with this method as sometimes it would be half a millimetre off To solve this accuracy issue, when cutting with the dovetail tool, it would get paused just before it gets cut, and checked to see if it was touching the timber perfectly, where it would be cut. Most of the time it was accurate, however during the times when it was not accurate, the robot would be paused and the timber panel would be manually moved to touch the tip of the router.

1. Drilling the holes and cutting out the base panels on plywood

2. Aligning the centre edge points on the panel to the centre edge points on the table

3. Using the dovetail router to cut the tenon or mortise out 
Overall, this series aided in the growth of knowledge in the design and fabrication with the robotic arm When designing the toolpath on Grasshopper and running the simulations, it was difficult to predict the errors that can occur until the prototypes are physically fabricated. This method of going from digital to physical was successful as only some parameters needed to be changed to resolve the issues such as making the joint wider. Although, it was mentioned that the design was changed to a circle as it only required one pass with the dovetail router which made a quicker cut. After the issues found with the joint not being large enough, it required the $6 \mathrm{~mm}$ straight router to cut 5 passes first before the dovetail router is able to go through. This method required the need to switch tools, which was not the most efficient way, however, it was the only solution to be able to make the mortise wider. The design of the joints relied on the tools that were readily available, however other tools could have been explored that were not a straight or a dovetail router.

This chapter focused on creating the joints and getting them to be at the high level of the criteria set without having a final design yet. The following chapter will focus on the design development of structure that can be constructed using the joints designed in this chapter. 


\section{INTRODUCTION}

This chapter outlines the design development of a pavilion that can be constructed using the joints designed in the previous chapter. Part of the final designed form was taken to the robotic arm to be fabricated. Although the full-scale pavilion was not physically fabricated, it was still fully designed to help understand the relationship between each panel. The pavilion was important to design as it gave an example to show how the joint system can be implemented into any structure that has panels connecting it at different angles. 

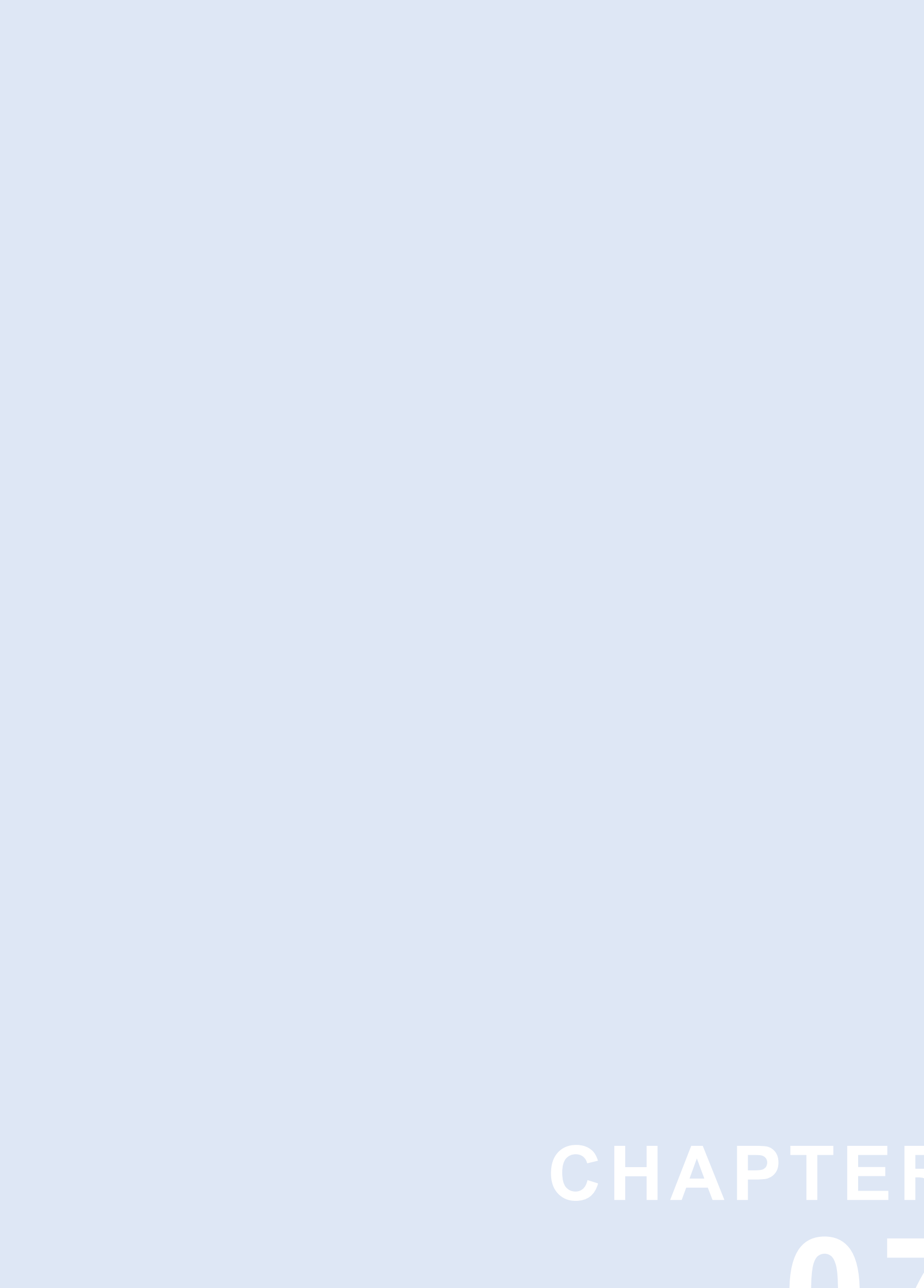

FORM EXPLORATION

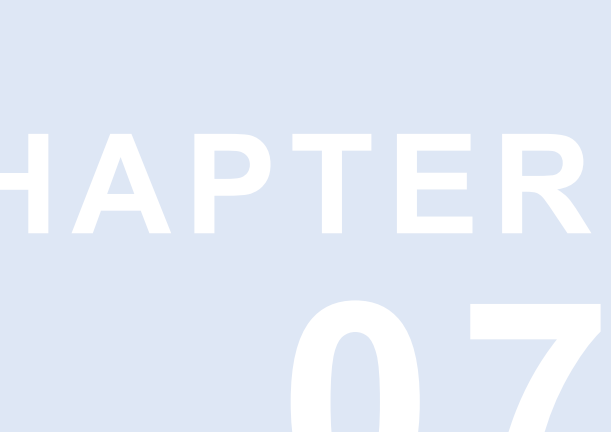

Creating a form for the joints to be used was important, as it helped create an understanding of what could be created with the joint system and also understand the limitations there would be. A brie was established to aid in the design development of the pavilion. The programme of the pavilion is an exhibition space which will exhibit information about the process of constructing the pavilion.

The brief created required

- Fit 5-6 people inside it

A pavilion that is located indoors

Have a seating area in it

Have a plinth for some panels to rest on to allow people to pull apart small scale panels, to understand how the structure works

The first concept sketches showed that there was a smaller area and a larger area within the form. This would enable the form to have two sections that can be used as different functions. For example, one side is a seating area and another side being the exhibition space. There was one opening in the design which is used for both the entrance and exit, as it would encourage people to walk in and experience the whole interior twice before they walked out 

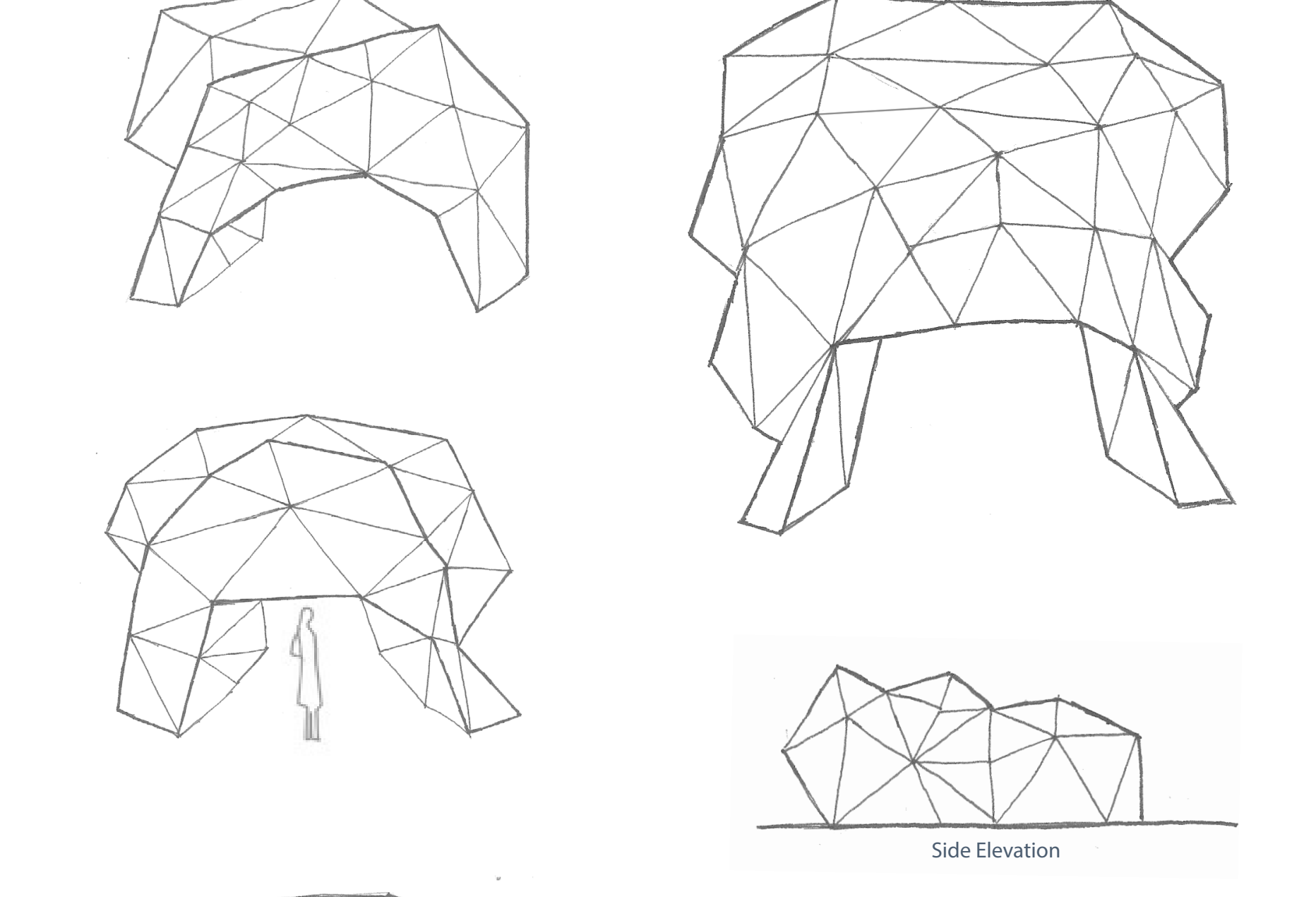

INTERIOR EXPLORATION

7.1.1

Due to the brief requiring a seating space and space for the panels to rest on. Plinths were placed into the pavilion. Current plinths are usually a box shape, however, due to the design being non-linear and having no 90 degree angles, the box plinth did work with the design. This then encouraged the designing of the plinths into the form, therefore the plinths were built into the pavilion and follow a form similar to the pavilion form to help integrate it better into the design.

The seating area was designed only into one section of the pavilion to allow the exhibition space area to have a fully focused standing area. The seats were also designed into the pavilion using the same jointing method as the panels.

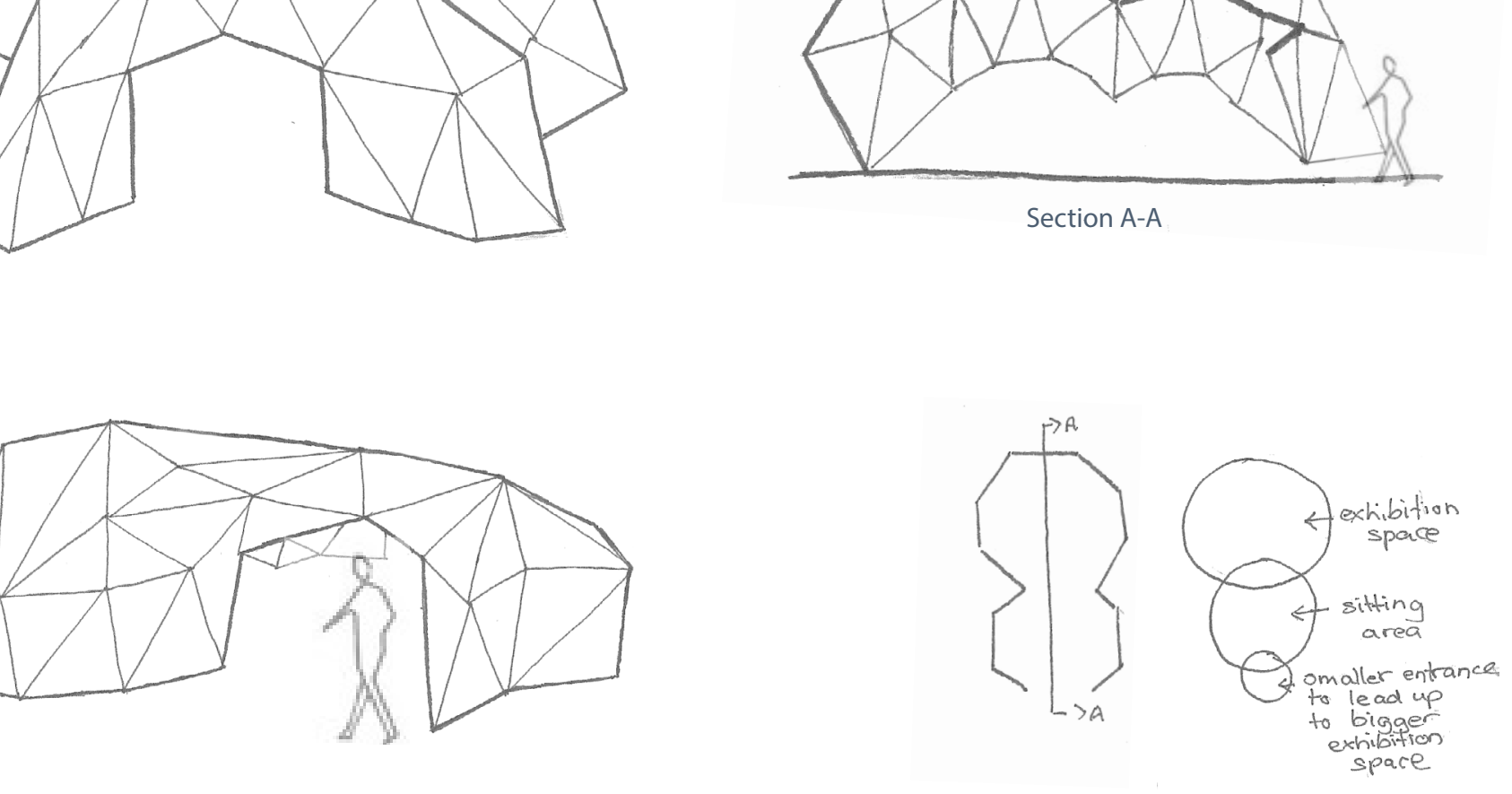

116. Figure 74: Interior exploration

chapter seven I form development

117. 
Very large opening for the entrance and exit, to show the interior to attract people to go in.

Smaller opening, with the entrance and exit located in the same place as concep one. Hides more of the interior.

\section{CONCEPTS} 7.1 .2

Instead of only have one entrance used to enter the structure, it was better to

have two entrances to attract people walking by on either side to allow them to peek inside to attract them to enter. 

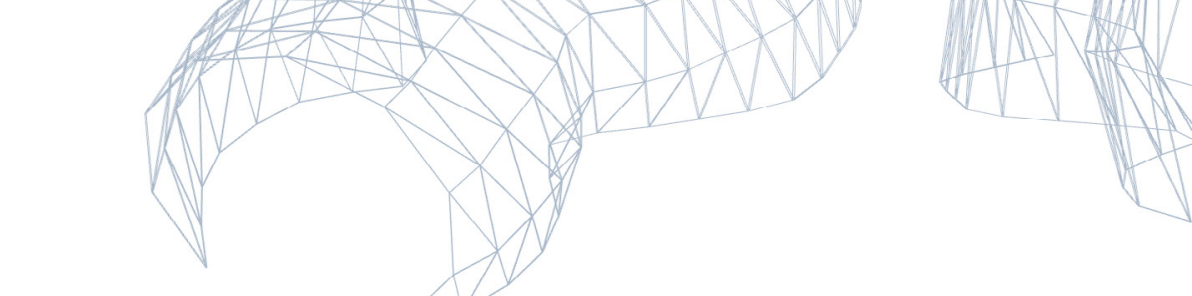

ITERATION ONE
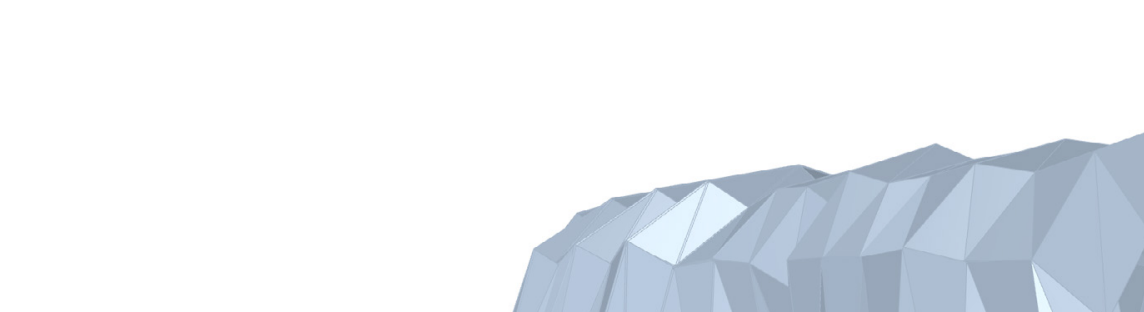

ITERATIONTWO
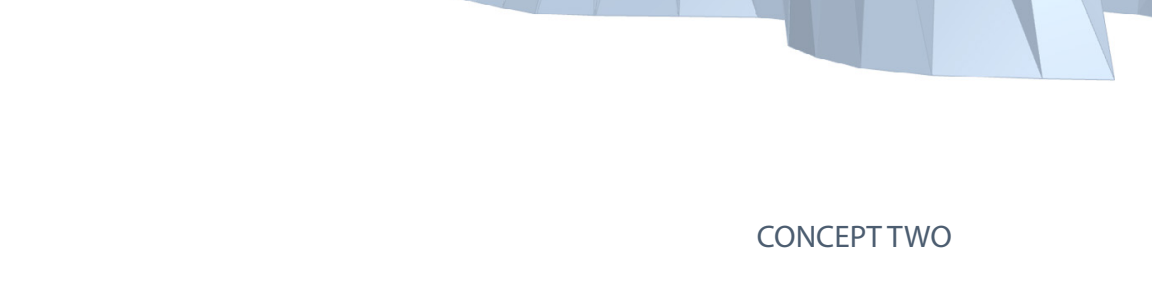

ITERATION THREE
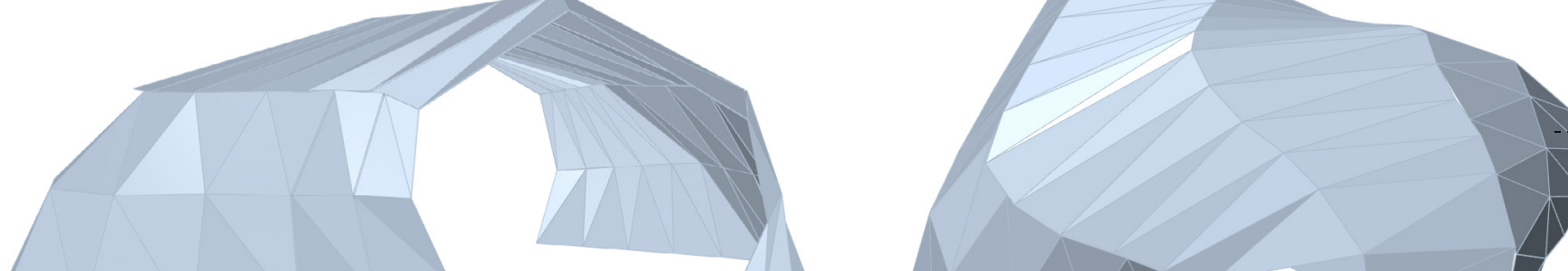

ITERATION FOUR

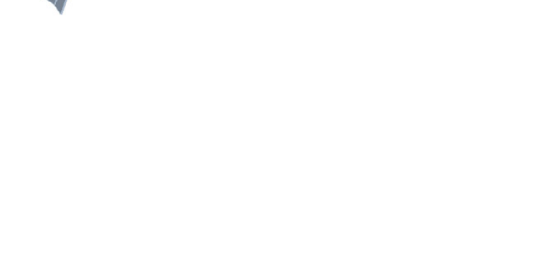

84 Panels
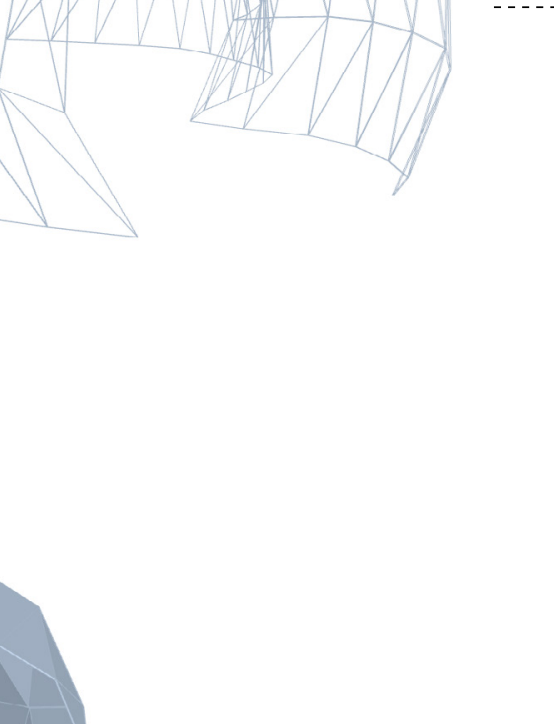

220 Panels

98 Panels

\section{ITERATIONS}

7.2.0

Each form that was designed had a different number of panels.

The fewer panels there were, the complexity for the average person to put the pavilion together lessened. The amount of waste created also decreased, as fewer mortise and tenons were cut due to less panels being required. The designs with fewer panels created a form with sharper and more angled edges, whereas the designs with lots of panels created a more fluid form. Although fluidity is a good aspect to have in a design, this research aimed to showcase the workflow to connect panels at different angles to create a structure. Therefore, the designs with fewer panels created sharper angles, which showcased the possibility of designs that lie outside the scope of conventional timber structures. 

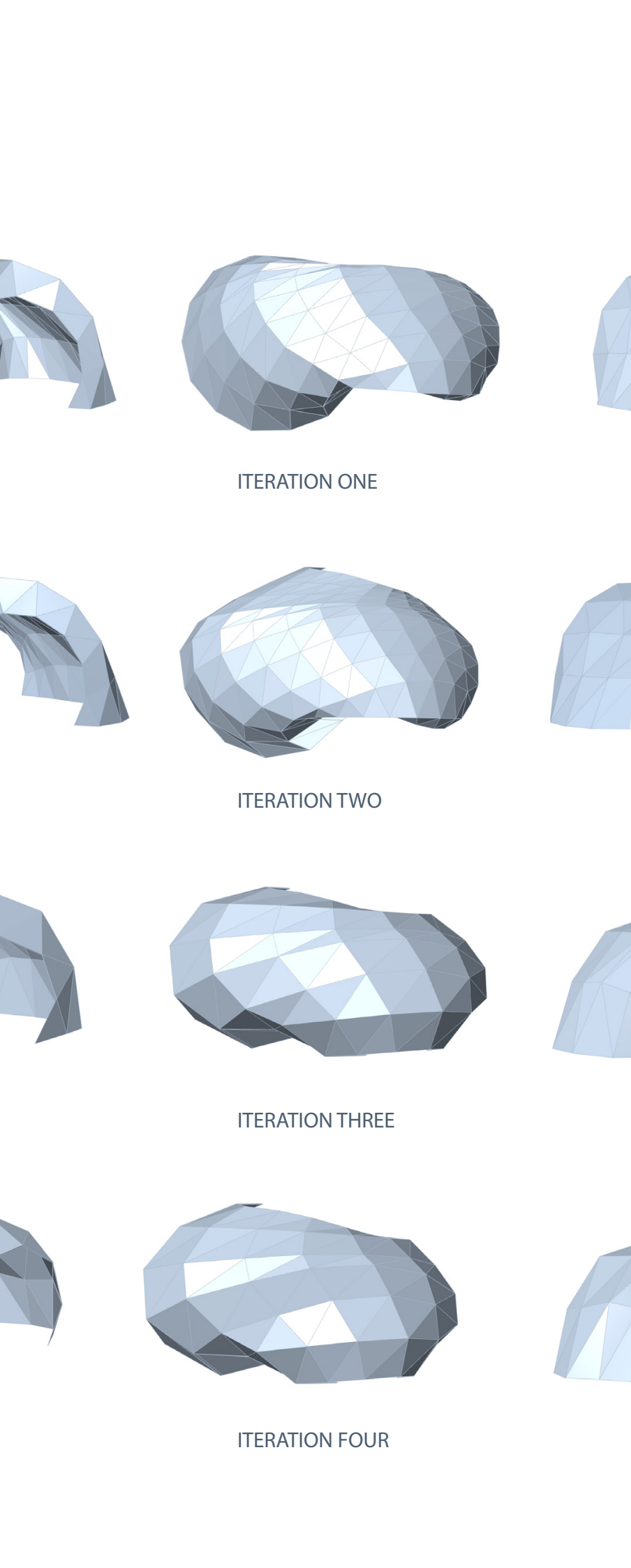

\section{CHOSEN DESIGN}

7.3.0

This design was selected to move forward to be used with the robotic arm due to it only consisting of 98 panels. The form also has two entrances which will be useful for an exhibition space, as it can allow people to access it from both sides. The two openings also naturally created two sections which was required in the brief. One side is used for seating and the other side is used for the exhibition space. Although this is the chosen design, the research is mainly focused on the workflow to create the joints itself, which can be used for any design that can be customised to people's preferences. This form was designed to create an example to show what forms can be achieved with the jointing method.

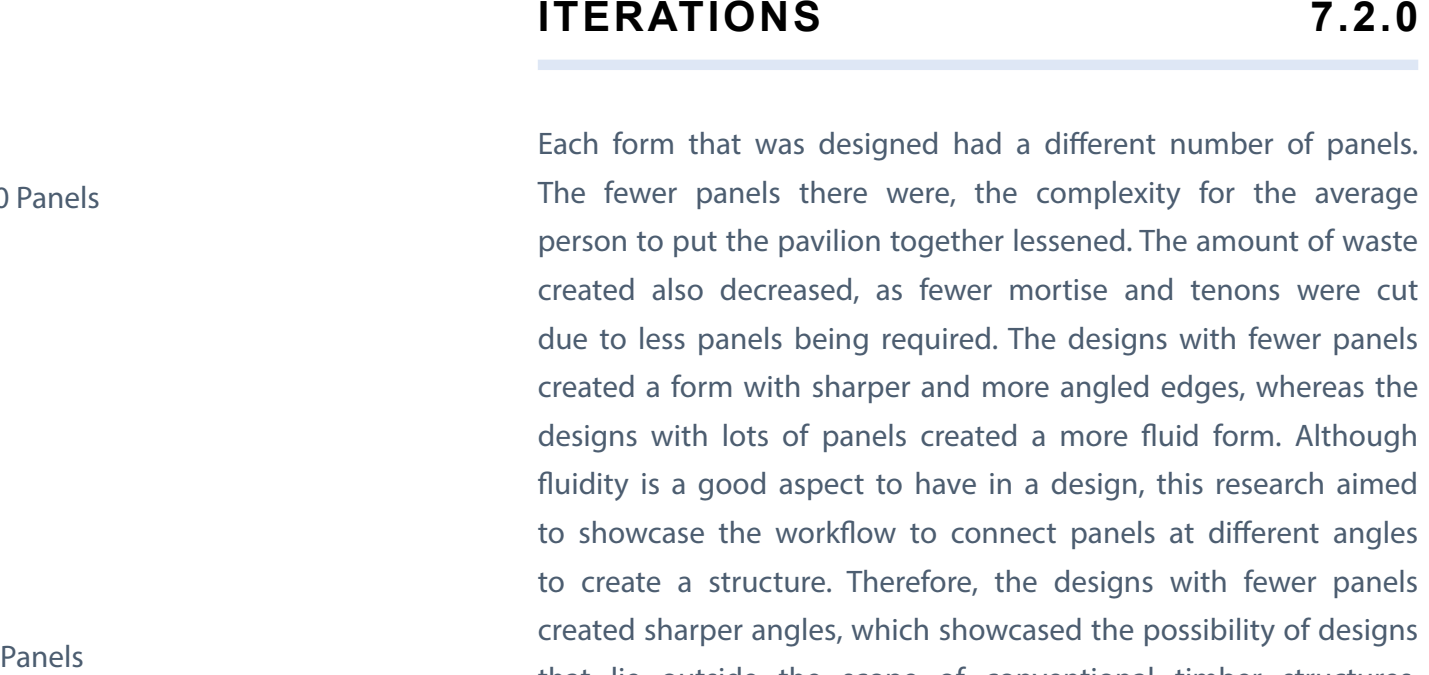

98 Panels

Requires 38 Sheets of $2400 \times 1200$ sheets of plywood 


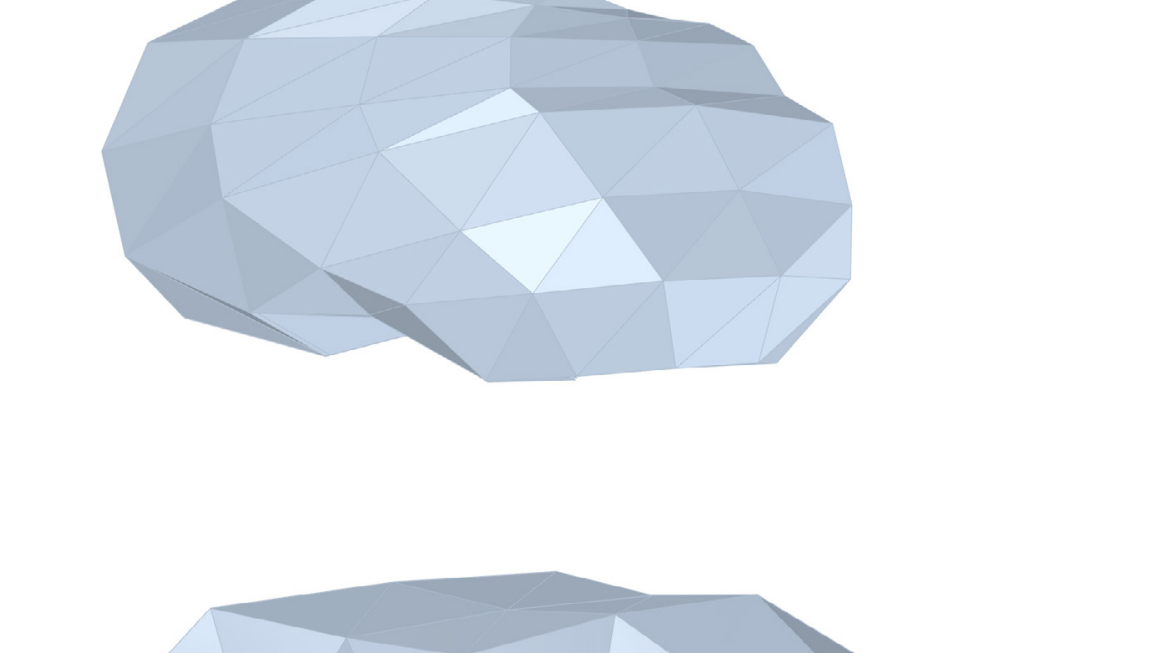

A 1:50 laser cut model was first created to understand the design better before being taken to the robotic arm to be cut. This model was cut on $0.5 \mathrm{~mm}$ brown card. Although the laser cutter gave it a straight cut instead of cutting on different angles for each panel. Tabs were made to allow the model could be folded instead of being glued to each other. Creating this model was a big learning process, as the location of each panel had to be manually figured out. For the model to stand up it did require the support of other panels, and by creating each panel one by one, the order of which panels were joined together was solved. The highlighted lines shown in figure 79 , are the panels that will be fabricated with the robotic arm.

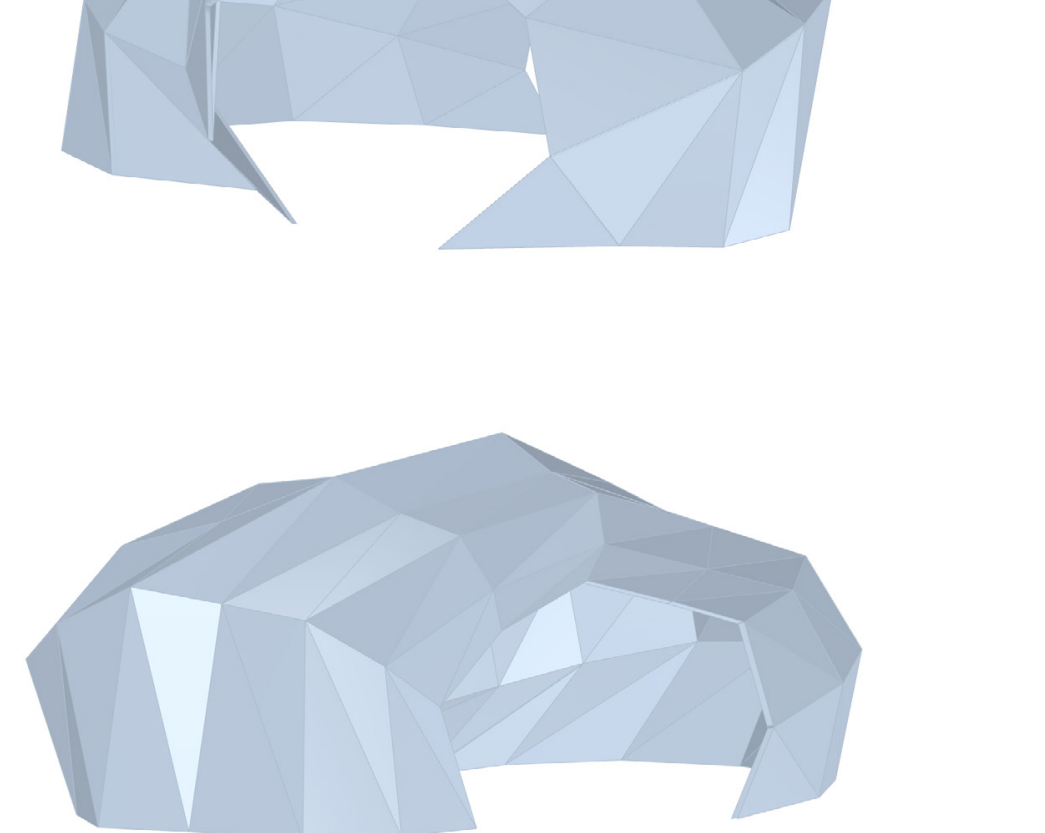




$$
\text { G) }
$$




$$
\begin{aligned}
& C>C \\
& (C) E
\end{aligned}
$$



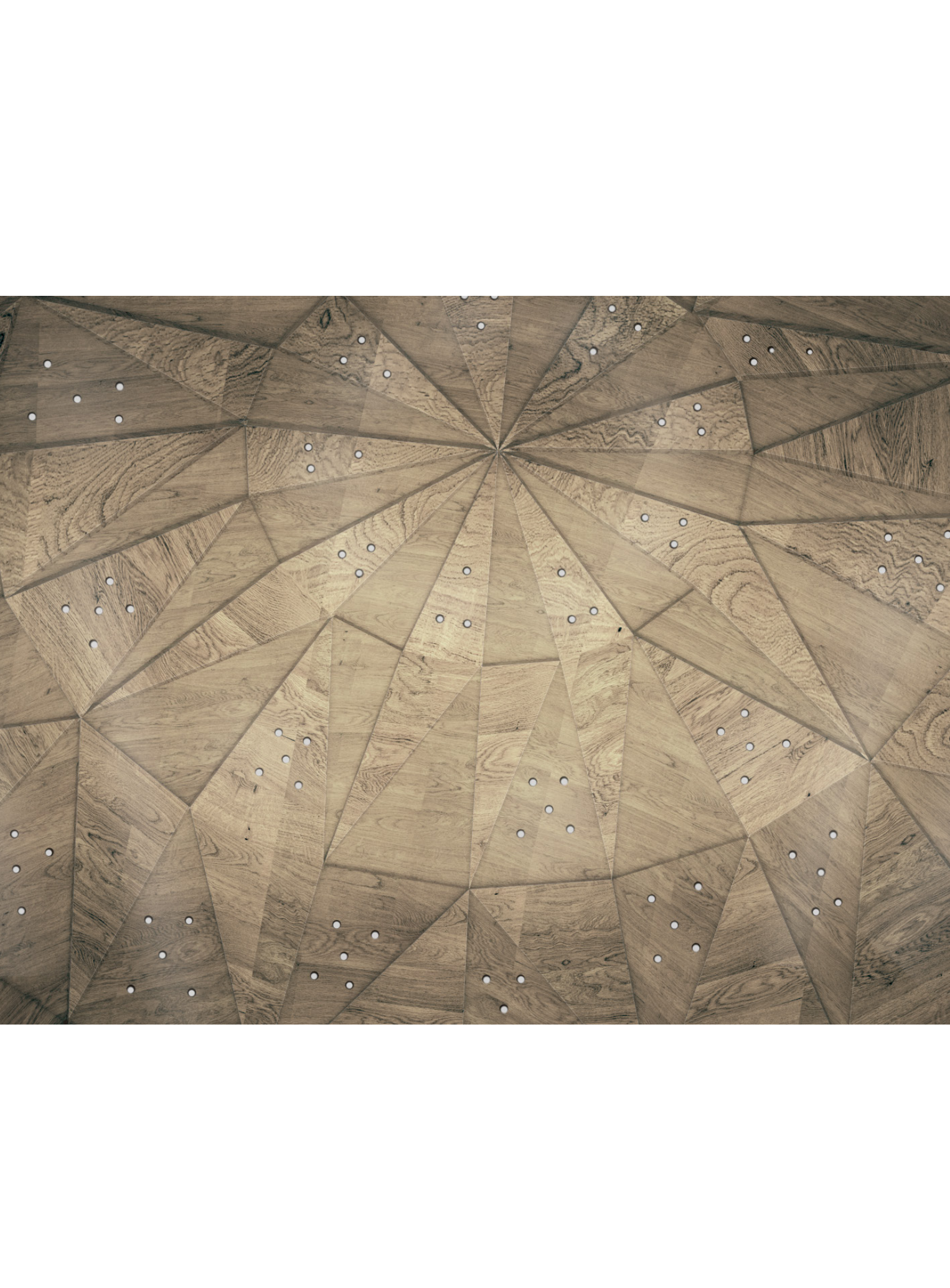
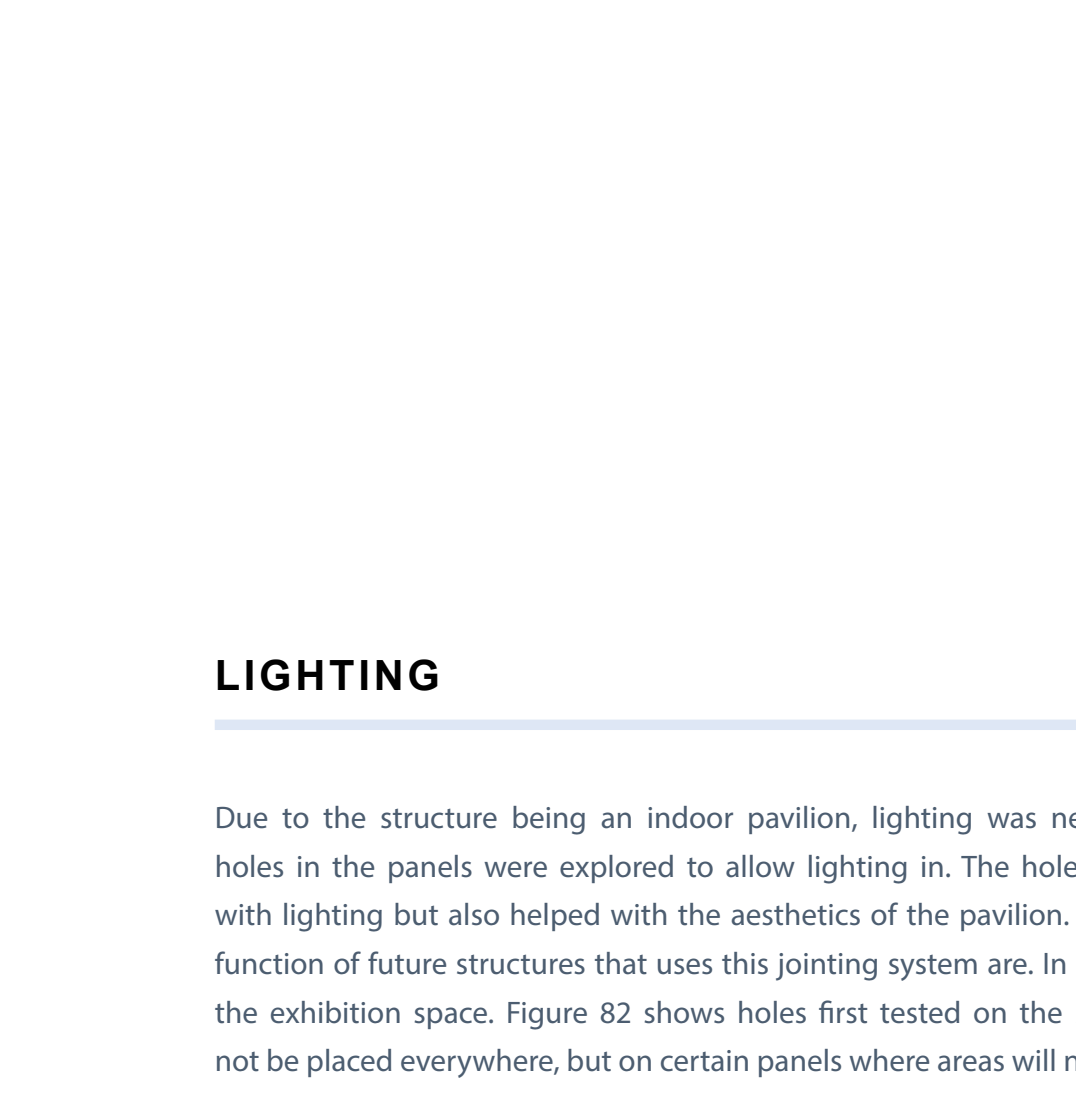

\section{LIGHTING ITERATIONS}

7.4.1

The holes were then tested digitally to assess how the voids would create light and shadow within the pavilion. The elements of the holes, light and shadow combined in different ways from each angle of the panels, which created an aesthetically pleasing experience not only from the form but also the light and shadow created. Depending on the size and placement of the holes, it would create a differen experience for the user.

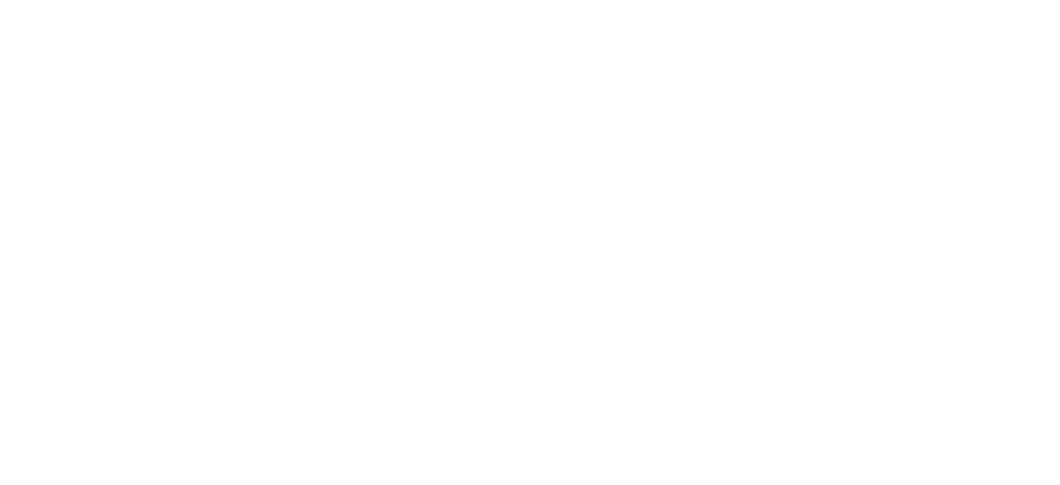

1. First set of holes tested in a triangle shape at the center of certain panels.

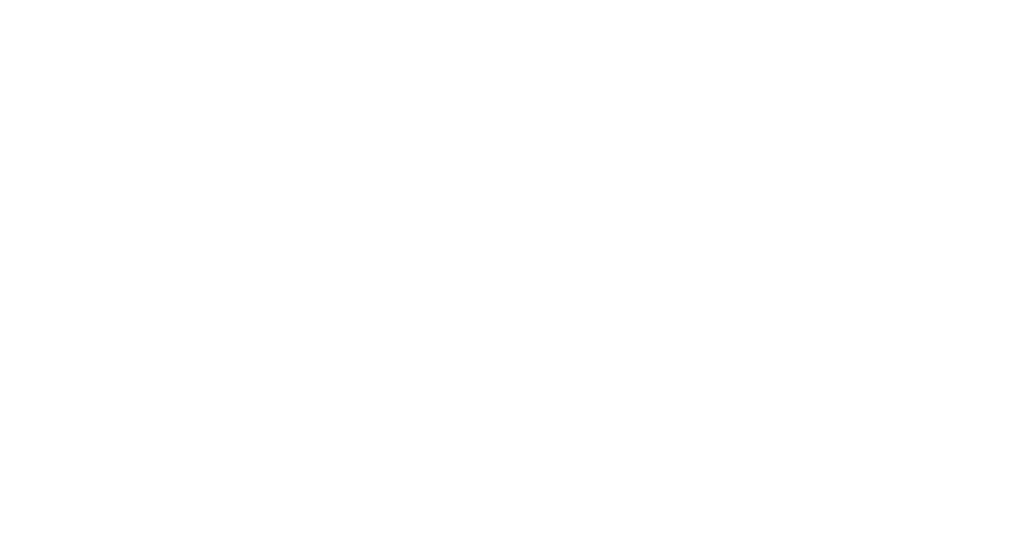

Enlarged radiuses of the circles, also place in the center of certain panels to create more light

3. Placement of these holes are the same as iteration one and two, however instead of a circle, squares and triangles were tested

4. Placement of randomly sized circles at random places on each panel. This was successful as it created light in random places inside the pavilion. 
A consistent pattern on selected panels was proven to be more successful. It comprised of holes with two different radiuses. The light and shadow quality from these holes were successful as it created areas with focus points and still allowed small points of light to surround it. Having these holes in the panels also made the panels lighter, and therefore there is less force on the joints, making the joints stronger. 


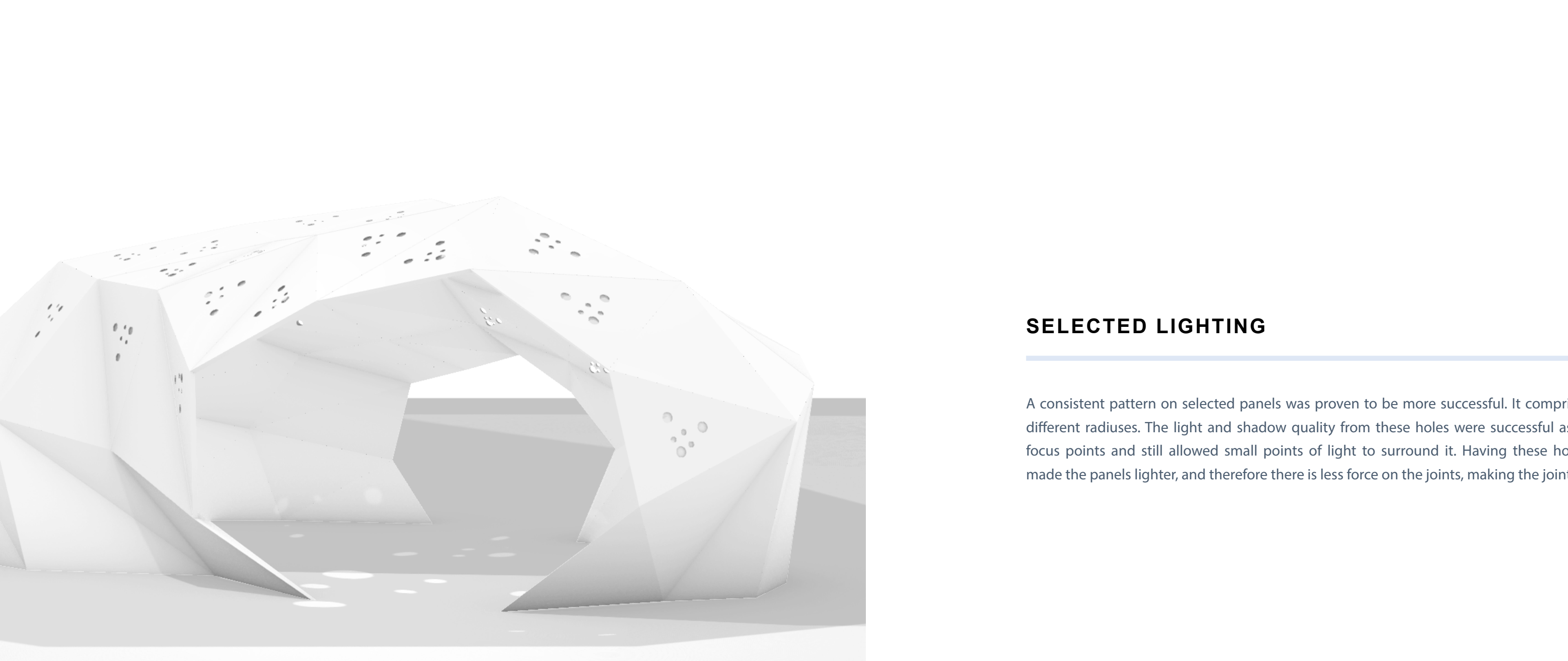




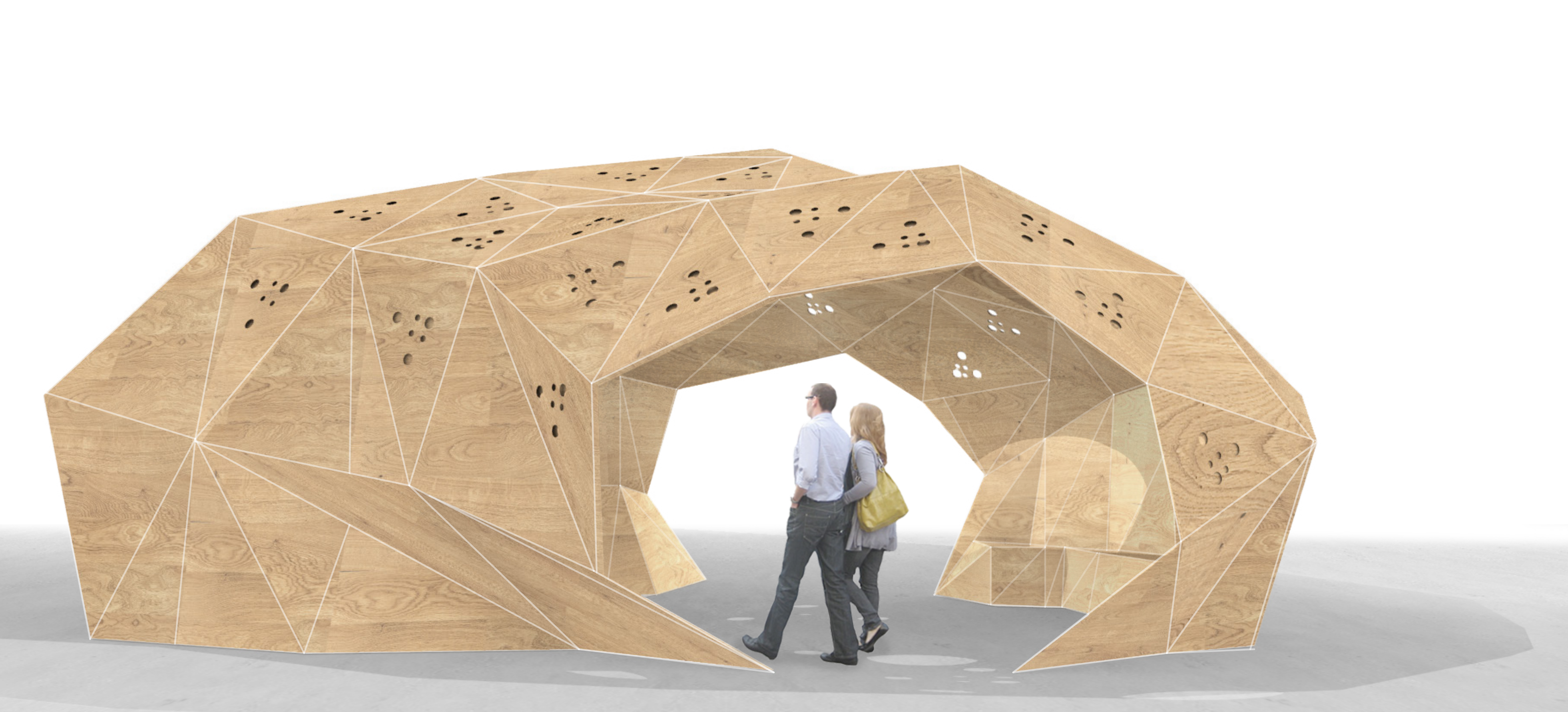

SECTION A-A 


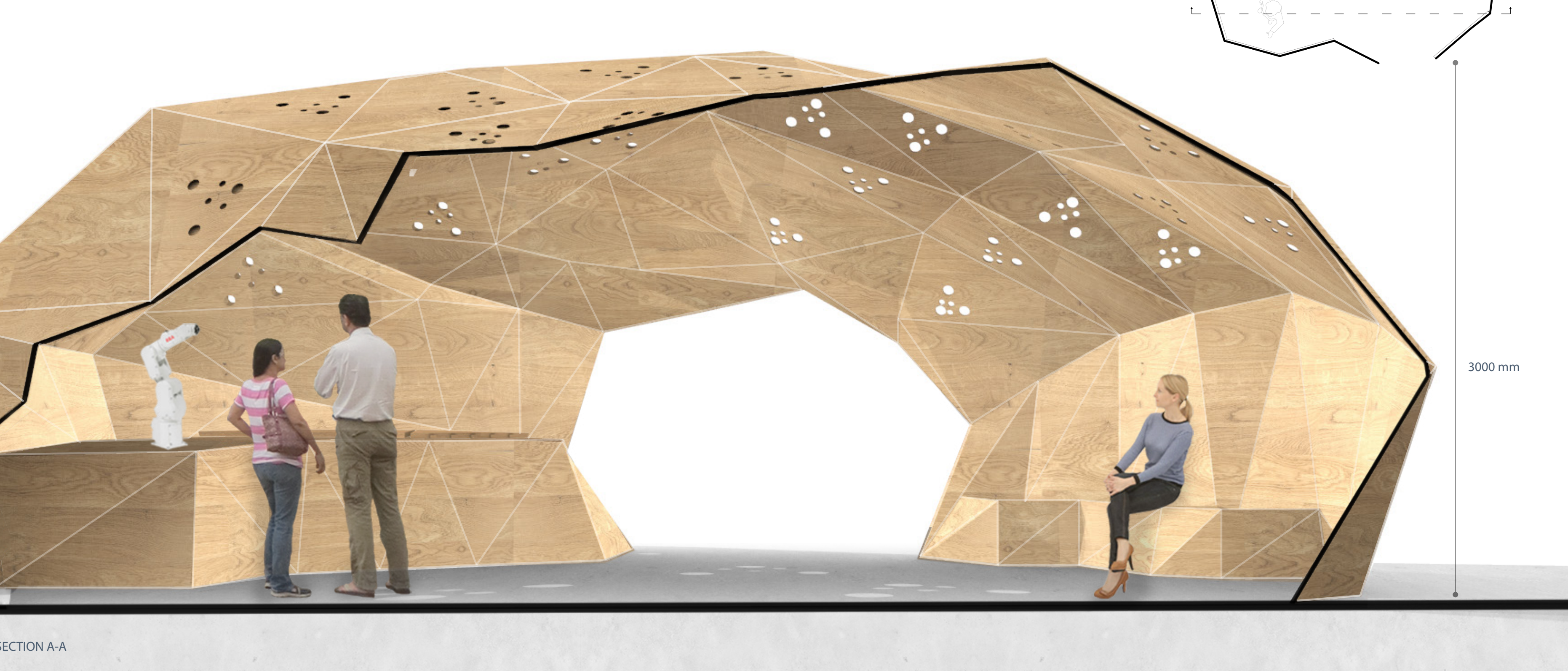



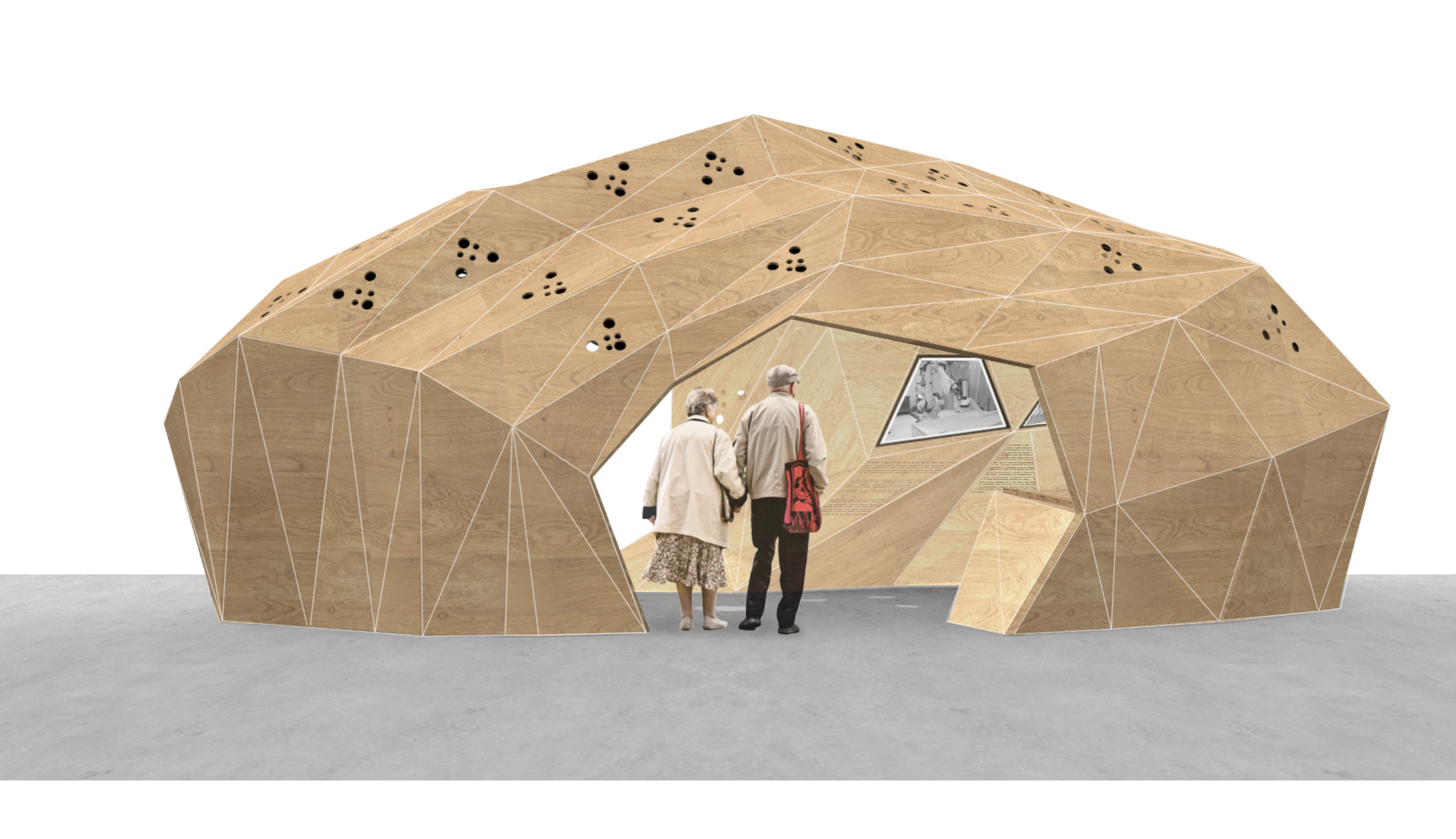
This chapter developed a structure that can be constructed using the joints designed in this thesis. Althoug this research mainly focused on the workflow to develop a joint for a self-supporting structure, a form was crucial to help understand how the joints can be used. A function for the structure was needed to showcase an example of the joints used in an actual structure. Although it is not limited to just the pavilion designed, the joints can be used for many variations of forms and functions. The same goes for the holes used for lighting in the pavilion. A limitation to the holes is that it needs to be site specific, to maximise the amount of lighting that can go in. However, because the structure can be fabricated, assembled, disassembled and reassembled in another location, the holes aren't designed to the maximum lighting advantage. Therefore, It is more for aesthetic purposes with the advantage of lighting coming inside, rather than focusing fully on the lighting in the set location the pavilion will temporarily be in. The overall form is a good exemplar to demonstrate the design possibilities that comes with robotic fabrication and computational tools. 


\section{INTRODUCTION}

This chapter focused on the fabrication and assembly of panels which were designed in the previous chapter. Five panels were taken from the design and fabricated with the robotic arm. The five panels all consists of the mortise and joint system designed in chapter six. The panels are at full scale, and creating them broadened the understanding of bringing a design from the digital world to the physical world. The fabrication and assembly of these panels also had issues, which were eventually resolved. This resolution of the issues created part of a structure that was able to hold itself with use the joints that were designed. No glue nor screws were needed which showcases the success of these joints. 


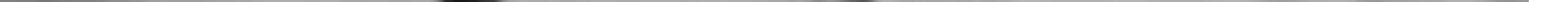

The cutting process established in chapter five was used in the fabrication of these panels. This starts with drilling the holes, then cutting out the panels. Then each panel is moved to the edge of the table surface to cut the mortise and tenon out. 


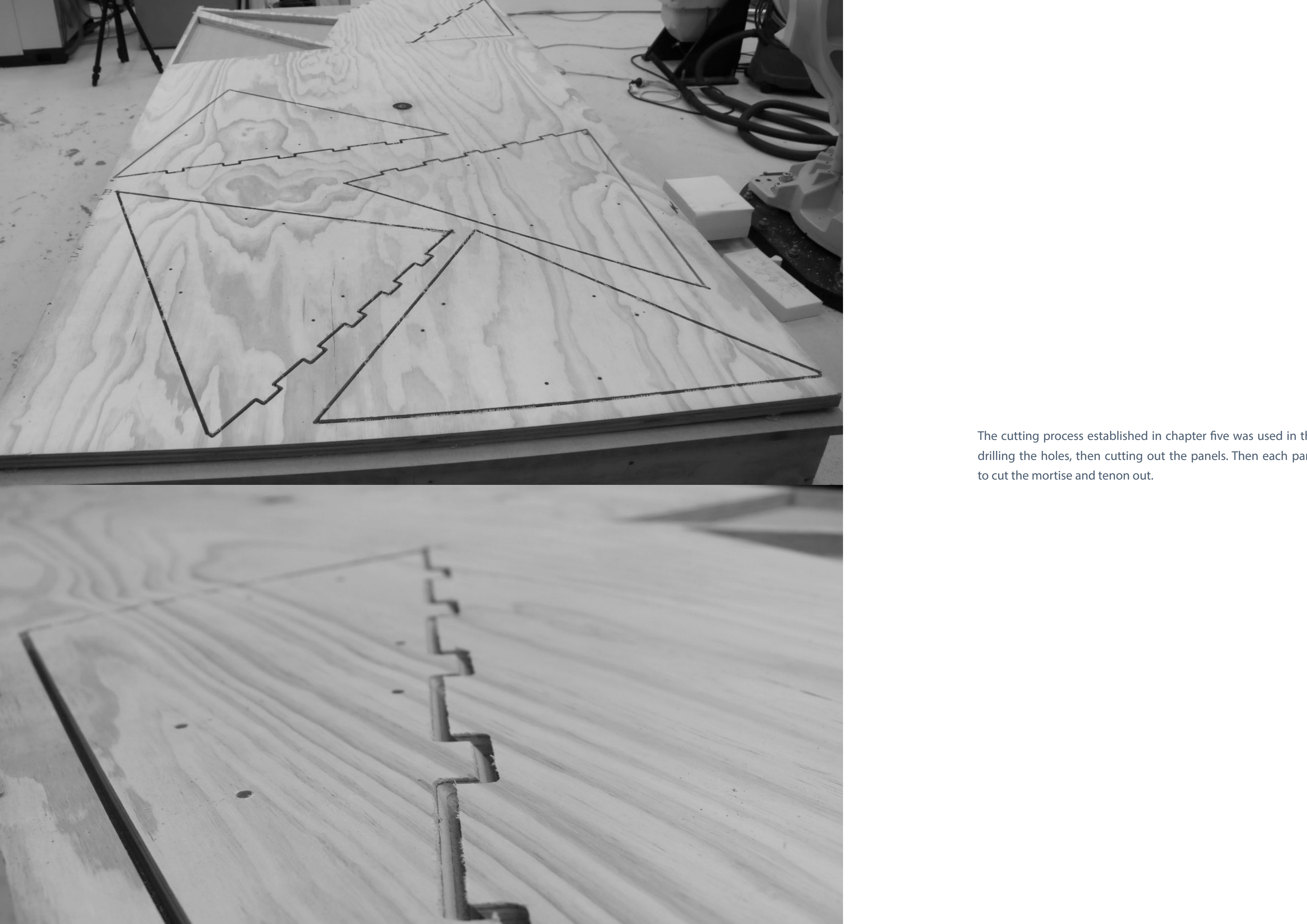

enon cut out with the router after being on the side edge of the table. 


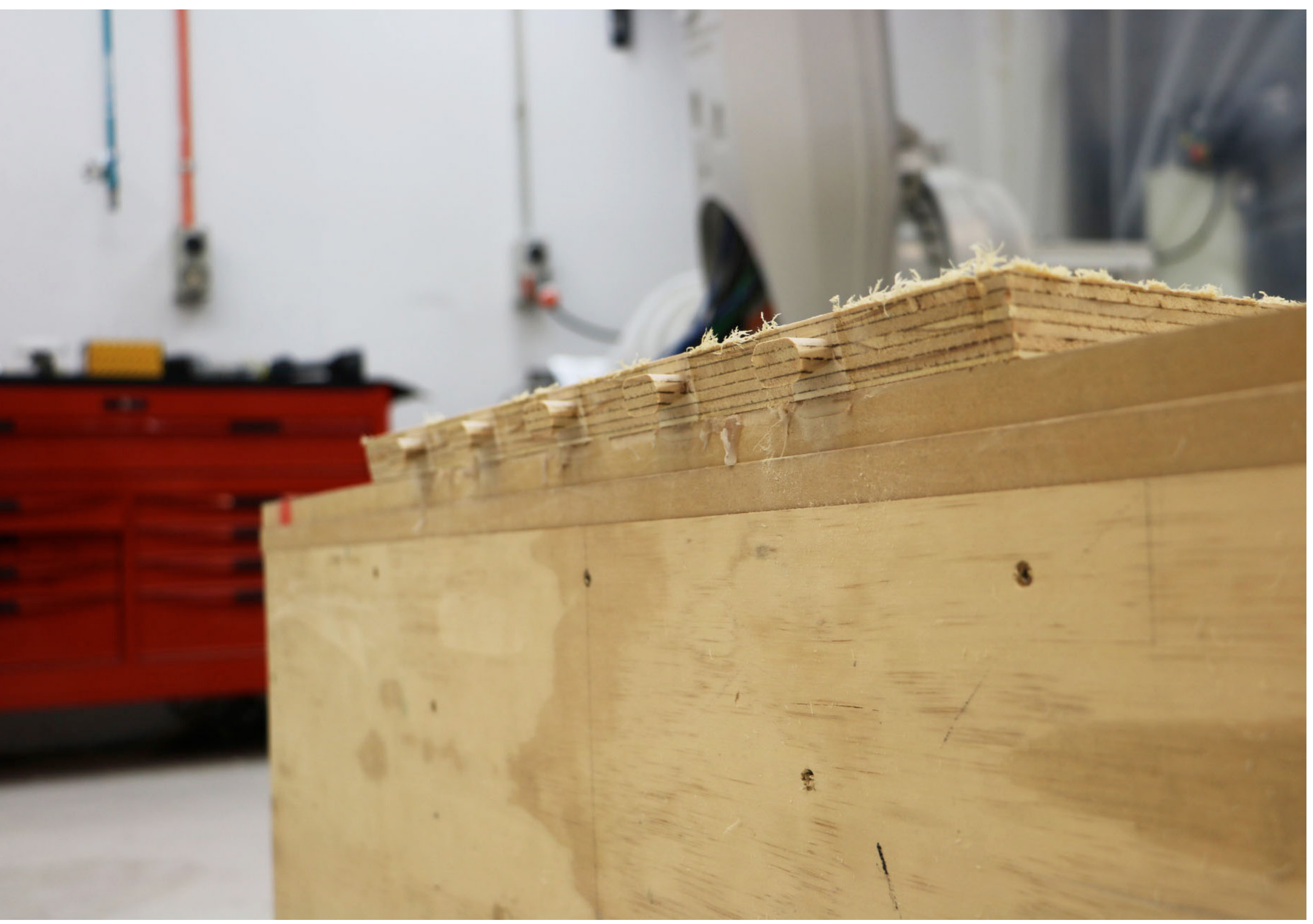

Process of mortise being cut out showing the air gap that is cut out before being cut with the $16 \mathrm{~mm}$ dovetail router. 

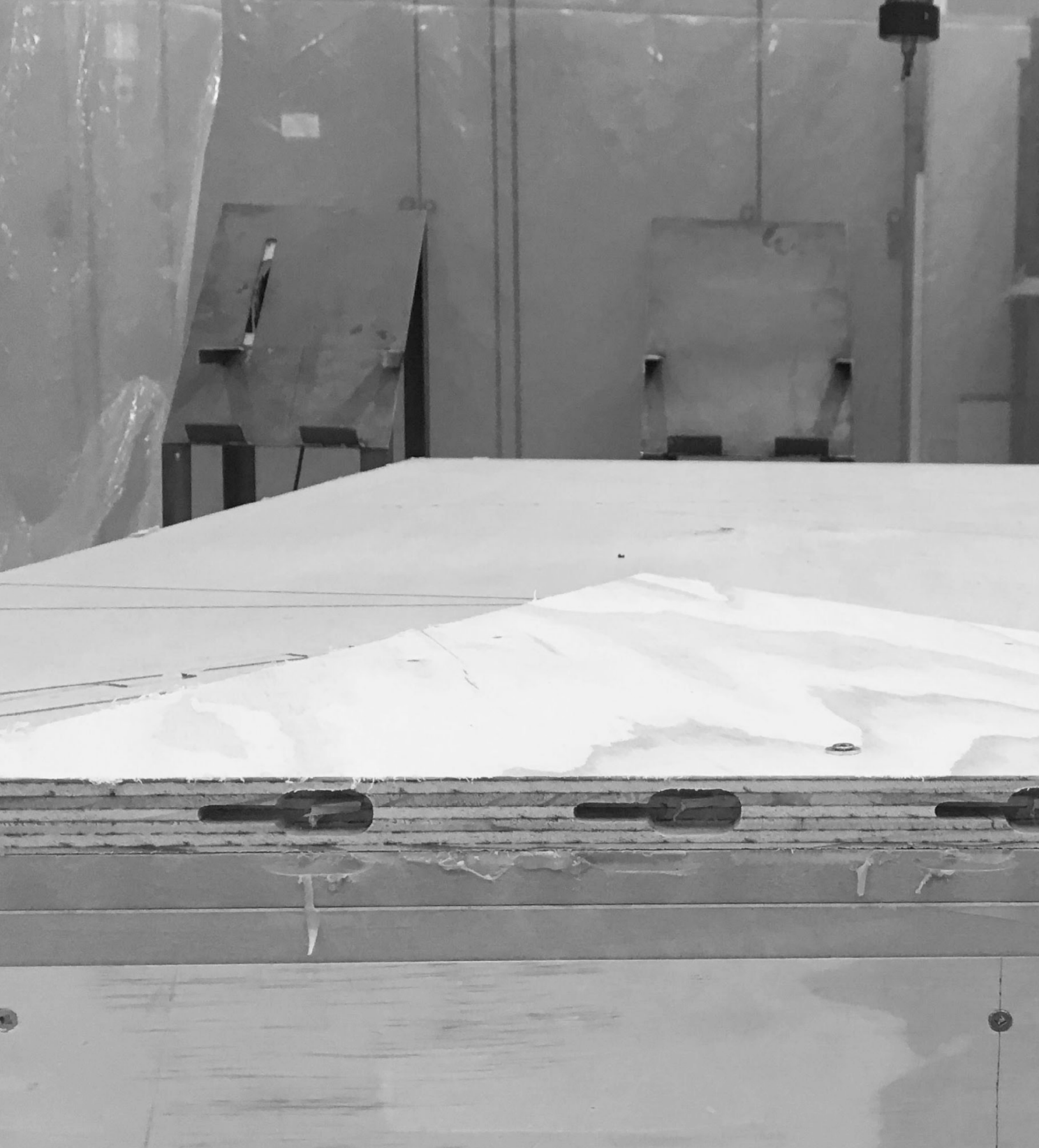

The process of cuting out the motise fully with the $16 \mathrm{~mm}$ dovetail router. This was important to show the movement of the mortise cut out with the dovetail router in one pass after the $6 \mathrm{~mm}$ straight router has cut it.

\section{STRENGTH}

The panels cut with the joints were looked at by Geoff Thomas, the Building Science Programme Director at Victoria University of Wellington, and it was mentioned that the joints seemed rigid enough to create a self-supporting structure. Due to the structure being indoors, compliance with the NZ Building Code is not required and if it does collapse, it will just be a health and safety issue, however, when the panels are joined together, it will be sturdy enough to hold itself up. 
ERRORS

8.2.0

Double checking the points are in the right place is an important step before exporting the code to the robotic arm. At the step of routing the holes $40 \mathrm{~mm}$ from the centre of each edge of each panel that would be cut, a point for one of the holes was under the work table. This caused the router to go through the plywood and work table, causing the need to use the emergency stop button for the machine. Safety was an important issue that was discovered in this process due to the robotic arm being unable to recognise any obstacles. Similar to most machinery, this is a drawback of the robotic arm. Other machinery such as woodworking machines are unable to move around six-axis and can only move to a certain degree, therefore safety is not a big issue for those machines. However, the robotic arm does have the ability to move around six-axis. Therefore if a point is in the wrong spot, the robotic arm will still go to that point regardless if there are any obstacles in the way. This highlights the need to ensure the points are accurately placed in the correct spot to ensure safety, prevent errors and save time.

156.

Figure 95: Aftermath of router bit going through the plywood

Figure 96: Diagram showing point under table

chapter eight I fabrication \& assembly

157. 


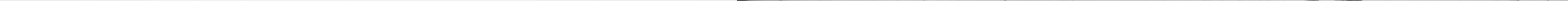



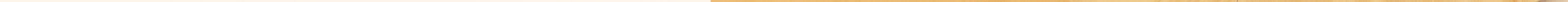


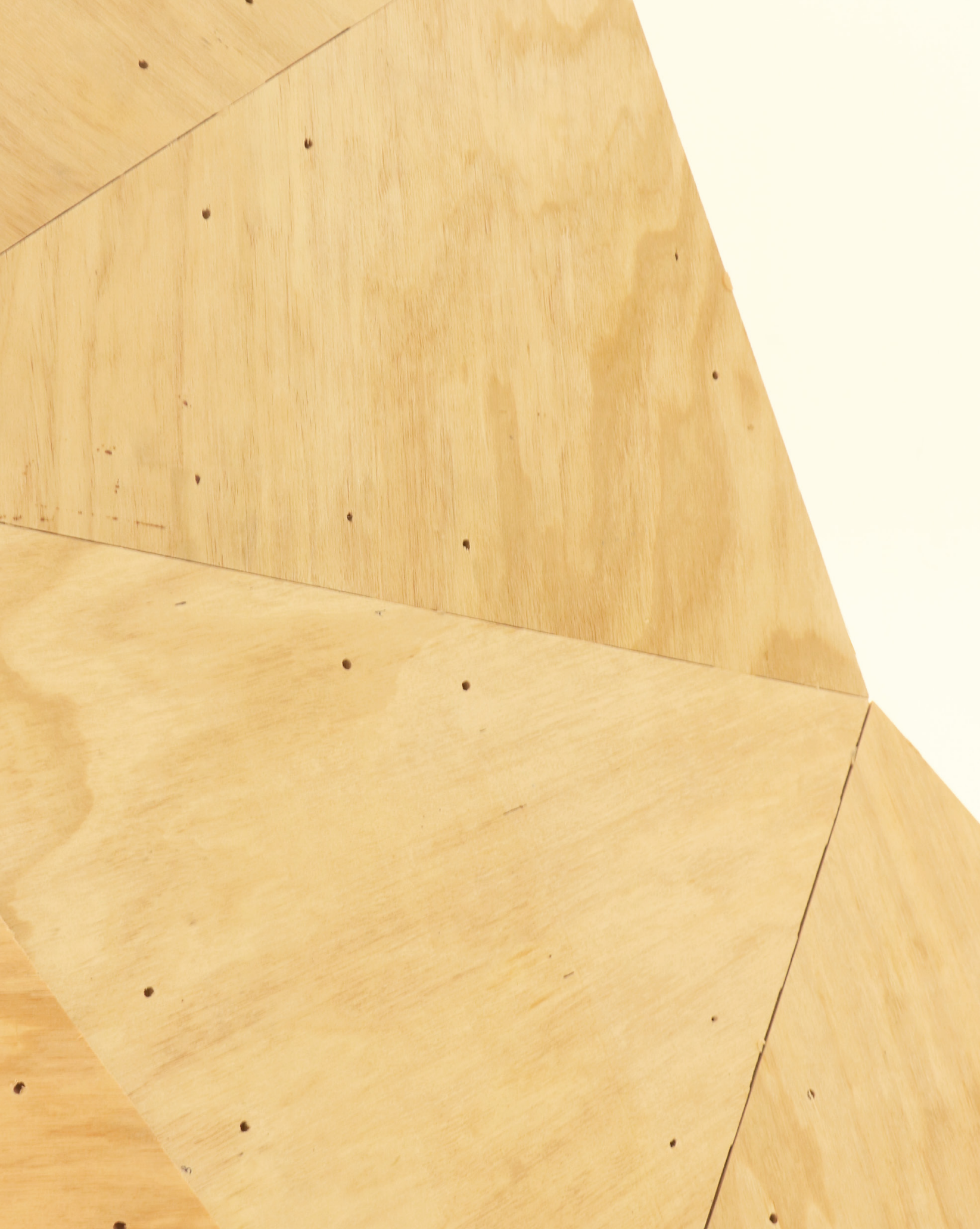



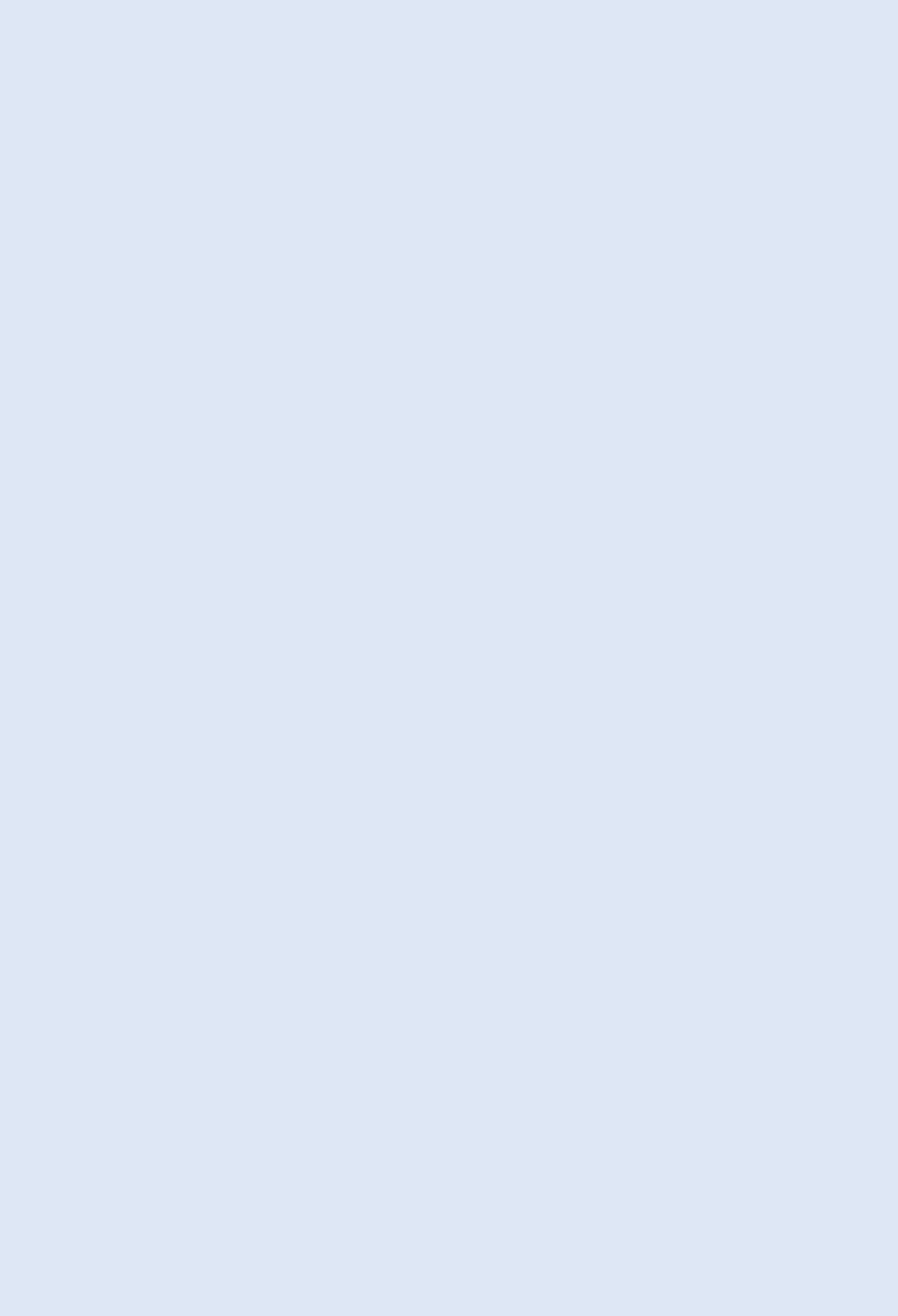

ASSEMBLY

When assembling the panels, it was difficult to recognise which panel was the panel's adjacent pane to connect with. There needed to be a system which would allow a quick recognition of a connecting panel, to allow for prompt assembly of the structure. Therefore, although this was not fabricated in this research, a system was designed after these five panels were fabricated. The system created a design within the endpoints of adjoining panels, which would only aesthetically show when the panels were connected. Each set was assigned a letter, to allow recognition of which centre point it belonged to. The design and letter would be etched onto the panel by the robotic arm. Finding the design that would be easily recognised was explored. This design would come with a pattern manual when it is assembled. A circle, triangle, star and hexagon was experimented with on the panels. To test how well it would work in reality, the panels with each design pattern were printed on A4 paper, cut out and given to two anonymous people. They were then timed on how long it took to figure out which piece belonged where. The results are as follows:

Person one

Gircle: 2 minutes 475 Triangle: 2 minute 20 seconds

Star: 1 minute 5 seconds : Person two

Hexagon: 40 seconds

Circle: 3 minutes 21 seconds

58 seconds

tar. 55 seconds

Circle: 3 minutes

Triangle: 2 minutes 15 seconds

Star: 1 minute

Hexagon: 34.5 seconds

The chosen design that is best to move forward with this research is the hexagon design, as it allowed for the faster recognition of where the panels went between both parties. It only took an average of 34.5 seconds to figure out which panels belong next to each other. However, there are many limitations with this study, firstly the test was done on A4 paper, not plywood and it was not to a 1:1 scale, therefore the timed numbers are not as accurate. Due to the large difference between the numbers when timed, it showed the hexagon worked best with the recognition of the panels. The circle design took the longest to solve due to the curves appearing the same on each panel, which meant there was no clear distinction that indicated panel one was different to panel two. The designs with more connection points were easier to determine which panels belonged were, such as the hexagon or the star, as shown by the timed results. However, the star still took longer than the hexagon, due to the need to figure out how many connection points there were before continuing to find the adjoining panels. Another limitation was that the paper was bending whilst attempting to figure out which panel belonged next to each other, which would cause the time to take to be longer. If tested on plywood at the right scale, the time may be a lot faster as the design would be a lot larger, and you will be able to see which pattern on the panel will clearly line up with each other. Due to the structure being completely prefabricated, each structure will also come with a visual manual to aid in the assembly. This will show the shape of the panels and how the design looks on it, to allow clients and builders to recognise how the panels should look next to each other. 
This project has established a parametric workflow to create a self-supporting structure, shown in figure 105. Current design to construction workflows take a step of reworking the drawings. This is often done by another contractor, due to inconsistencies going from the design to fabrication phase. Compared to current workflows, full control is given to the architect/designer with this new workflow going from the design to the assembly phase, as no rework is needed to be done. This is due to the parametric workflow, where one component in the design is changed, the robotic toolpath will automatically update itself to allow it to be ready for fabrication, following on with assembly. Not only is this a more productive workflow, it also allows the creation of a complex self-supporting structure from sheet materials using robotic fabrication and computational tools.

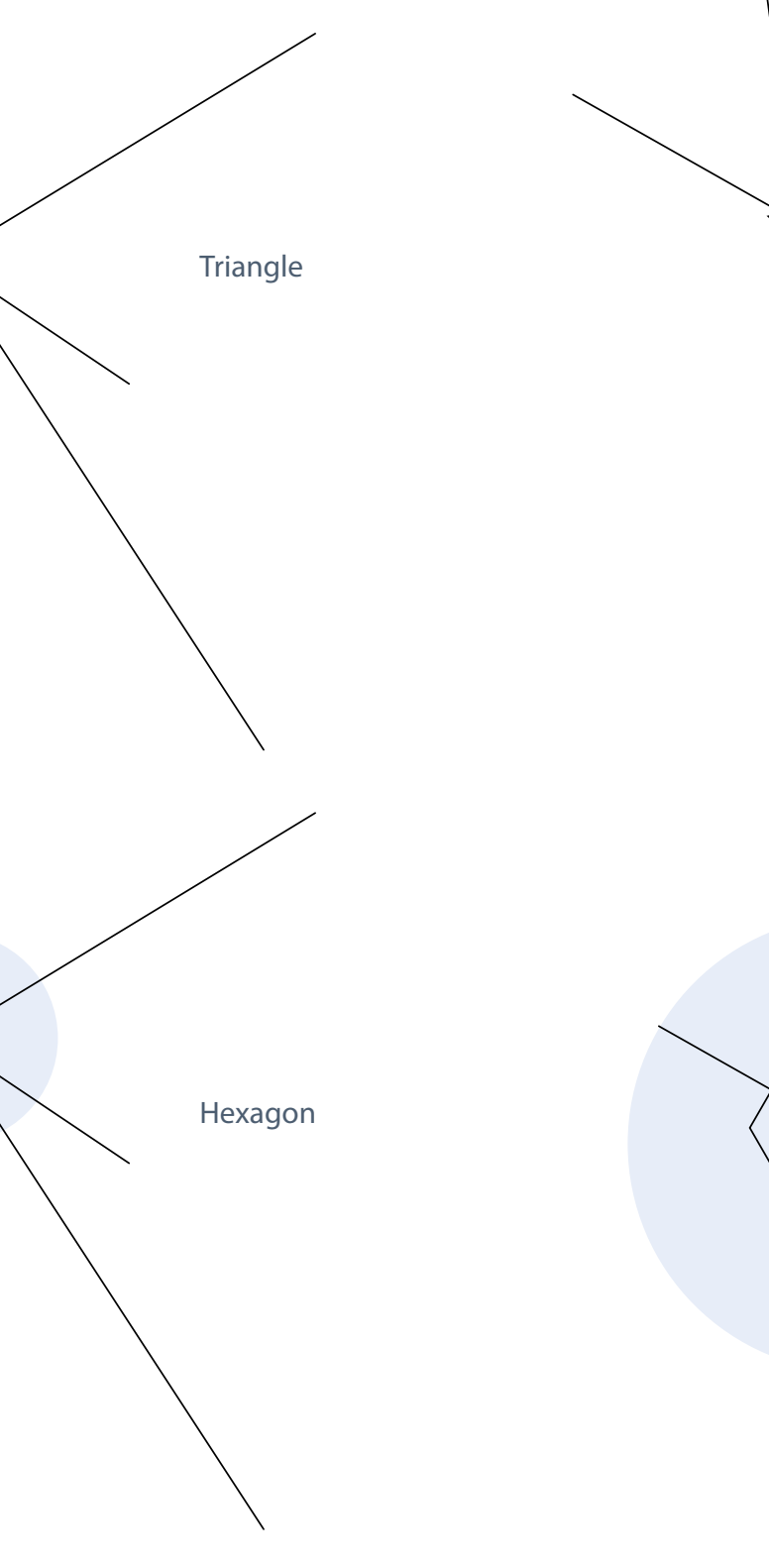


Overall, this chapter displayed the fabrication and assembly of the robotically fabricated plywood panels using the parametric workflow that has been established. The fabrication of the panels was not as straightforward as anticipated, as many issues had risen. Such as points not being in the correct place, and placement of the panels not being as accurate. The fabrication involved a fabricating, recoding, and re-fabrication process to ensure the panels were cut correctly. The need to rework the code was time consuming and does not necessarily entail a 100\% success rate. This is because the cutting process involved a manual placement of the panels, which does not involve the robotic arm when preparing for mortise and tenon to be cut. This caused the mortise to be $1.5 \mathrm{~mm}$ shallower than needed, which led to the mortise not being wide enough for the tenon to fit through. This meant that the panel had to be moved $1.5 \mathrm{~mm}$ closer to the edge of the table and re-cut to allow the tenon to fit If this were to be redone, the manual placement of the panels would be removed and the use of the robotic suction gripper tool would be attached to the end of the arm and used to place the panels in the right position. Due to robotic access constraints, this method was unable to be tested, however, due to the accuracy of coding combined with the robotic arm, it is predictable that this method would be more successful than the current method used.

The technique to assemble to create a self-supporting structure was also unable to be tested on plywood panels, however, this method will lessen the time required to figure out which panel is which, shown by the paper test. Although there were many limitations with the test, such as an accurate representation of the time with plywood, the design and letters etched on the panels should provide a simple and interactive way for the builders to construct the structure. 
This research took on a project that involved the use of new technology and advanced software to connect sheet materials at different angles, therefore many limitations were to be expected.

Unfamiliarity with the programming of and using the robotic arm was a drawback to begin with. Learning to use the robotic arm to mill timber was a huge learning process that took a lot of time to learn the functions and to understand how to control it. Multiple errors were made each time the robotic arm began cutting, which led to reworking a lot of the code to ensure it is performing the task correctly. This led to spending many hours on just one cut, which was time consuming and not necessarily faster than manual methods. However, once everything was working correctly, the same code could be used and repeated for another design.

Once the five panels were fabricated with the robotic arm, the robotic workshop had closed for earthquake strengthening. This meant additional prototyping could not be undertaken, and the idea for the assembly of the panels could not be tested. Therefore presumptions were made for the success of this idea.

As stated in the scope of this thesis, a full-scale structure was envisioned, but not built due to cost and time constraints. Instead, a part of the structure was fabricated and assembled, which also kept the time and focus on the development of a workflow to get to that stage. It is also difficult to predict whether the design will fully stand up when structural testing was not done on it, and when only a part of it was fabricated and assembled.

These limitations created other opportunities that can be built on in the future and helped strengthen this project. 
For this research to develop further, there are several improvements that could be implemented to address the issues found. Firstly, collaboration with structural engineers will increase the structural stability of this system and also increase the potential of this research to be used in future structures.

Plywood sheets that may be thicker or thinner can be tested in further research, as it may impact the design of how the joints connect together and identifies the need to use different router bits. The router bits used were the ones readily available at the university workshop, which limited the depth of the joints using the dovetail router bit to only a maximum of $16 \mathrm{~mm}$. Other sized and shaped router bits can be explored and prototyped in the future.

Implementing a second robotic arm in a larger workspace, can allow the fabrication and assembly of structures to be faster and can take out the manual human intervention needed in this workflow.

A full-scale structure will establish a greater degree of accuracy, thus with more time and funding, a fullscale structure based on this workflow can be explored in further research. The full-scale structure can be flat packed and taken to exhibitions and events and assembled on site then disassembled to demonstrate the sustainable advantages of this system.

Although this system was designed for structures located indoors, exterior potentials could be looked into in the future. This would mean weather tightness and possibly external cladding would need to be researched to allow structures using this system to be implemented in an exterior environment.
This research was undertaken to investigate how a self-supporting timber panel structure could be designed and manufactured using computational tools and robotic fabrication. Resulting in the development of a parametric workflow that controls the entire process of architectural form to detail requirements and tool path control of robotic arm. The workflow enhanced productivity, as the whole process was able to be controlled by one person, due to the workflow being parametric.

Robotic fabrication is still developing in architecture, however, it is opening up new opportunities in the industry. Preliminary research showed that prototypes of robotically fabricated structures still relied on fasteners to hold it into place, which contributes to global $\mathrm{CO}_{2}$ emissions. It became clear that a sustainable design approach was needed, which would avoid the need of metal fasteners. This led into the research of traditional Japanese joinery techniques where wood to wood joints held structures together. The technique used in Japanese joinery inspired this research to bring back the technique in contemporary structures.

Timber fabrication techniques were limited in the past because of time and tool constraints, however, this research went outside the limits of timber fabrication. Computer-aided design and manufacturing helped aided with this and was extensively important in this research, being one of the main reasons part of a complex structure was achievable. Parametric software enabled the opportunity of customisation demonstrated by the robotic toolpath. This research has created a direct link with parametric design and fabrication, overcoming the many limitations that have occurred previously.

There were four stages to this research which aided in the growth of knowledge of the design and fabrication using the robotic arm. Computational simulations was the methodology adopted for this research, enabling us to run an iterative process to act as a substitute for the actual physical prototyping and highlight the issues found

Five final panels were fabricated with the robotic arm. The five panels all comprised of the sliding mortise and joint system. The creation of these panels broadened the understanding of bringing a design from the digital world to the physical world. When designing the toolpath on Grasshopper and running the simulations, it was difficult to predict the errors that can occur until the prototypes are physically fabricated. This method of going from digital to physical was successful as only some parameters needed to be adjusted to resolve the issues found. The resolution of the issues created part of a structure that implemented joints that were designed to connect itself together at different angles. No glue nor screws were needed, which showcased the success of these joints. Although this research did not create a full structure, it substantiated that parametric software combined with robotic fabrication can create timber connections to connect sheet materials at different angles. A full-scale structure will establish a greater degree of accuracy, thus a full-scale structure based on this workflow can be explored in further research.

The design of this workflow to create a self-supporting structure demonstrated that timber joints can replace steel connections to create a more sustainable and simpler construction method. The workflow, which included creating a script to control the robot, contributes to the opportunity of developing bespoke architectural forms with the help of the robotic arm. Mass customisation is prioritised over mass production in this research, which takes advantage of the design opportunities offered by robotic fabrication and computational tools. This thesis has evidently shown that robotic fabrication combined with computational tools can create a parametric workflow to create a self-supporting structure. 
About BuildNZ. (2020). Retrieved January 14, 2020, from https://www.buildnz.com/visitor-information/ about-buildnz/

Alison Furuto. (2011, September 19). Acoustic Environments / AREA and Electrotexture Lab. Retrieved April 3, 2019, from http://www.archdaily.com/170078/acoustic-environments-area-and-electrotexture-

APA Wood. (2018). A Guide to Engineered Wood Products. Retrieved May 11, 2019, from https://www. apawood.org/publication-search?q=c800\&tid=1

Baranyk, I. (2017, February 4). PRODUCE Workshop Debuts Plywood-based "Fabricwood" Pavilion for Herman Miller's Shop-in-Shop. Retrieved April 4, 2019, from http://www. archdaily.com/804590/ produce-workshop-debuts-plywood-based-fabricwood-pavilion-for-herman-millers-shop-in-shop

Beorkam, C. (2013). Material Strategies in Digital Fabrication. New York: Routledge.

Brink, N. (2016). Archimedia designs faceted te oro community center in auckland. Retrieved December 12, 2019, from https://www.designboom.com/architecture/archimedia-te-oro-community-centerauckland-new-zealand-01-15-2016/

Chilton, J., \& Tang, G. (2017). Timber Gridhsells; Architecture, structure and craft. New York: Routledge. Ding, D. (2015, June 8). ART OF JOINERY IN ARCHITECTURAL DESIGN. Retrieved September 16, 2019, from https://medium.com/thinking-building/art-of-joinery-used-in-recent-japanese-architecture5e3d0e5aa4c1

Dooley, K. (2002). Simulation Research Methods. In Companion to Organizations (pp. 1-39). London: Blackwell.

Doscher, M. (2012). Disposable Code; Persistent Design. In Digital Workflows in Architecture: Design-Assembly-Industry (pp. 206-211). Base//Berlin/Boston, SWITZERLAND: Walter de Gruyter GmbH. Retrieved December 17, 2019, from http://ebookcentral.proquest.com/lib/vuw/detail. action?doclD=1020494

Dunn, N. (2012). Digital Fabrication in Architecture. London, UNITED KINGDOM: Laurence King Publishing. Retrieved September 18, 2019, from http://ebookcentral.proquest.com/lib/vuw/detail. action?doclD=1876132

EWPAA. (2018). Structural Plywood and LVL Design Guide. Engineered Wood Products Association of Australasia. Retrieved April 21, 2019, from https://ewp.asn.au/wp-content/uploads/2018/12/EWPAAStructural-Plywood-LVL-Design-Guide-v5-FINAL-1.pdf

Gershenfeld, N. (2012). How to make almost anything: The digital fabrication revolution. Foreign Affairs, 91(6), 43-57. Retrieved December 17, 2019, from https://link.galegroup.com/apps/doc/A314650288/ AONE?sid=Ims 
Green, M., \& Taggart, J. (2017). Tall Wood Buildings: Design, Construction and Performance. Basel/ Berlin/Boston, SWITZERLAND: Walter de Gruyter GmbH. Retrieved December 12, 2019, from http:/ ebookcentral.proquest.com/lib/vuw/detail.action?doclD=4851850

Hisatoku, T., Nakahar, K., Nagase, T., \& Takahashi, Y. (2000). Earthquake Response of Ancient Five Storey Pagoda Structure of Horyu-Ji Temple in Japan. Presented at the Twelth World Conference on Earthquake Engineering, Auckland.

Hough, R. (2019). Rethinking Timber Buildings. London: Arup.

Jabi, W. (2013). Parametric Design for Architecture. London: Laurence King Publishing Ltd.

Kolarevic, B. (2003). Architecture in the Digital Age. New York: Spon Press.

Laylin, T. (2011). Winnipeg Ice-Skating Shelters Mimic Buffalos Bracing Against The Wind. Retrieved April 3, 2019, from https://inhabitat.com/winnipeg-ice-skating-shelters-mimic-buffalos-bracing-against-thewind/

Locher, M., Simmons, B., \& Kuma, K. (2010). Traditional Japanese Architecture: An Exploration of Elements and Forms. North Clarendon, UNITED STATES: Tuttle Publishing. Retrieved September 16, 2019, from http://ebookcentral.proquest.com/lib/vuw/detail.action?doclD $=895742$

Marble, S. (2012). Digital Workflows in Architecture: Design - Assembly - Industry. Basel/Berlin/Boston SWITZERLAND: Walter de Gruyter GmbH. Retrieved December 17, 2019, from http://ebookcentral. proquest.com/lib/vuw/detail.action?doclD=1020494

Marriage, G. (2018, May 15). Tight-knit: Mt Pleasant Community Centre. Retrieved December 12, 2019, from /articles/tight-knit-mt-pleasant-community-centre/

Menges, A. (2012). Material Resourcefulness: Activating Material Information in Computational Design. Architectural Design, 82(2), 34-43. http://doi.org/10.1002/ad.1377

Menges, A. (2017). Integrative Design Computation for Advancing Wood Architecture. In Advancing Wood Architecture (p. 97). New York: Routledge.

Menges, A., Schwinn, T., \& Kreig, O. D. (2017). Advancing Wood Architecture; A Computational Approach. New York: Routledge.

Oh, E. (2015, October 27). EmTech TWISTs Plywood at the Timber Expo in Birmingham. Retrieved April 4, 2019, from http://www.archdaily.com/775842/emtechs-twist-displayed-at-the-timber-expo-inbirmingham

Owen-Hill, A. (2018, June 12). Can a Robot Outperform a CNC Machine for Robot Machining? Retrieved April 10, 2019, from https://robodk.com/blog/robot-machining-vs-cnc/

Pagnotta, B. (2011, September 10). 2011 matR Project: "The Passage." Retrieved April 3, 2019, from http://www.archdaily.com/161894/2011-matr-project-the-passage/
Riggs, T. (2015). Gale Encyclopedia of U.S. Economic History (2nd ed., Vol. 3).

Scheurer, F. (2012). Digital Craftsmanship from Thinking to Modelling to Building. In Digital Workflows in Architecture: Design_Assembly-Industry. Basel/Berlin/Boston, SWITZERLAND: Walter de Gruyter GmbH. Retrieved December 17, 2019, from http///ebookcentral.proquestcom/lib/vuw/detail action?doclD $=1020494$

Schwinn, T. (2017). Landesgartenschau Exhibition Hall. In Advancing Wood Architecture (pp. 111-124). New York: Routledge.

Schwinn, T., Krieg, O. D., \& Menges, A. (2013). Robotically Fabricated Wood Plate Morphologies. In S. Brell-Çokcan \& J. Braumann (Eds.), Rob | Arch 2012 (pp. 48-61). Springer Vienna.

Smith, S. (2019, April 8). Construction industry needs to consider shift from steel to engineered wood-MP. Stuff. Retrieved December 15, 2019, from https://www.stuff.co.nz/business/111817240/constructionindustry-needs-to-consider-shift-from-steel-to-engineered-wood--mp

Steeman, M. (2019, September 24). The New Zealand Green Building Council calls for new buildings to be rid of gas and coal. Stuff. Retrieved December 15, 2019, from https://www.stuff.co.nz business/1 16042182/the-new-zealand-green-building-council-calls-for-new-buildings-to-be-rid-ofgas-and-coal

Steurer, A. (2006). Developments in Timber Engineering. Germany: Birkhauser.

Tarantola, A. (2011, October 6). How Japan's Oldest Wooden Building Survives Earthquakes. Retrieved September 16, 2019, from https://www.gizmodo.com.au/2011/10/how-japans-oldest-woodenbuilding-survives-earthquakes/

Tennant, H., \& Brown, E. (2012). 2012 BEST Design Awards- NG

The PortHole / TOMA! (2015, July 21). Retrieved April 4, 2019, from http///www.archdaily.com/770555/ the-porthole-toma

University of Stuttgart. (2011). ICD/TTKE Research Pavilion 2011 Institute for Computational Design and Construction. Retrieved March 25, 2019, from https://icd.uni-stuttgart.de/?p=6553

Willma, J., Block, P., Hutter, M., Byrne, K., \& Schork, T. (2018). Robotic Fabrication in Art Architecture, Art and Design 2018. Switzerland: Springer Nature Switzerland.

Woodbury, R. (2010). Elements of Parametric Design. Routledge.

Yuan, P. (2017). Confluence of High Performance-Based Architecture and Digital Fabrication. In Digita Fabrication (p. 61). People's Republic of China: Tongji University Press. 
Figure 01: Plywood layers

Figure 02: Horyu-ji Temple retrieved from https://en.wikipedia.org/wiki/H\%C5\%8Dry\%C5\%AB-jit/ media/File:Horyu-ji06s3200.jpg

gure 03: Engineered connection retrieved from

Figure 04: Joint diagrams

Figure 05: Laser cutter at Victoria University of Wellington

figure 06: 3-axis CNC machine retrieved from https://www.baseheight.com/home/portfolio-item/ kennedy-center-basswood/

Figure 07: Robotic Arm at Victoria University of Wellington

Figure 08: Acoustic Environments / AREA and Electrotexture Lab retrieved from https://www.archdaily. com/170078/acoustic-environments-area-and-electrotexture-lab/2_archdaily_1280px

Figure 09: 2011 matR Project: "The Passage" retrieved from https://www.archdaily.com/161894/2011matr-project-the-passage/olympus-digital-camera-305

Figure 10: Winnipeg Skating Shelters retrieved from https://www designboom.com/architecture/patkauarchitects-winnipeg-skating-shelters

Figure 11:The Porthole retrieved from https://www.archdaily.com/770555/the-porthole-toma

Figure 12: Fabricwood retrieved from https://www.archdaily.com/804590/produce-workshop-debutsplywood-based-fabricwood-pavilion-for-herman-millers-shop-in-shop/5894d41de58ece099300032bproduce-workshop-debuts-plywood-based-fabricwood-pavilion-for-herman-millers-shop-in-shopimage

Figure 13: TWIST Installation retrieved from https://www.archdaily.com/775842/emtechs-twistdisplayed-at-the-timber-expo-in-birmingham/56285554e58ece127a00037d-emtechs-twist-displayedat-the-timber-expo-in-birmingham-photo

igure 14: Robotic Wood Tectonics Project retrieved from https://books.google.co.nz/books?id=rEVLDw AAQBAJ\&pg=PT23\&lpg=PT23\&dq=Robotic + Wood+Tectonics + Project\&source=bl\&ots=aeUx-5xtLZ\& sig=ACfU3U2zITjt6ihZ65LMzFbXPBoqJGgJwQ\&hl=en\&sa=X\&ved=2ahUKEwjdqpP1 wsDmAhWGxzgG HWGuCVgQ6AEWDXoECACQAQ\#v=onepage\&q=Robotic\%20Wood\%20Tectonics\%20Project\&f=false

Figure 15: Bandsaw End-Effector retrieved from https://books.google.co.nz/books?id=rEVLDWAAQBA \&\&pg=PT23\&lpg=PT23\&dq=Robotic+Wood+Tectonics + Project\&source=bl\&ots=aeUx-5xtLZ\&sig=AC U3U2zITjt6ihZ65LMzFbXPBoqJGgJwQ\&hl=en\&sa=X\&ved=2ahUKEwjdqpP 1 wsDmAhWGXzgGHWGuC VgQ6AEwDXoECAcQAQ\#v=onepage\&q=Robotic\%20Wood\%20Tectonics\%20Project\&f=false

Figure 16: Landesgartenschau Exhibition Hall retrieved from https://www.archdaily.com/520897/ landesgartenschau-exhibition-hall-icd-itke-iigs-university-of-stuttgart

Figure 17: Interior of Exhibition Hall retrieved from https://www.archdaily.com/520897/ landesgartenschau-exhibition-hall-icd-itke-iigs-university-of-stuttgart

Figure 18: ICD/TKE Research Pavilion retrieved from https://www.archdaily.com/200685/icditkeresearch-pavilion-icd-itke-university-of-stuttgart

Figure 19: Interior of Research Pavilion retrieved from https://www.archdaily.com/200685/icditkeresearch-pavilion-icd-itke-university-of-stuttgart

Figure 20: Exterior of Te Oro retrieved from https://www.archdaily.com/794648/te-oro-archimedia

Figure 21 Interior of Kakano Pod retrieved from https://www.archdaily.com/405034/nga-purapuratennent-brown/51ec35a9e8e44eff9f000085-nga-purapura-tennent-brown-photo?next_project=no

Figure 22: Interior of Mt Pleasant Community Center retrieved from https://architecturenow.co.nz/ articles/tight-knit-mt-pleasant-community-centre/

Figure 23: Screws shown in the interior of Te Oro retrieved from https://www.archdaily.com/794648/ te-oro-archimedia

Figure 24: Exterior of Kakano pod but still located inside a building retrieved from https://nzplaces.nz/ place/nga-purapura-otaki
Figure 25: Mt Pleasant Community Center retrieved from https://architecturenow.co.nz/articles/tightknit-mt-pleasant-community-centre/

Figure 26: Laser Cut Models

Figure 27: Paper Models

igure 28: CNC Joint Mode

Figure 29: Bridle Joint Model

Figure 30: Parametric forms created digitally

Figure 31: Grasshopper script to create the parametric form

Figure 32: Pattern exploration

Figure 33: Grasshopper script to create pattern

Figure 34: Curved Panels

Figure 35: Straight panels

Figure 36: Pattern experimentation on a different form

Figure 37: Script to create joints from a form

Figure 38: Finger joints on laser cut models

Figure 39: Dovetail joint on laser cut models

Figure 40: Full grasshopper script created

Figure 41: Creation of passes

Figure 42: Rhino interface showing plane direction of robotic arm

Figure 43: Robotic workspace at Victoria University of Wellington

Figure 44: Router tool bit rack

Figure 45: Diagram of initial method to measure TCP

Figure 46: Script showing new \& faster way to measure TCP

igure47: Plywood sheets retrieved from https://weemakechange.co.nz/blog-import//2014/12/ formaldehyde-off-gas-from-plywood.htm

Figure 48: Base form and the panels flattened with number recognition

Eigure 49: Base form with dovetail finger joints on the digital model

Figure 50: Mortise \& tenon joint

Figure 51: Sliding mortise \& tenon joint diagram

Figure 52: Square shaped mortise

igure 53: Cuts needed when using the $6 \mathrm{~mm}$ router bit

Figure 54: Mortise cut with dovetail router bit

Eigure 55: Tenon cut with dovetail router bit

Figure 56: Robotic arm cutting tenon

Figure 57: Direction of tenon cut

Figure 58: Final models of robotically fabricated mortise \& tenon

Figure 59: $13 \mathrm{~mm}$ vs $16 \mathrm{~mm}$ dovetail router bit mortise cut

Figure 60: Tenon broken off during the cutting process

Figure 61: Tenon broken off over time

igure 62: Final panels of the first set

Figure 63: Cut with the $6 \mathrm{~mm}$ straight router bt

Figure 64: Final cut after the dovetail router bit has cut it

Figure 65: Close up of wide tenon

Figure 66: Four mortises cut into a pane

Figure 67: Timber producing smoke from the cut

Figure 68: $6 \mathrm{~mm}$ air gap

Figure 69: Script to change the size of the joints

Figure 70: Build sequence with base form 
Figure 71: Non-sliding tenon

Figure 72: Cutting process

Figure 73: Exploration of form

Figure 74: Interior exploration

Figure 75: Concept exploration

Figure 76: Iterations

Figure 77: Chosen design

Figure 78: Laser cut model

Flgure 79: Highlighted panels will be fabricated with the robotic arm

Figure 80: Floor plan size

Figure 81: Floor plan exploration

Figure 82: Holes tested on base form

Figure 83: Sketches of holes

Figure 84: Hole exploration

Figure 85: Chosen design to work with

Figure 86: Render of design from one side

Figure 87: Rendered section of model

Figure 88: Render of design from other side

Figure 89: Close up render of panels

Figure 90: Panels cut out

Figure 91: Close up of a panel cut out

Figure 92: Tenon cut out

Figure 93: Air gap

Figure 94: Process of mortise being cut

Figure 95: Aftermath of router bit going through the plywood

Figure 96: Diagram showing point under table

Figure 97: Final panels cut out and laid out on work surface

Figure 98: Final joints

Figure 99: Panels assembled in the robotic arm's workroom

Figure 100: Final panels disassembled

Figure 101: Final panels assembled

Figure 102: Close up of final panels

Figure 103: Assembly of panels

Figure 104: Assembly design concept

Figure 105: Proposed workflow diagram

Figure 106: Current workflow diggram

Figure 107: Close up of panels with assembly design concept 
Figure 71: Non-sliding tenon

Figure 72: Cutting process

Figure 73: Exploration of form

Figure 74: Interior exploration

Figure 75: Concept exploration

Figure 76: Iterations

Figure 77: Chosen design

Figure 78: Laser cut model

Flgure 79: Highlighted panels will be fabricated with the robotic arm

Figure 80: Floor plan size

Figure 81: Floor plan exploration

Figure 82: Holes tested on base form

Figure 83: Sketches of holes

Figure 84: Hole exploration

Figure 85: Chosen design to work with

Figure 86: Render of design from one side

Figure 87: Rendered section of model

Figure 88: Render of design from other side

Figure 89: Close up render of panels

Figure 90: Panels cut out

Figure 91: Close up of a panel cut out

Figure 92: Tenon cut out

Figure 93: Air gap

Figure 94: Process of mortise being cut

Figure 95: Aftermath of router bit going through the plywood

Figure 96: Diagram showing point under table

Figure 97: Final panels cut out and laid out on work surface

Figure 98: Final joints

Figure 99: Panels assembled in the robotic arm's workroom

Figure 100: Final panels disassembled

Figure 101: Final panels assembled

Figure 102: Close up of final panels

Figure 103: Assembly of panels

Figure 104: Assembly design concept

Figure 105: Proposed workflow diagram

Figure 106: Current workflow diggram

Figure 107: Close up of panels with assembly design concept 